FELIPE CRUZ RODRIGUES DE CAMPOS

\title{
ANÁLISE DOS CRITÉRIOS DE ESTABILIDADE PARA PROJETOS DE PLATAFORMAS DO TIPO MONOCOLUNA
}


FELIPE CRUZ RODRIGUES DE CAMPOS

\title{
ANÁLISE DOS CRITÉRIOS DE ESTABILIDADE PARA PROJETOS DE PLATAFORMAS DO TIPO MONOCOLUNA
}

\author{
Dissertação apresentada à Escola \\ Politécnica da Universidade de São \\ Paulo para obtenção do título de \\ Mestre em engenharia
}


FELIPE CRUZ RODRIGUES DE CAMPOS

\title{
ANÁLISE DOS CRITÉRIOS DE ESTABILIDADE PARA PROJETOS DE PLATAFORMAS DO TIPO MONOCOLUNA
}

\author{
Dissertação apresentada à Escola \\ Politécnica da Universidade de São \\ Paulo para obtenção do título de \\ Mestre em engenharia \\ Área de concentração: \\ Engenharia Naval e Ocêanica \\ Orientação: Prof. Dr. Kazuo \\ Nishimoto
}

São Paulo 


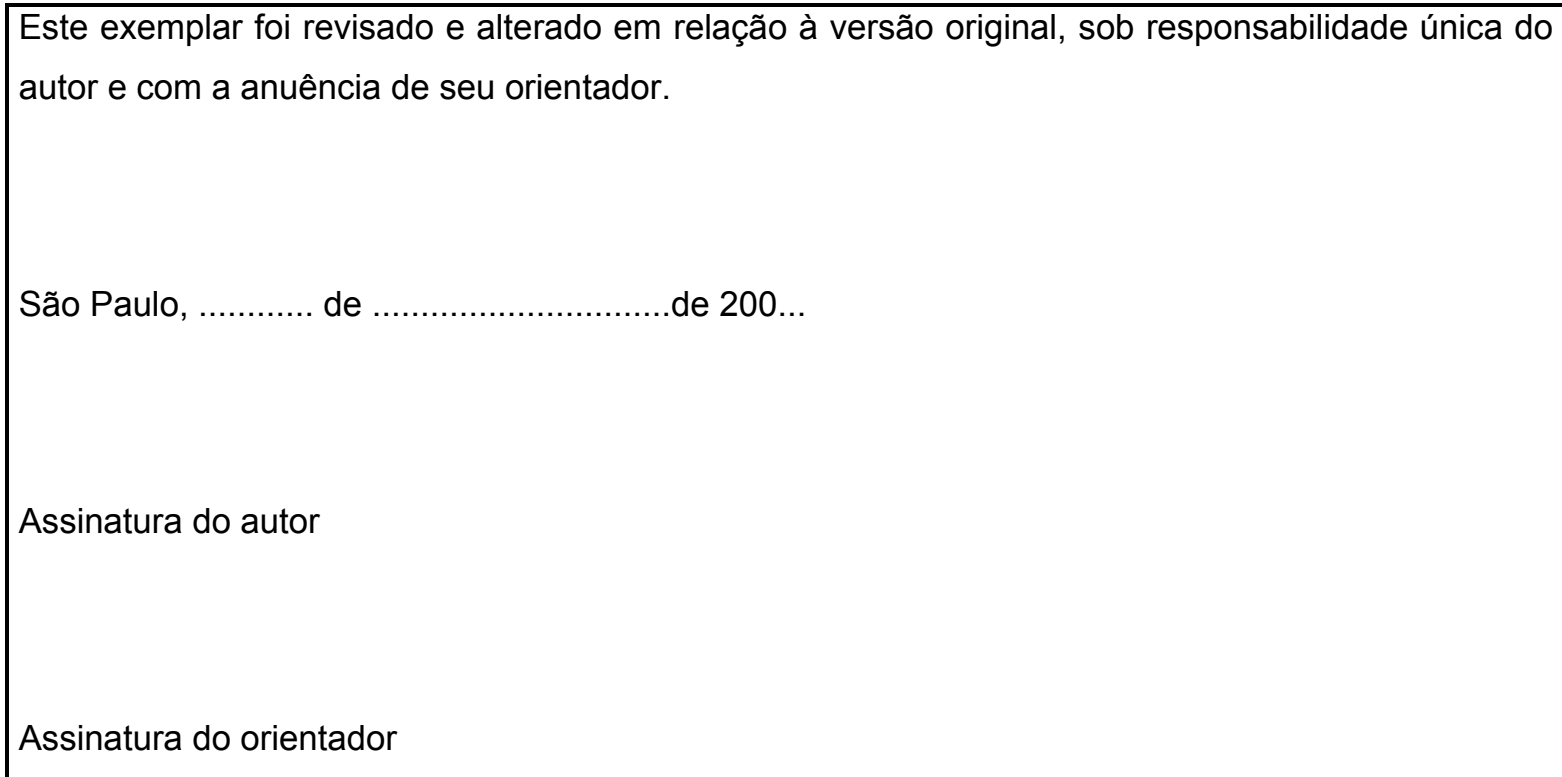

\section{FICHA CATALOGRÁFICA}

\section{Campos, Felipe Cruz Rodrigues de}

Análise dos critérios de estabilidade para projetos de plataformas do tipo monocoluna / F.C.R. de Campos. -- São Paulo, 2008.

88 p.

Dissertação (Mestrado) - Escola Politécnica da Universidade de São Paulo. Departamento de Engenharia Naval e Oceânica.

1.Plataforma continental (Regulamentação; comportamento estrutural) 2.Estruturas offshore flutuantes (Análise; comportatamento estrutural) 3. Tanque de provas 4. Hidrodinâmica da plataforma continental I.Universidade de São Paulo. Escola Politécnica. Departamento de Engenharia Naval e Oceânica II.t. 


\section{AGRADECIMENTOS}

Essa dissertação não seria possível sem o estímulo de minha mãe, que desde sempre me deu a capacidade e vontade de me superar, de meu pai, que sempre me fez colocar os pés no chão, de minha irmã, que foi meu contraponto e minha revisora, de meu ex-chefe e amigo Gleiber Morato, que sempre acreditou que a pesquisa é fundamental e por fim de minha namorada e companheira, que me fez acreditar sempre quando eu me questionava. 


\section{RESUMO}

Para serem classificadas e aprovadas por uma sociedade classificadora, todas as estruturas offshore são submetidas a análises baseadas em regras padrão; os critérios de estabilidade utilizados são baseados no código IMO - MODU (Internacional Maritime Organization - Mobile Offshore Drilling Units), que referencia quase todos os tipos de unidades flutuantes, como de superfície, semi-submersíveis, e auto elevatórias, entretanto, encontram-se problemas ao tentar enquadrar alguns conceitos inovadores a um desses tipos, devido às grandes diferenças entre o existente e os novos projetos.

A fim de prever o comportamento de uma estrutura flutuante, são necessárias análises de estabilidade que predigam o comportamento da plataforma em operação intacta, e eventualmente em caso de avarias.

Com o propósito de superar dificuldades e encontrar os critérios apropriados, foi realizado. em conjunto pelo Departamento de Engenharia Naval e Oceânica da USP e Petrobras, esse estudo para gerar análises que cerceiem o comportamento desses novos tipos de plataforma e adéqüem as regras existentes aos novos conceitos para certificações futuras.

Pode se observar que unidades do tipo FPSO são as mais comuns em campos de produção brasileiros por apresentarem grande área de convés, capacidade de armazenamento e serem unidades cuja operação é muito conhecida, além de terem baixos custos de construção, seja ela inteiramente construída ou apenas convertida. Entretanto, esse tipo de unidade apresenta movimentos não adequados para a utilização de Steel Catenary Risers (SCR's), inviabilizando sua utilização em águas ultra-profundas.

Analisando as condições brasileiras, nota-se que ao considerar ondas, corrente e vento, as relações dimensionais de um FPSO não teriam a melhor proporcionalidade possível, principalmente devido às interferências hidrodinâmicas proporcionadas pelo swell. Isso impeliu o desenvolvimento de um novo conceito que atendesse melhor a função especifica da unidade, batizado monocoluna.

Para esse conceito, foram gerados inúmeros cascos, porém apenas alguns deles foram escolhidos como ideais para serem submetidos a mais minuciosas análises, e 
nessa dissertação se discutem os critérios de estabilidade que devem ser aplicados a monocoluna.

Todas as análises foram conduzidas considerando métodos numéricos e as dimensões finais foram aplicadas a ensaios em tanques de provas para que se comprovasse a eficiência dos sistemas criados.

\section{PALAVRAS CHAVE}

Estabilidade. Monocoluna. Normas de estabilidade. Projeto conceitual. Sociedades classificadoras. 


\section{ABSTRACT}

To be classified and approved by a classification society, all offshore structures shall be submitted and analyzed according to standard rules. The stability criteria are based on the IMO - MODU (International Maritime Organization - Mobile Offshore Drilling Units) Code which has reference to almost all types of floating units such as surface, column-stabilized and self elevating.

Although it refers to a wide range of naval systems, problems were found when dealing with new concepts due to differences between these concepts and those presented by the rules.

In order to predict the behavior of a floating structure, it is necessary to perform stability analyses that foresee how the platform will respond when in operation either intact or eventually damaged. With that in mind, this study that would analyze and evaluate the existing rules came up along with the Department of Naval and Ocean Engineering of the University of São Paulo and Petrobras, this study intends to check the applicability of the existing rules and propose more adequate rules for the monocolumn.

It is possible to observe that FPSO units are more common at the Brazilian oil fields due to the presence of great deck area and storage capacity, their operation is well known, they have low constructions costs either if they are built from scratch or converted. Even so, this type of unit presents inadequate responses to the use of Steel Catenary Risers (SCR's), what doesn't allow its use in ultra deep water.

Analyzing the Brazilian weather and sea condition, specially focusing on waves, sea strings and wind, the FPSO dimensions are not the best, especially due to the swell hydrodynamic responses. That forced the development of a new concept that better fulfill the units' specific function, named monocolumn.

Lots of units were defined as valid, but only some with the best responses were chosen for deeper analysis, therefore this study discusses the stability criteria that shall apply to this concept.

All the analyses were conduced considering numerical methods and among all the possibilities, final dimensions were generated and prototypes were built and tested in test tanks to prove their efficiency. 


\section{KEY WORDS}

Classification Societies. Conceptual design. Monocolumn. Stability. Stability rules. 


\section{LISTA DE FIGURAS}

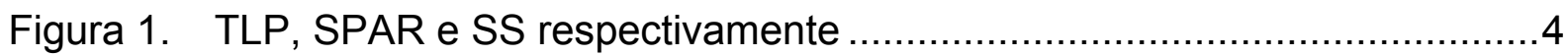

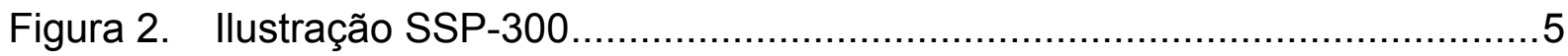

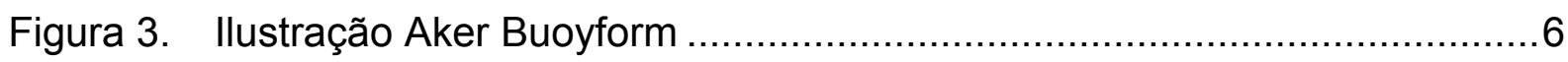

Figura 4. Diferentes possibilidades de monocolunas ..................................... 8

Figura 5. Modelo com a saia em destaque..............................................

Figura 6. Modelo com a praia em destaque. .................................................

Figura 7. Modelo com o moonpool em destaque......................................... 10

Figura 8. Cd versus Reynolds para adoçamento de 10\% (modificado de [6]) ........11

Figura 9. Cd vs Reynolds seção quadrada (modificado de [6]) ..........................11

Figura 10. Casco quadrado com adoçamento ...........................................11

Figura 11. Tanques no formato de gomos ............................................ 12

Figura 12. Tanques com subdivisão convencional (inicial) .............................13

Figura 13. Duas camadas de tanques ................................................. 13

Figura 14. Exemplares da família monocoluna ....................................... 16

Figura 15. Esquema geral da espiral de projetos.....................................19

Figura 16. Fluxograma de dimensionamento ......................................... 21

Figura 17. Equilíbrios estável, instável e indiferente (modificado de [6]) ..............23

Figura 18. Força peso e empuxo agindo na plataforma a $0^{\circ}$ (não há braço GZ) ..24

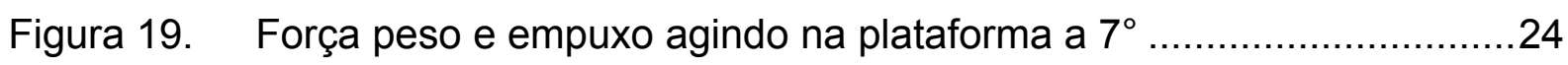

Figura 20. Risco de emborcamento (modificado de [6]) ................................25

Figura 21. Energia de restauração e momento emborcador (modificado de [6]) ..26

Figura 22. Momento restaurador vs emborcador (modificado de [6]) ..................26

Figura 23. Critério estabilidade Intacta ............................................... 27

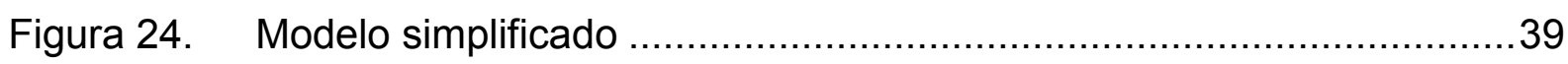

Figura 25. Processo de análise de estabilidade......................................42

Figura 26. Classificação dos compartimentos no Sstab (modificado de [7])........44

Figura 27. Razão de área para diferentes aproamentos...............................46

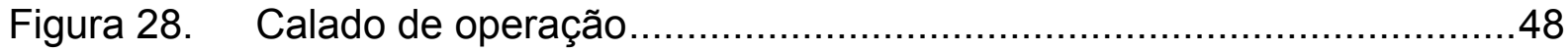

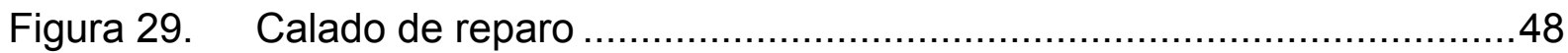

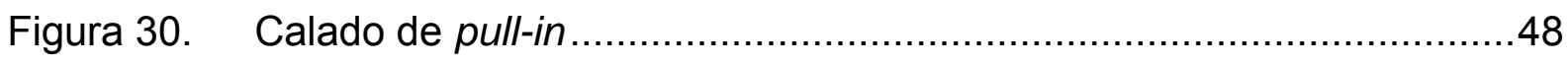




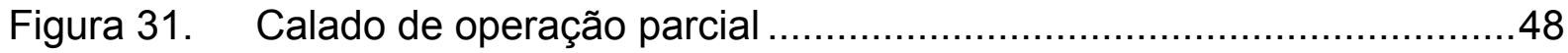

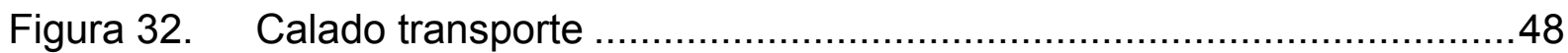

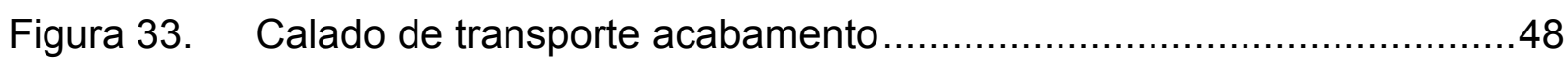

Figura 34. Plataforma com um tanque avariado / após compensação ..................49

Figura 35. Plataforma com dois tanques avariados /após compensação .............49

Figura 36. Plataforma com oito tanques avariados / após compensação ..............50

Figura 37. Comparação entre Monocoluna (A) e SSBR (B)................................54

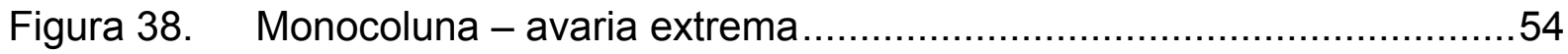

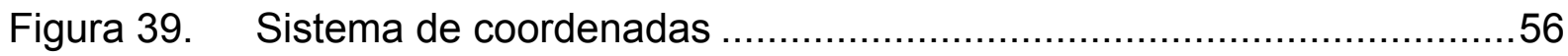

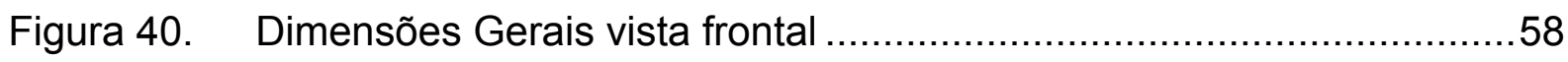

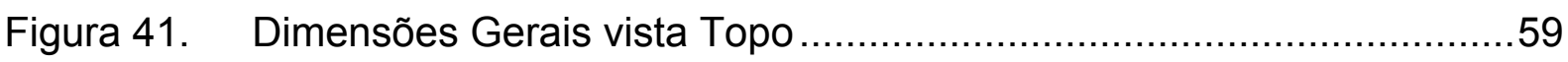

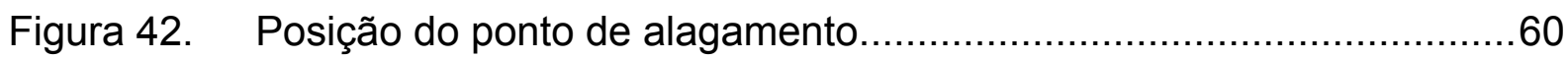

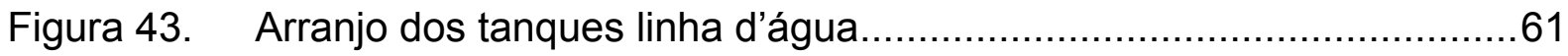

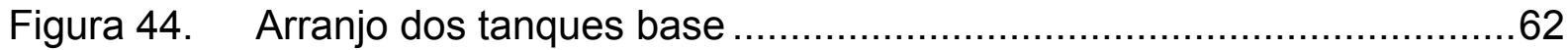

Figura 45. Modelo empregado para análise de influência do vento.......................63

Figura 46. Incidência do vento com azimutes (entre parêntesis) ..........................64

Figura 47. Curva de momento emborcador - estabilidade intacta .......................66

Figura 48. Curva de momento emborcador - estabilidade avariada.....................66

Figura 49. Curva de estabilidade intacta - aproamento $135^{\circ}$ (SE) ....................69

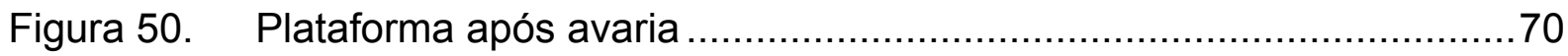

Figura 51. Curva de estabilidade calculada com unidade avariada .....................72

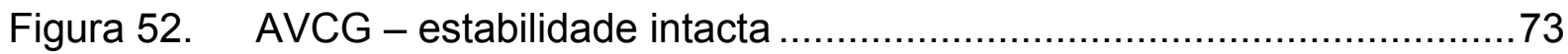

Figura 53. AVCG com dois tanques de lastro adjacentes externos avariados......74

Figura 54. Comparação entre VCG em condição de operação e AVCG para avaria

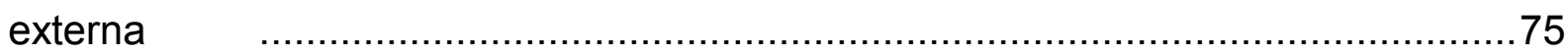

Figura 55. Comparação entre VCG em condição de operação e AVCG para avaria

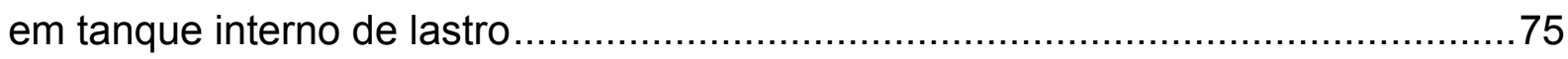

Figura 56. Compensação de avaria (1 tanque) .................................................77

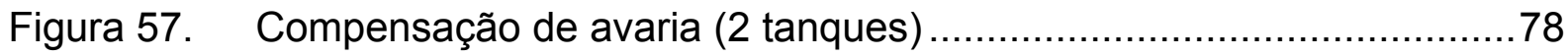

Figura 58. Esquema das áreas weathertight e watertight - Azimute $0^{\circ}$ e $180^{\circ} \ldots .79$

Figura 59. Esquema das areas weathertight e watertight - Azimute $90^{\circ}$ e $270^{\circ} . .80$

Figura 60. Certificação DNV para um design do conceito monocoluna ................82 


\section{LISTA DE TABELAS}

Tabela 1 - Comparação dos fatores constituintes dos critérios...........................33

Tabela 2 - $\quad$ Figuras dos calados para análise de estabilidade ............................48

Tabela 3 - Dimensões principais - monocoluna ........................................ 51

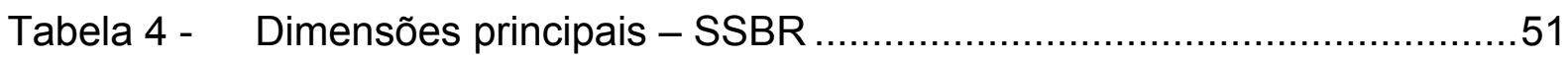

Tabela 5 - Resumo P\&C monocoluna.................................................. 52

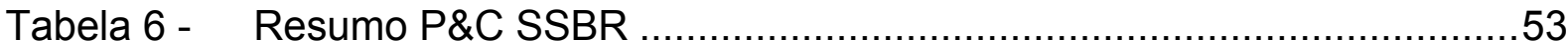

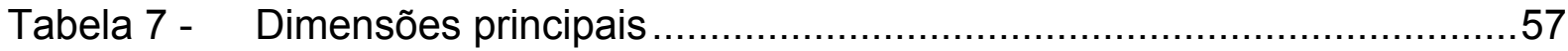

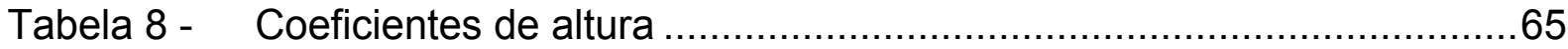

Tabela 9 - Descrição dos grandes grupos e coeficientes de forma .....................65

Tabela 10 - Respostas Monogom - Estabilidade Intacta ...............................68

Tabela 11 - Principais parâmetros de estabilidade .....................................69

Tabela 12 - Condição $90 \%$ ocupação - Calado 39,5 m ..................................71

Tabela 13 - Características gerais dos tanques após avaria ............................71

Tabela 14 - $\quad$ AVCG com tanques adjacentes externos avariados .....................74

Tabela 15 - Condição de carregamento dos tanques - 1 tanque danificado .......77

Tabela 16 - Condição de carregamento dos tanques - 2 tanques danificados....78 


\section{LISTA DE ABREVIATURAS E SIGLAS}

Air-Gap:

Altura compreendida entre a linha d'água até o convés;

ABS:

American Bureau of Shipping;

ANP:

Agência nacional de petróleo;

AVCG:

VCG máximo;

CENPES:

Centro de Pesquisa da Petrobras;

DNV:

Det Norske Veritas;

FPS:

Floating Production Systems - Sistemas Flutuantes de Produção;

FPO:

FPSO: Floating Production and Offloading - Sistemas Flutuantes de Produção e descarregamento;

FPSO:

Floating Production, Storage and Offloading - Sistemas

FSU:

Flutuantes de Produção, Armazenamento e Descarregamento;

IMO: International Maritime Organization;

IMO - MODU: $\quad$ Internacional Maritime Organization - Mobile Offshore Drilling Units;

Máx: Máximo;

MG:

Mesh Generator - Software de geração de malhas para Sstab da Petrobras);

Mín: Mínimo;

MonoBR: $\quad$ Caso específico de alguns ciclos de projetos da família monocoluna;

MonoGOM: $\quad$ Caso específico da família monocoluna projetado para operar no Golfo do México;

MPU-SEMO: $\quad$ Monohull semi-submersible - um conceito de FPSO;

NMD: $\quad$ Norwegian Maritime Directorate;

ONU: $\quad$ Organização das Nações Unidas;

P\&C: $\quad$ Pesos e centros;

P-36: Plataforma de produção de petróleo que foi operada pela Petrobras;

SCR: $\quad$ Steel Catenary Risers - Risers de aço em catenária; 
SPAR: $\quad$ Unidades flutuantes de grande calado;

SS:

Plataformas semi-submersíveis;

SSBR:

Projeto de semi-submersível projetado pela Petrobras;

SSTAB:

Software de cálculo de estabilidade da Petrobras;

Tecgraf:

Grupo de Tecnologia em Computação gráfica da PUC-Rio;

TLP:

Tension-Leg Plataform;

WAMIT:

Software para cálculo de propriedades hidrodinâmicas. 


\section{LISTA DE SÍMBOLOS}

AVCG: $\quad$ VCG máximo;

B: $\quad$ Centro de carena;

BM: Inércia de linha d'água dividida por deslocamento em volume;

Cd: $\quad$ Coeficiente de arrasto;

CG: $\quad$ Centro de gravidade;

Ch: $\quad$ Coeficiente de altura;

Cs: $\quad$ Coeficiente de forma;

D: $\quad$ Boca;

F: $\quad$ Força do vento;

FP: $\quad$ Flooding point - ponto de alagamento;

g: $\quad$ Aceleração da gravidade;

GM: $\quad$ Altura metacêntrica;

GMFS: $\quad$ GM considerando efeito de superfície livre;

I: Inércia;

lad: Inércia adicional;

$I_{\mathrm{w}}$ : $\quad$ Inércia de linha d'água;

KB: $\quad$ Distância da base da unidade até o centro de carena;

KG: $\quad$ Distância da base da unidade até o centro de gravidade;

KGFS: $\quad$ KG considerando efeito de superfície livre;

m: $\quad$ Massa do corpo;

ma: $\quad$ Massa adicional do corpo;

Tn: $\quad$ Período natural;

VCG: $\quad$ Coordenada vertical do centro de gravidade da unidade flutuante;

WHA: $\quad$ Momento emborcador devido ao vento;

$\rho: \quad$ Densidade da água;

$\nabla: \quad$ Deslocamento da unidade $\left(\mathrm{m}^{3}\right)$ - volume deslocado

$\Delta: \quad$ Deslocamento da unidade $(\mathrm{kg})$; - peso 


\section{SUMÁRIO}

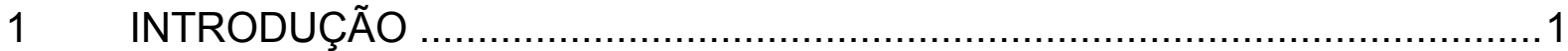

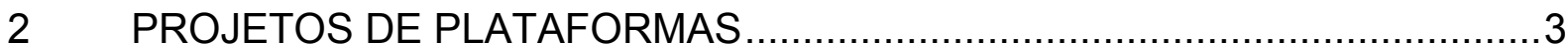

2.1 Plataformas de produção em operação......................................................

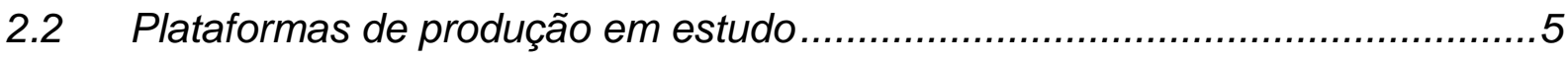

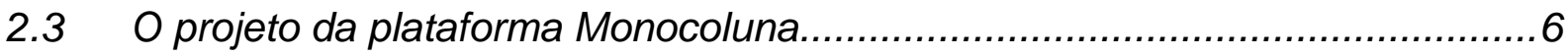

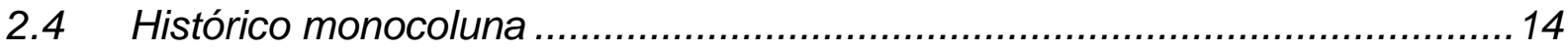

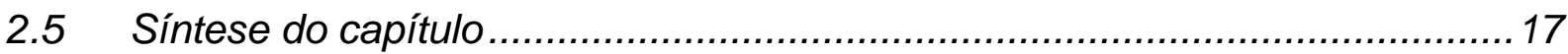

3 METODOLOGIA DE GERAÇÃO DE CASOS .......................................18

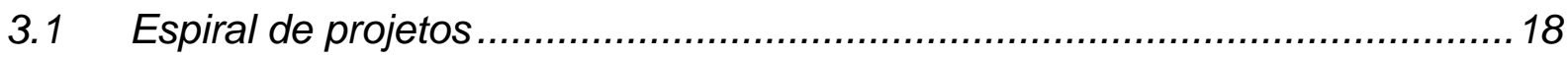

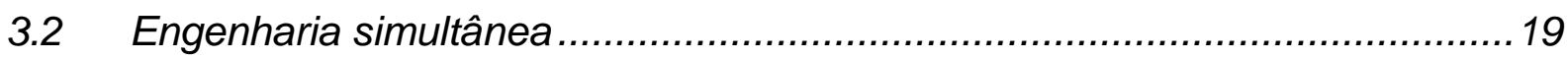

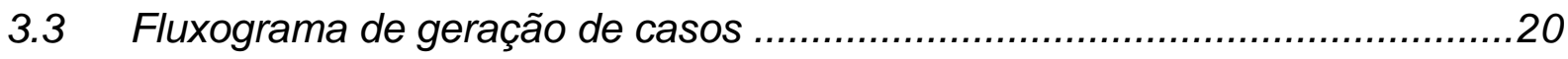

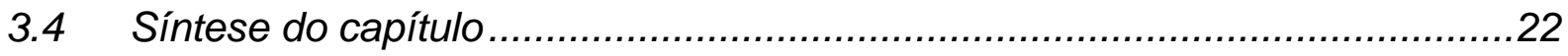

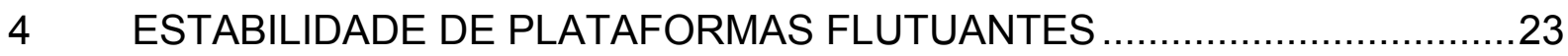

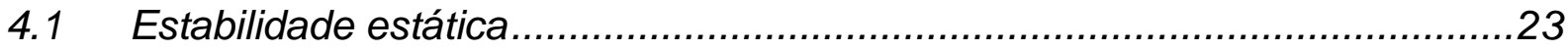

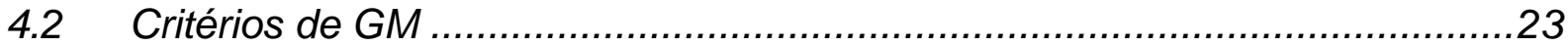

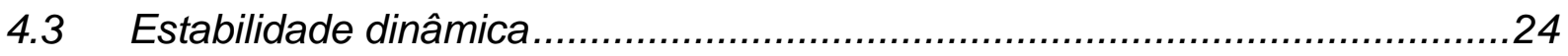

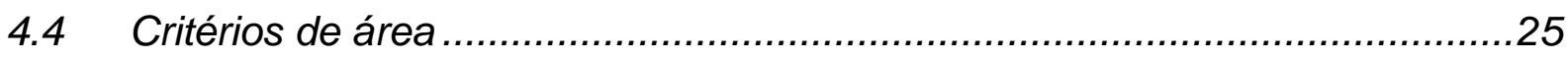

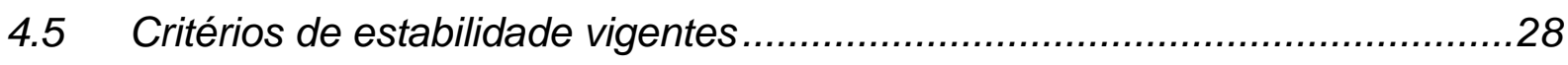

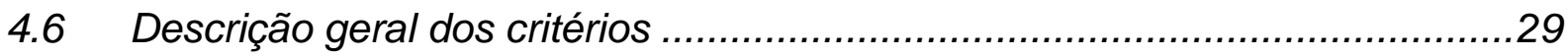

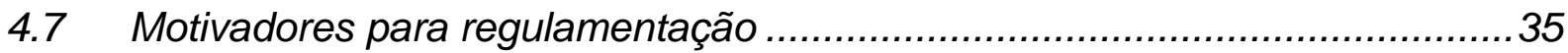

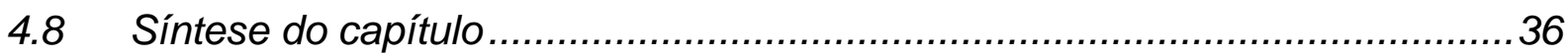

5 METODOLOGIA PARA ANÁLISE DE ESTABILIDADE - MONOCOLUNAS .37

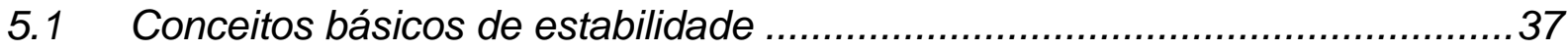

5.2 Fluxograma para análise de estabilidade de monocolunas .........................42

5.3 Programa utilizado para análises - SSTAB ............................................ 43

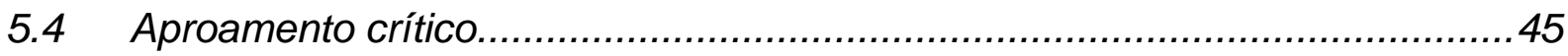

5.5 Calados para análise de estabilidade da monocoluna ................................46

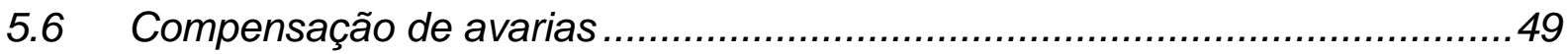

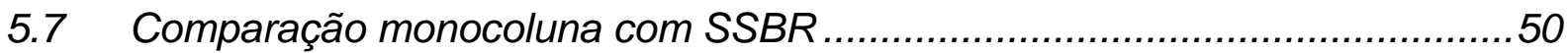

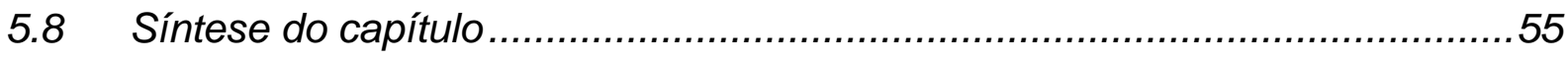




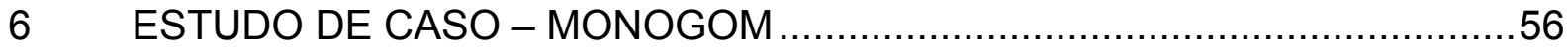

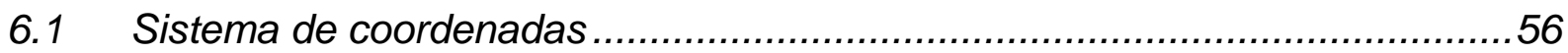

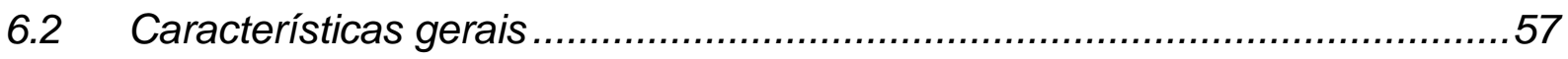

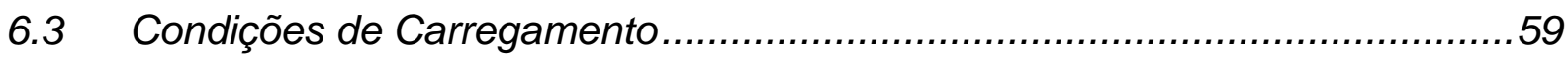

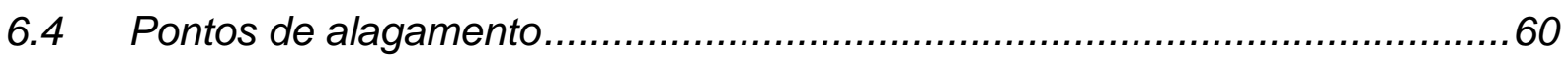

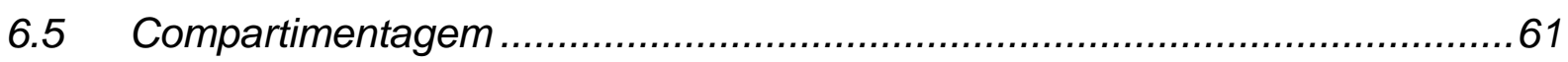

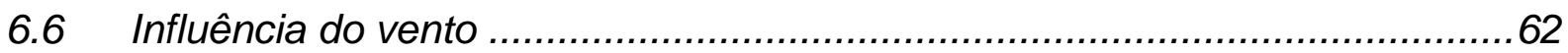

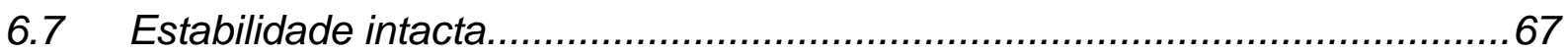

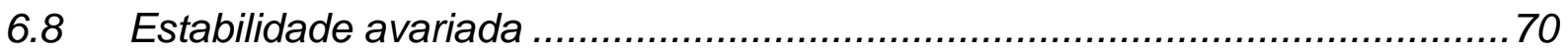

6.9 Análise de máxima altura metacêntrica .....................................................72

6.10 Análise de compensação de avarias ...................................................... 76

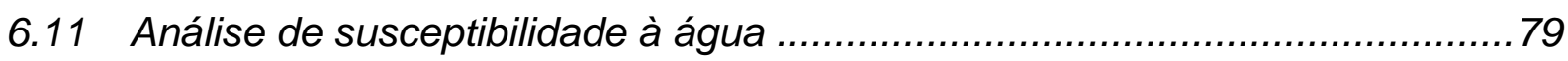

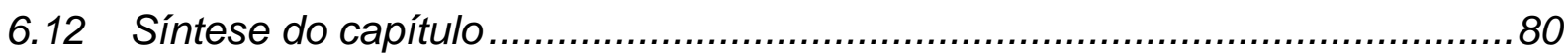

7 ANÁLISE DOS CRITÉRIOS DE ESTABILIDADE PARA MONOCOLUNA .....81

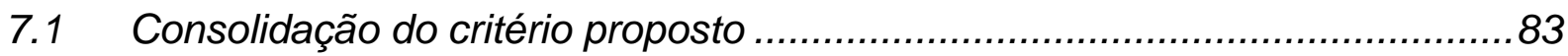

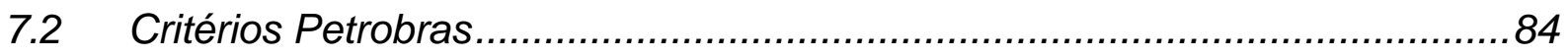

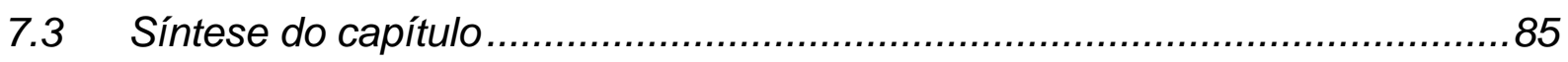

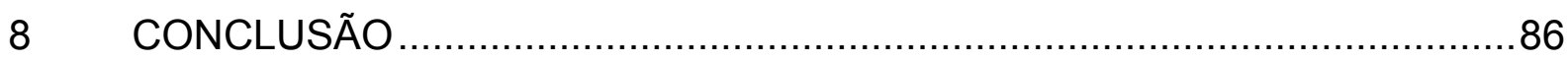

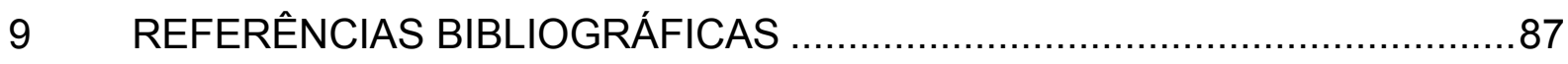

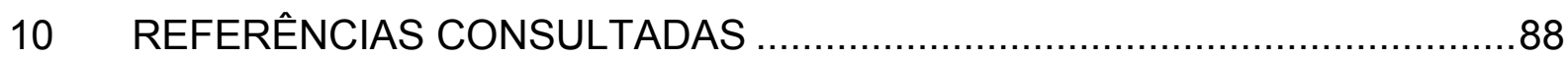




\section{INTRODUÇÃO}

Ao longo da história da indústria petrolífera, a busca de novas tecnologias para possibilitar o suprimento das necessidades mundiais sempre foi uma constante. Tal fato pode ser observado, por exemplo, nos processos de exploração, inicialmente terrestres, que evoluíram a ponto de chegar aos gigantescos sistemas flutuantes modernos. No âmbito nacional, devido às características geológicas e geofísicas, as descobertas de reservas de petróleo têm acontecido em águas cada vez mais profundas, daí a utilização maciça de unidades flutuantes na produção brasileira. Atualmente, na Bacia de Campos, dois tipos de unidades estão instaladas em águas profundas e ultra-profundas, os FPSOs e as Semi-Submersíveis.

Com as novas descobertas acontecendo em profundidades cada vez maiores, novas tecnologias são necessárias, como a utilização de risers de aço em catenária (SCR), que suportam as altas pressões existentes. Para ser possível a utilização deste tipo de risers, as plataformas devem apresentar movimentos de pequena amplitude, menores que os apresentados atualmente pelas unidades tradicionais. Em conseqüência disso, são desenvolvidos constantemente projetos de unidades exploradoras de petróleo em grandes profundidades.

Através de diversos projetos de pesquisa, surgiram unidades com conceito de vanguarda, que estão na pauta dos melhores institutos de pesquisas ao redor do mundo. Esse conceito tem como principais características e vantagens, capacidade de produção com custo benefício otimizado, capacidade de operação em águas ultra-profundas, baixos movimentos em ondas e a fácil construção e instalação.

Embora a unidade monocoluna se assemelhe geometricamente às SPAR's e tenha as mesmas funcionalidades de uma semi-submersível, algumas características são notoriamente diferentes, tornando necessários estudos que analisem o desempenho desse tipo de unidade, e a aplicabilidade das regras vigentes, já que nem sempre a inovação pode se adequar aos padrões existentes. Ao estudar novos conceitos de plataformas focando especificamente a compartimentagem e a estabilidade das mesmas, comparando-as com unidades já consagradas como FPSO e SemiSubmersíveis, surge à necessidade de alteração nos padrões regulamentadores, reformulando normas que assegurem o desempenho adequado dessas unidades. 
O desafio principal é a crítica e análise das regras das sociedades classificadoras, validação dos critérios vigentes e definição dos novos critérios apropriados para enquadrar estes tipos de unidades.

Para isso foram geradas diversas dimensões e compartimentagens para um casco do tipo monocoluna que teve seu desempenho testado nas condições intacta e avariada, mapeando as conseqüências das avarias, e por fim comparando-as com unidades existentes.

De forma geral, essa dissertação tem por objetivo apresentar um critério de estabilidade adequado para plataformas do tipo monocoluna, utilizando para isso metodologia de dimensionamento de cascos e de análise de estabilidade fundamentadas nos princípios de espiral de projetos e engenharia simultânea.

Os principais resultados gerados são a validação de um dos conceitos gerados por essa metodologia pela DNV e a elaboração de um critério aderente às características das unidades monocolunas, e em meio a esses resultados são também, apresentados inúmeros casos de monocolunas gerados, que constituem o histórico do projeto na USP, e a forma como esse estimulou diversos trabalhos ao redor do comportamento dessa unidade. 


\section{PROJETOS DE PLATAFORMAS}

\subsection{PLATAFORMAS DE PRODUÇÃO EM OPERAÇÃO}

Define-se por plataformas de produção em operação as plataformas que já estão em operação há mais de dez anos, e que por isso já tiveram muitas análises em torno de seu comportamento no mar. Atualmente existem vários tipos de plataformas em operação no mundo, entre elas se destacam as seguintes:

Plataformas Fixas - geralmente são constituídas de estruturas modulares de aço, instaladas no local de operação sob estruturas chamadas jaquetas, presas com estacas cravadas no fundo do mar. As plataformas fixas são projetadas para receber todos os equipamentos de perfuração, estocagem de materiais, alojamento de pessoal, bem como todas as instalações necessárias para a produção dos poços.

Plataformas semi-submersíveis (SS) - As plataformas semi-submersíveis são compostas de estrutura de um ou mais conveses, apoiada em flutuadores. Essa característica faz com que ela tenha ancoragem e comportamento em ondas específicos para que o último corresponda as suas necessidades de operação. Além do sistema de ancoragem, existe em alguns casos o sistema de posicionamento dinâmico, que controla o posicionamento da plataforma. Nesse sistema, não existe ligação física da plataforma com o fundo do mar, exceto a dos equipamentos de perfuração. Sensores acústicos determinam a deriva, e propulsores no casco acionados por computador restauram a posição da plataforma.

Tension-Leg Platform (TLP) - São unidades flutuantes bastante semelhantes à plataforma semi-submersível, entretanto sua ancoragem ao fundo mar é diferente, utilizando-se de tendões fixos ancorados por estacas e mantidos esticados pelo excesso de flutuação da plataforma, o que reduz severamente os movimentos da mesma.

Sistemas Flutuantes de Produção - Os Sistemas Flutuantes de Produção, também conhecidos como Floating Production Systems (FPS), são navios, em geral de grande porte, com capacidade para produzir, processar e/ou armazenar petróleo e 
gás natural, estando ancorados em um local definido. Em seus conveses, são instaladas plantas de processo para separar e tratar os fluidos produzidos pelos poços. Depois de separado da água e do gás, o petróleo produzido pode ser armazenado nos tanques do próprio navio e/ou transferido para terra através de navios aliviadores ou oleodutos. O gás comprimido é enviado para terra através de gasodutos e/ou re-injetado no reservatório. Os principais tipos de FPS são:

Floating Production and Offloading (FPO) - Unidades Flutuantes de Produção e Descarga.

Floating Production, Storage and Offloading (FPSO) - Unidades Flutuantes de Produção, Armazenamento e Descarga.

Floating Storage Unit (FSU) - Unidades Flutuantes de Armazenamento.

As maiores FPSs têm capacidade de processo em torno de 200 mil barris de petróleo por dia, com produção associada de gás de aproximadamente dois milhões de metros cúbicos por dia.

SPAR - Unidades flutuantes que foram desenvolvidas como uma alternativa às plataformas convencionais. Consiste em um cilindro vertical de grande diâmetro, que suporta a planta de produção. Aproximadamente $90 \%$ da estrutura é subaquática. Historicamente, SPARs eram bóias utilizadas como marcador náutico para recolhimento de dados oceanográficos. Seu grande calado produz características muito favoráveis de movimento comparadas a outras plataformas, podendo ser utilizadas em grandes profundidades.

A Figura 1 ilustra algumas das plataformas em operação.

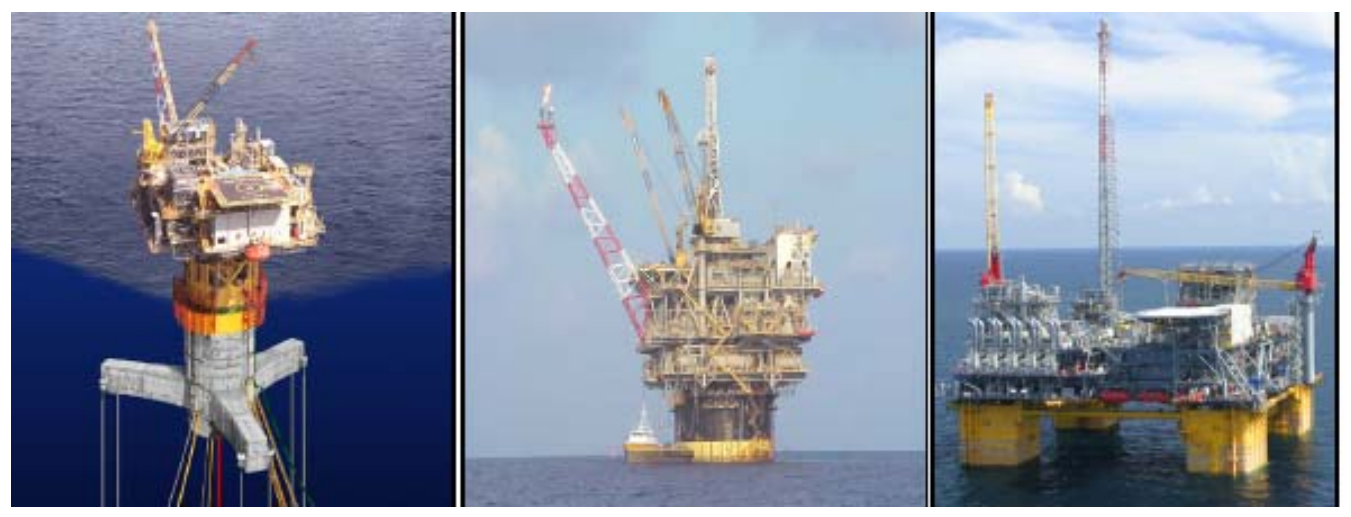

Figura 1. TLP, SPAR e SS respectivamente 


\subsection{PLATAFORMAS DE PRODUÇÃO EM ESTUDO}

Define-se por plataformas de produção em estudo, plataformas que estão em fase de projeto conceitual, básico, de detalhamento, ou que começaram sua operação há menos de 5 anos e portanto ainda estão passando por diversos estudos para prever ou medir seu comportamento no mar. Nesse cenário podemos destacar:

SSP-300 - FPSO cilíndrico, monolítico com uma capacidade de armazenamento de óleo de 300 mil barris, capacidade processamento de óleo de $30 \mathrm{mil}$ barris/dia, apresentada na Figura 2

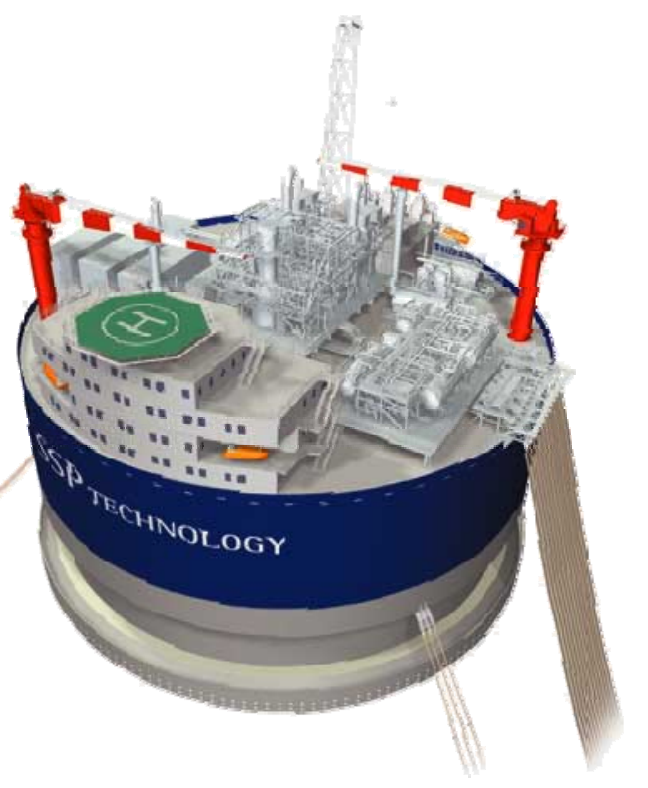

Figura 2. Ilustração SSP-300

BUOYFORM - formato inovativo da monocoluna proposto por AKER KVAERNER com capacidade de armazenamento do óleo de 300 mil barris, ilustração apresentada na Figura 3. 


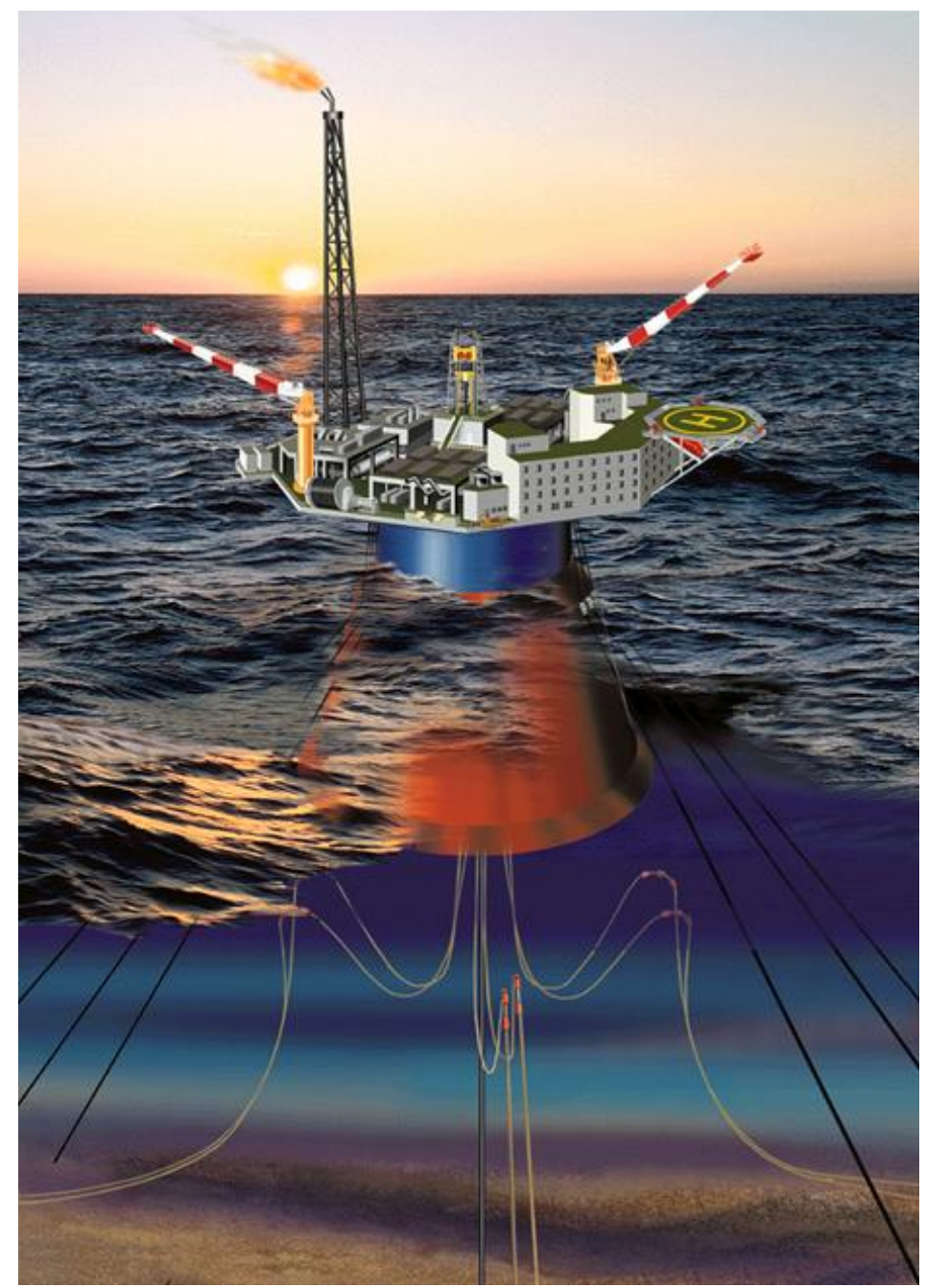

Figura 3. Ilustração Aker Buoyform

FOXBOX - ainda em nível do projeto conceitual, combina perfuração com produção, armazenamento e offloading.

Monocoluna - objeto de estudo nessa dissertação - é uma plataforma com formato monolítico com diversas características que estão apresentadas no item 2.3.

\subsection{O PROJETO DA PLATAFORMA MONOCOLUNA}

A monocoluna se assemelha à SPAR por ter forma cilíndrica e também por ser projetada para operação em grandes profundidades, entretanto tem características diferentes por ter uma razão diâmetro/calado muito maior do que as SPARs. O 
formato cilíndrico oferece significativa redução do movimento da estrutura em decorrência das ações do mar e do vento, o que também é favorável aos processos de recebimento e tratamento do óleo a bordo. Devido à estrutura simétrica da plataforma, o processo de construção se torna mais simples, se comparado com a opção convencional, que é a conversão de um navio petroleiro em FPSO.

A Sevan Marine acaba de colocar em operação junto à Petrobras a primeira unidade de produção desse tipo no campo de Piranema, a SSP Piranema, que corresponde ao modelo SSP-300, tem capacidade de produção equivalente a 30 mil barris de petróleo por dia e capacidade de armazenamento de 300 mil barris de petróleo trabalhando em lâmina d'água entre 1.100 e 1.600 metros, de acordo com [1].

Várias plataformas com diversas respostas de movimento e estabilidade podem ser geradas a partir do conceito monocoluna, e ao grupo de plataformas estudadas foi dado o nome de "família monocoluna". Dentre a família podem ser encontradas plataformas cilíndricas ou poligonais em geral, com arestas chanfradas ou não, dependendo do tipo de operação e do campo designado. Podem assumir diversas relações boca/calado e podem ser equipadas com apêndices para redução de movimento. Suas vantagens principais são:

Custo do sistema de ancoragem mais baixo devido à simetria cilíndrica do casco; diferentemente das SPARs, as monocolunas geralmente aceitam cargas elevadas no convés e têm uma área razoável disponível para a montagem da planta de processo; o conceito da monocoluna pode ser projetado para grande capacidade de armazenamento de óleo, chegando até 1.600 .000 barris, apresentando um peso de aço $20 \%$ mais baixo do que o FPSO equivalente (sempre com ambos sob as mesmas premissas).

A eficácia de uma plataforma não está meramente no peso estrutural e na estratégia da construção, deve-se procurar satisfazer às características operacionais particulares, o que pode aumentar o valor do conceito, com projetos personalizados para cada campo.

Os cascos da monocoluna apresentam uma estrutura monolítica com inércia elevada na diagonal do cilindro, tornando-a não muito sensível aos momentos causados por ondas do mar e por planta de carregamento. Do mesmo modo, o diâmetro máximo e sua simetria não fornecem forças de torção significativas no cálculo de dimensões estruturais. 
A Figura 4 mostra dois modelos de monocolunas, uma com seção horizontal cilíndrica e outra com seção horizontal poligonal.
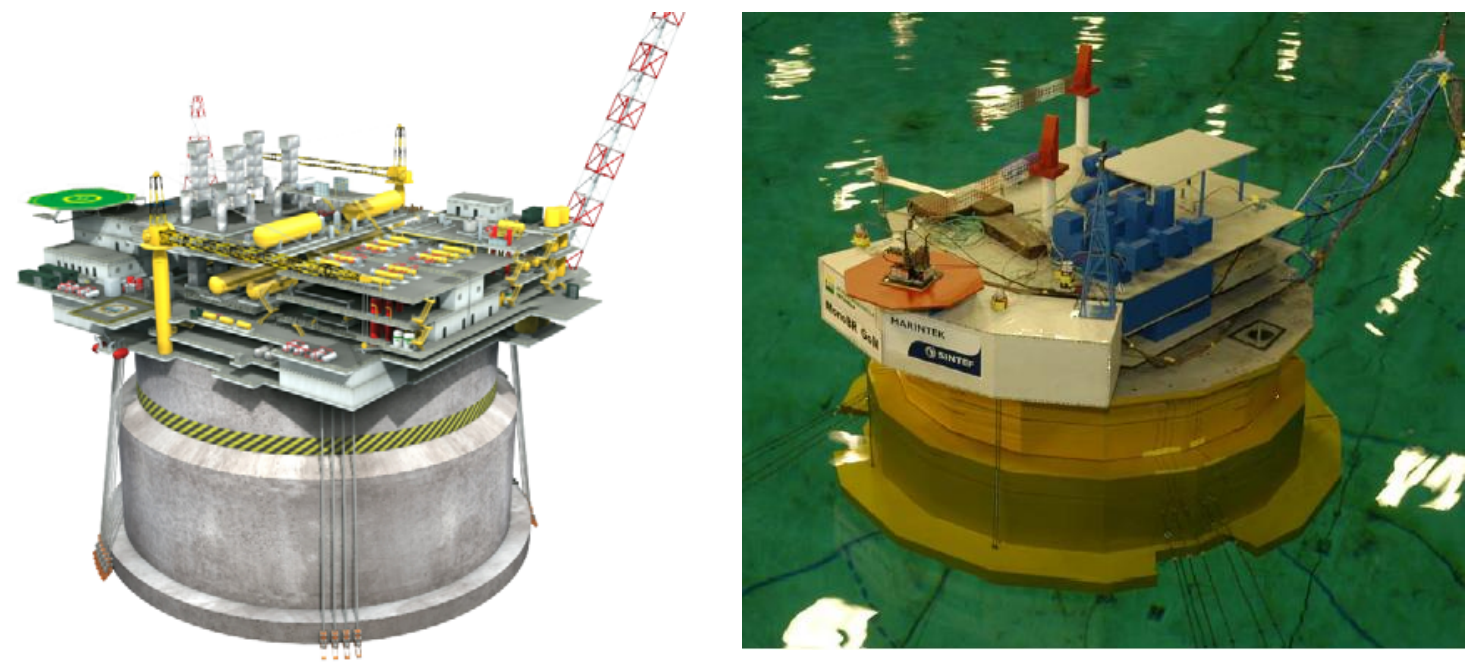

Figura 4. Diferentes possibilidades de monocolunas

Com o intuito de reduzir os movimentos da plataforma sem ser necessário aumentar seu deslocamento, foi estudada a utilização de dispositivos de minimização de movimentos no projeto de monocolunas: dispositivos que têm como principal função alterar a freqüência natural do sistema deslocando-a para fora da região de alta energia do espectro de ondas. Para isso, foram utilizados os dispositivos denominados: moonpool, saia e praia [10].

Embora o efeito do uso de bolinas seja proporcional ao aumento de suas dimensões, existe limitação devido ao aumento da resistência ao avanço. Como os sistemas oceânicos são estacionários, não há limitação de resistência ao avanço quanto ao aumento das dimensões da bolina, o que pode transformá-la em uma saia estruturada (Figura 5). Com isso obtemos dois efeitos: o aumento do amortecimento e aumento da massa e inércia adicionais. 


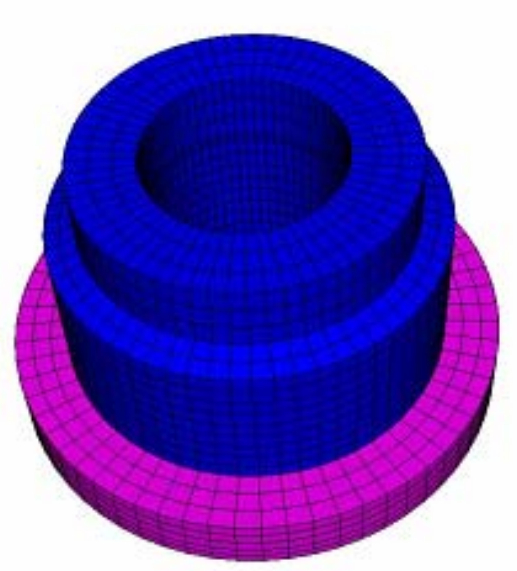

Figura 5. Modelo com a saia em destaque.

Outro apêndice utilizado na monocoluna é a praia, esse dispositivo (Figura 6) visa, além de aumentar a massa e inércia adicionais, reduzir o diâmetro do corpo cilíndrico gerando diminuição da altura metacêntrica e, conseqüentemente, um aumento no período natural do sistema.

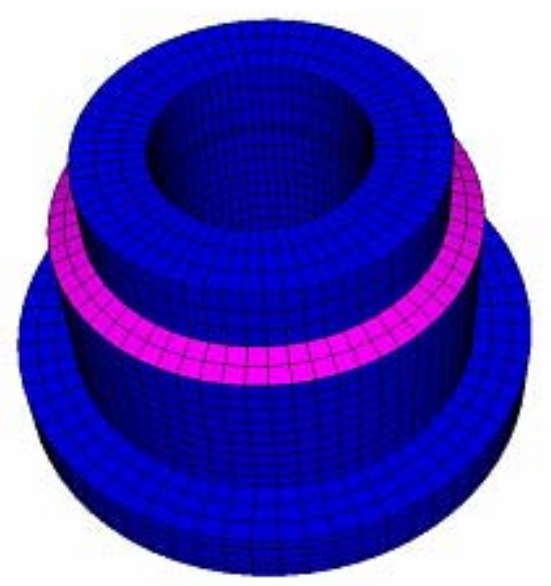

Figura 6. Modelo com a praia em destaque.

O moonpool (Figura 7), muito utilizado para a passagem de equipamentos em plataformas de perfuração, consiste em um tanque, normalmente no centro da embarcação, ligado com o oceano através de uma restrição ao fundo. Sua aplicação usual visa reduzir o movimento da água interna ao tanque, para que não haja avaria nos equipamentos que serão movimentados através do moonpool. Nesse projeto o moonpool e sua restrição foram ajustados para diminuir também o movimento da plataforma. 


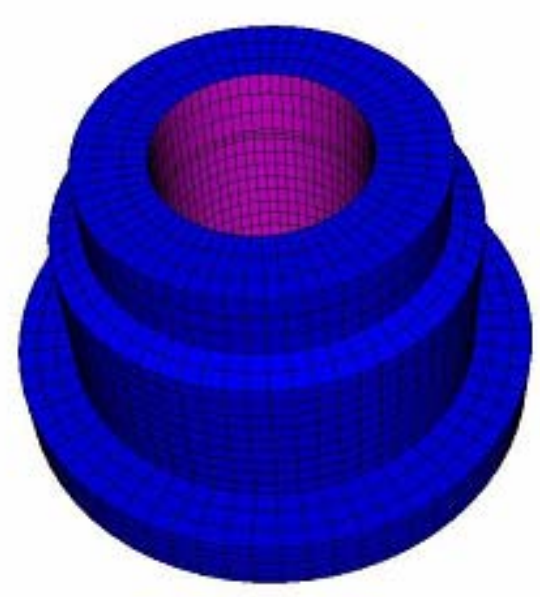

Figura 7. Modelo com o moonpool em destaque.

A monocoluna pode ser projetada com seção horizontal redonda ou poligonal, em geral. As principais diferenças de estabilidade entre a monocoluna de seção quadrada para a de seção redonda, que seriam os dois extremos do conceito, são as duas listadas abaixo:

- Para as mesmas dimensões máximas, o formato quadrado tem maior inércia de linha d'água, o que implica em uma altura metacêntrica maior (GM), e pode ser calculado por meio da equação:

$$
\mathrm{GM}=\mathrm{KB}+(|\mathrm{W}| / \nabla)-\mathrm{KG}
$$

- O coeficiente de arrasto ( $\mathrm{Cd}$ ) é maior no formato quadrado que no redondo, 2 e 0,5 respectivamente. $O$ uso de cantos arredondados (adoçamentos) no formato quadrado (Figura 10) diminui essa diferença.

Observa-se que para alguns números de Reynolds, um formato quadrado com adoçamento, ou seja, com cantos arredondados (com raio igual a $10 \%$ do lado do quadrado), já faz com que o coeficiente de arrasto baixe de 2,0 (Figura 9) para 0,7 (Figura 8), o que pode ser considerado aceitável, dependendo das condições de operação da plataforma. As duas figuras seguintes apresentam resultados de ensaios para cascos quadrados com adoçamento e sem adoçamento. 


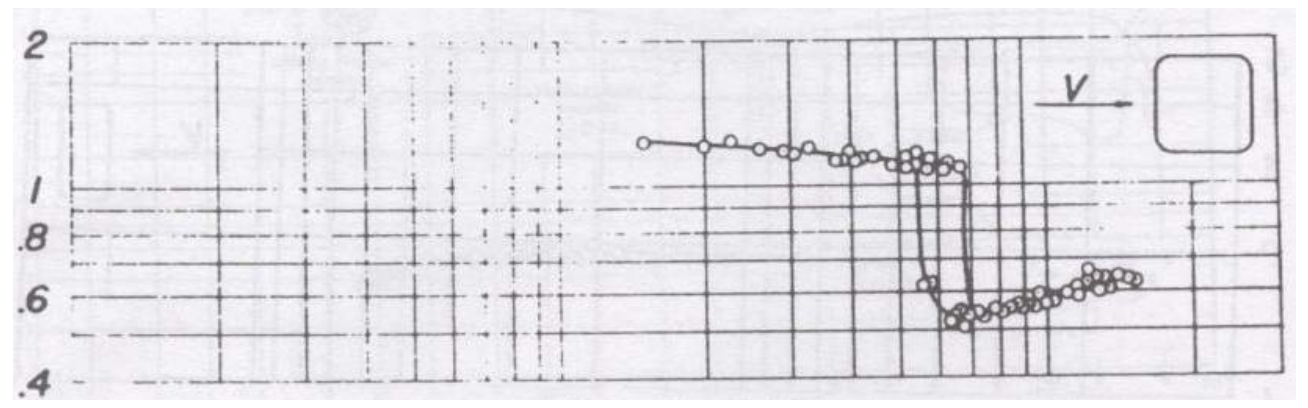

Figura 8. Cd versus Reynolds para adoçamento de $10 \%$ (modificado de [6])

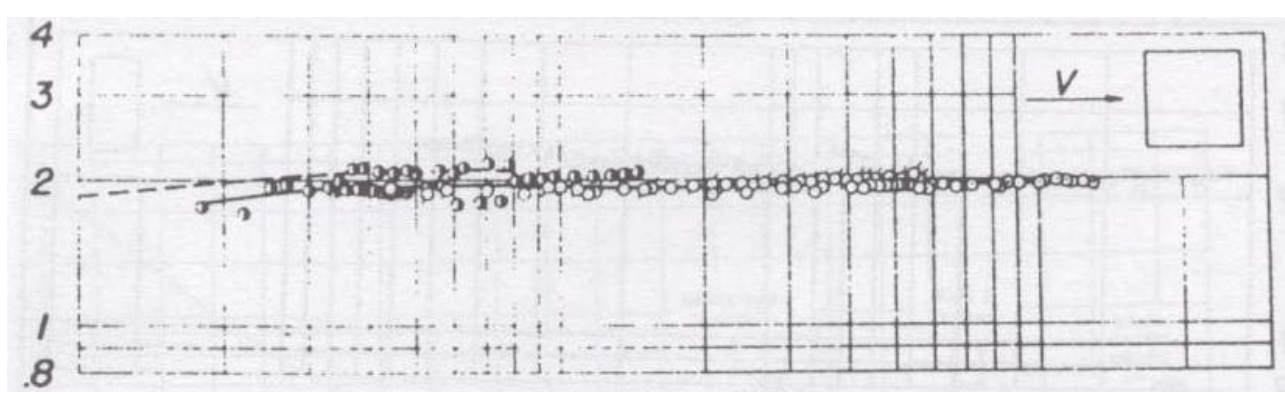

Figura 9. Cd vs Reynolds seção quadrada (modificado de [6])

Em todos os casos gerados, nenhuma geometria se provou ser superior a outra, suas diferenças em relação à hidrodinâmica e estabilidade podem ser eventualmente contrabalanceadas com possíveis diferenças construtivas e de custos, o que leva a crer que se deve manter não apenas um caso como resultado dos estudos, e sim uma família de cascos embaixo do conceito monocoluna.

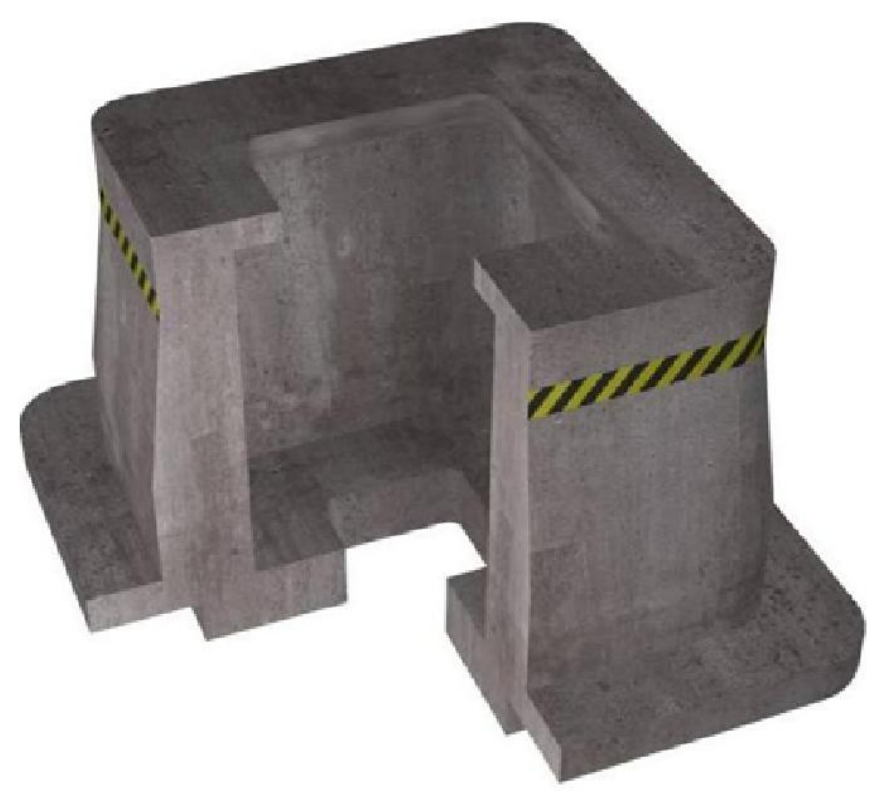

Figura 10. Casco quadrado com adoçamento 
Ainda em relação a forma da monocoluna pode-se destacar a compartimentagem, que é a subdivisão interna da unidade para que essa tenha compartimentos que recebam lastro, óleo, combustível, acomodações, passagens, etc. Nesse trabalho, mencionado o termo compartimentagem, está se referindo à filosofia de subdivisão dos tanques de óleo e lastro - que no caso de uma unidade de produção e estocagem de petróleo são os de maior número e volume.

Inicialmente a compartimentagem foi gerada com base nas análises de semelhantes, dividiu-se a plataforma da seguinte maneira: foram utilizadas anteparas radiais (seguindo o padrão das plataformas do tipo SPAR), dividindo o casco em partes que tomam toda a altura do casco. Cada parte foi subdividida em tanques por anteparas horizontais. Esses tanques foram definidos por análises de tanques semelhantes, para que eles possuíssem tamanho similar aos que já existem, para que fossem operacionais no lastramento e deslastramento.

Mais tarde notou-se que eram possíveis diversos tipos de compartimentagem já que a plataforma comumente apresenta boa resposta em avaria.

Ao se compartimentar uma plataforma, pode se ter como premissa a facilidade de construção, a segurança, a acessibilidade. Na monocoluna, por essa ter característica geométrica singular, é possível imaginar diversos tipos de subdivisão, como por exemplo, tanque no formato de gomos (Figura 11), com subdivisão convencional (Figura 12) ou com duas camadas de tanque (Figura 13):

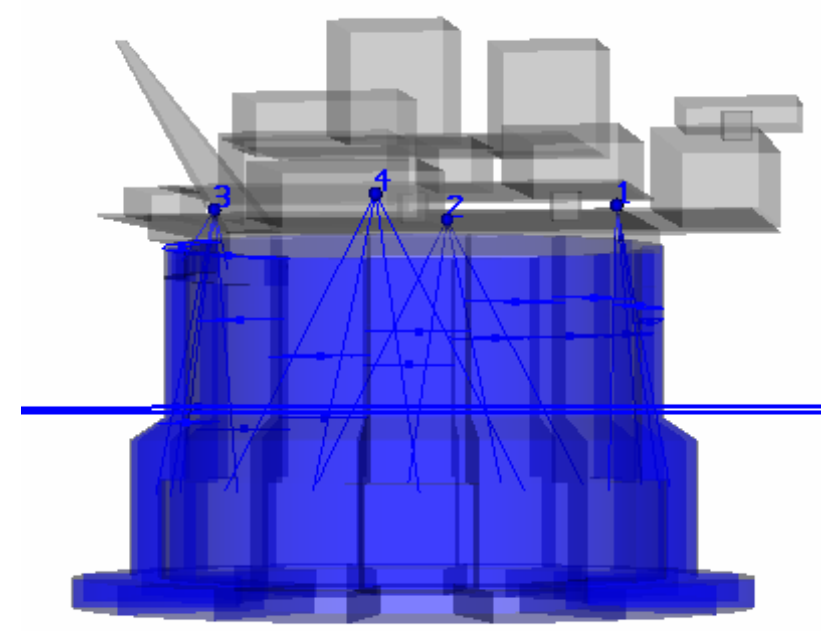

Figura 11. Tanques no formato de gomos 


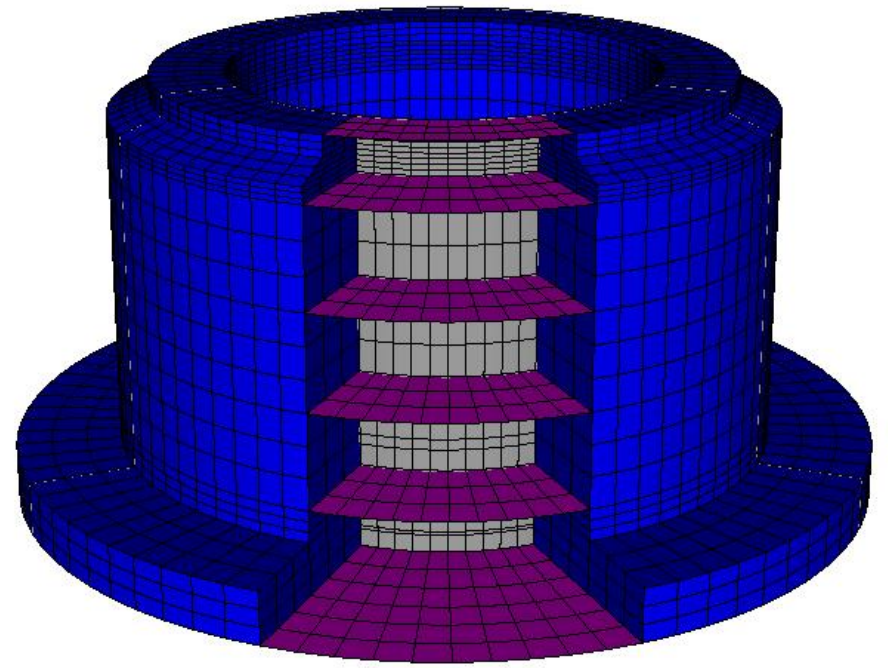

Figura 12. Tanques com subdivisão convencional (inicial)

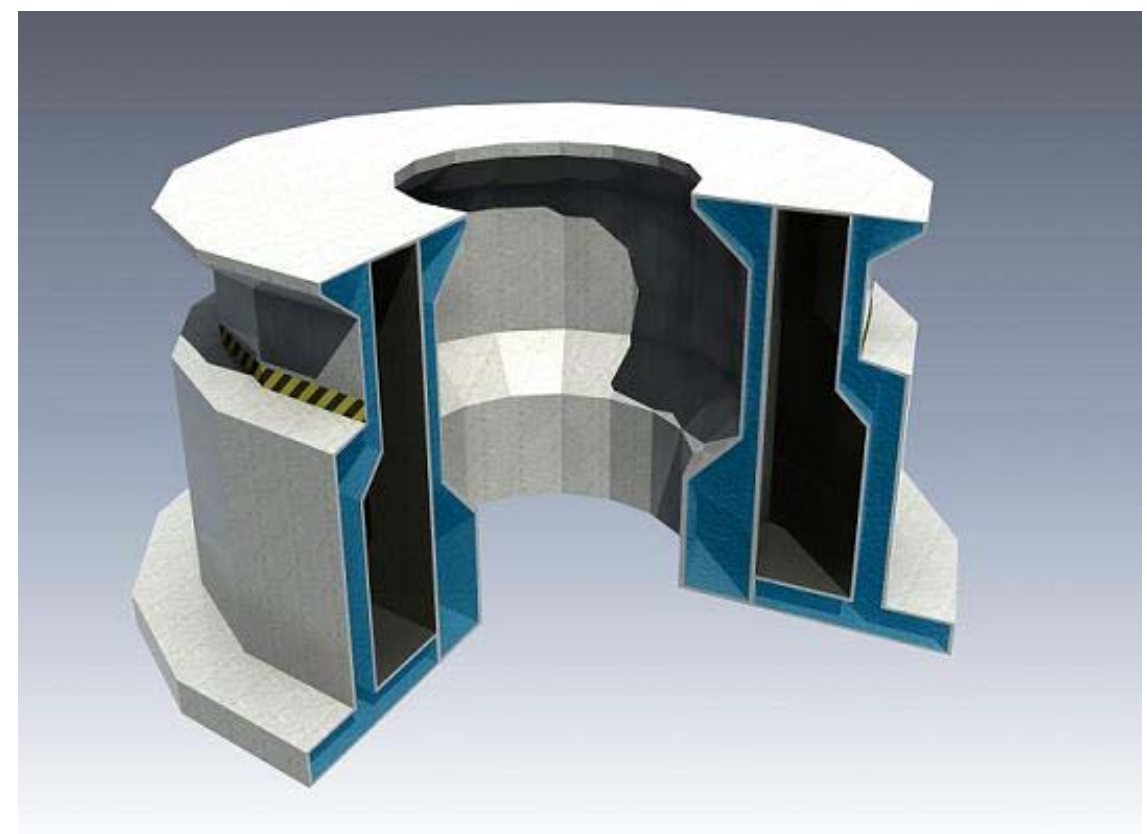

Figura 13. Duas camadas de tanques 


\subsection{HISTÓRICO MONOCOLUNA}

Todas essas características foram testadas com diversas combinações, entretanto houve um longo percurso para se chegar ao formato apresentado. A partir da idéia de um casco monolítico surgiu um grupo de pesquisa com apenas três pessoas e três grandes áreas: arquitetura naval, hidrodinâmica e risers e amarração. Essa pesquisa gerou diversos estudos de sistemas flutuantes, que se desenvolveram em pequenos projetos de unidades monocoluna, ou seja, possibilidades de formatos e tipos de plataformas monocolunas diversas, de onde surgiu o conceito de monocoluna com apêndices para redução de movimento quais foram avaliados e validados como apresentados anteriormente nesse capítulo. Surge assim, o primeiro caso monocoluna, batizado de MonoBR. Esse foi o nome dado para diversos cascos com diversas formas no início do grupo de projetos, já que havia constantes mudanças de premissas e metodologias de análise.

Mais tarde, com um grupo de projetos bem maior impulsionado pela repercussão positiva dos casos iniciais MonoBR, foram colocados em prática métodos de gerenciamento de projeto, que trouxeram organização e rapidez para as análises.

Com um grupo mais bem estruturado, foi possível perceber que todas as análises geraram não apenas um casco de plataforma, e sim um novo conceito de plataforma, a família monocoluna, que tem diversos elementos que quando combinados dão origem a inúmeros cascos que apresentam diferentes comportamentos em ondas, podendo ser utilizados em diversos campos. Ao longo dos projetos, surgiram seções horizontais redondas, quadradas, poligonais, com ou sem adoçamento, com ou sem compartimentagem vertical, com casco simples ou duplo. Para exemplificar, a seguir apresentam-se os casos mais importantes gerados e que possuem maior detalhamento:

MonoBR - seção horizontal redonda, saia, praia, moonpool, muito compartimentada, diversos deslocamentos

MonoBR 37KT - seção horizontal redonda, saia, praia, moonpool, muito compartimentada, deslocamento 37 mil ton.

MonoBR 37KT quadrada - seção horizontal quadrada com adoçamento, saia, praia, moonpool, muito compartimentada, deslocamento 37000 ton. 
MonoBR 37KT poligonal com tanques em gomo - seção horizontal poligonal sem adoçamento, saia, praia, moonpool, poucos tanques, deslocamento 37000 ton. Itapoá - seção horizontal redonda, saia, praia, moonpool, poucos tanques em gomos, sem armazenagem, casco duplo (plataforma desenvolvida para um concurso internacional de estudantes).

MonoGOM - plataforma desenvolvida para a Petrobras America para operação no golfo do México, seção horizontal poligonal, saia, praia, moonpool, poucos tanques em gomos, com armazenagem, casco duplo.

P56 - plataforma desenvolvida para operação no campo de Marlim Sul, seção horizontal poligonal, saia, praia, moonpool, poucos tanques em gomos, com armazenagem, casco duplo.

Esses casos tiveram projetos que passaram por diversos ciclos da espiral de projetos e conseqüentemente, foram bem detalhados, foram submetidos a testes em tanques de prova, e alguns têm potencial para evoluírem para projeto básico e detalhado. A Figura 14 mostra alguns exemplares da família monocoluna, que compõe fases de seu histórico.

Dado o caráter inovador do conceito, havia dúvida sobre a segurança e reserva de estabilidade desse tipo de plataforma monolítica. Este foi um dos grandes motivadores para essa dissertação, evidenciando que se comprovou a boa segurança da mesma após muitas análises em diversos formatos possíveis. 


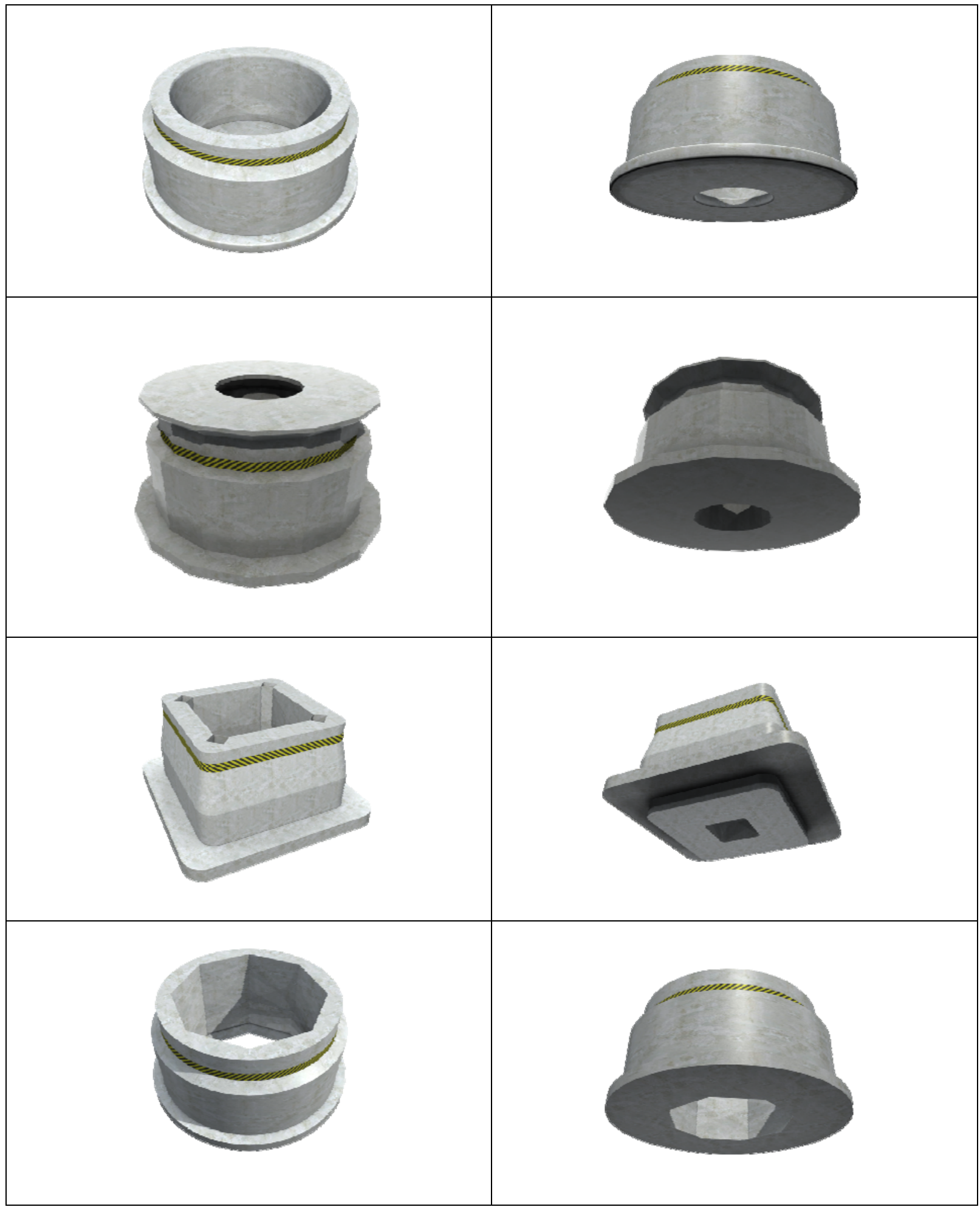

Figura 14. Exemplares da família monocoluna 


\subsection{SÍNTESE DO CAPÍTULO}

Dentre os projetos de plataformas define-se a segregação em duas classes: plataformas em operação e plataformas em estudo. Das plataformas em estudo surge um novo conceito de plataformas, a monocoluna, com o propósito de atender condições específicas de certos campos de produção. Esse conceito possui elementos que o caracterizam como saia, praia e moonpool, além de poder ser construído em diversas formas e tamanhos, para que se adeqüe a diversas características de campos de produção. Essas possibilidades geraram uma nova família de plataformas a qual foi dado o nome de família monocoluna. Essas plataformas podem ser projetadas para atender diversos campos de produção por apresentarem grande flexibilidade no dimensionamento. 


\section{METODOLOGIA DE GERAÇÃO DE CASOS}

Para que fosse possível a criação de diversos casos a partir de poucas premissas, foi necessário desenvolver uma metodologia de geração de unidades monocoluna. Essa metodologia baseou-se principalmente em dois conceitos de gerenciamento de projetos: Espiral de Projetos e Engenharia Simultânea. Esses dois conceitos atrelados a uma cadência lógica de atividades, fizeram com que fosse possível a geração de diversos tipos de monocoluna e também diversas variações do mesmo tipo (opções para campos de produção distintos), em um curto espaço de tempo, o que foi fundamental para que se testasse por repetidas vezes a estabilidade desse sistema flutuante.

\subsection{ESPIRAL DE PROJETOS}

Fazer um projeto baseado numa espiral de projetos é partir de análises superficiais e ir progressivamente refinando-as para que ao término de todas as rodadas do projeto se obtenha o resultado esperado, a Figura 15 ilustra esse conceito e nela as letras representam os processos e análises como: dimensionamento, análise hidrodinâmica, compartimentagem, análise de estabilidade, análise estrutural, e assim por diante. Imagine que a letra A seja o dimensionamento do casco, ele é feito e revisado inúmeras vezes (setas) para que se atinja o resultado final (centro da espiral), de forma análoga acontece com todos os outros processos. Essa metodologia viabiliza a concepção do projeto a partir de diversas inferências a priori, fazendo com que seja possível montar um esboço inicial do projeto, revalidando-o a cada ciclo. 


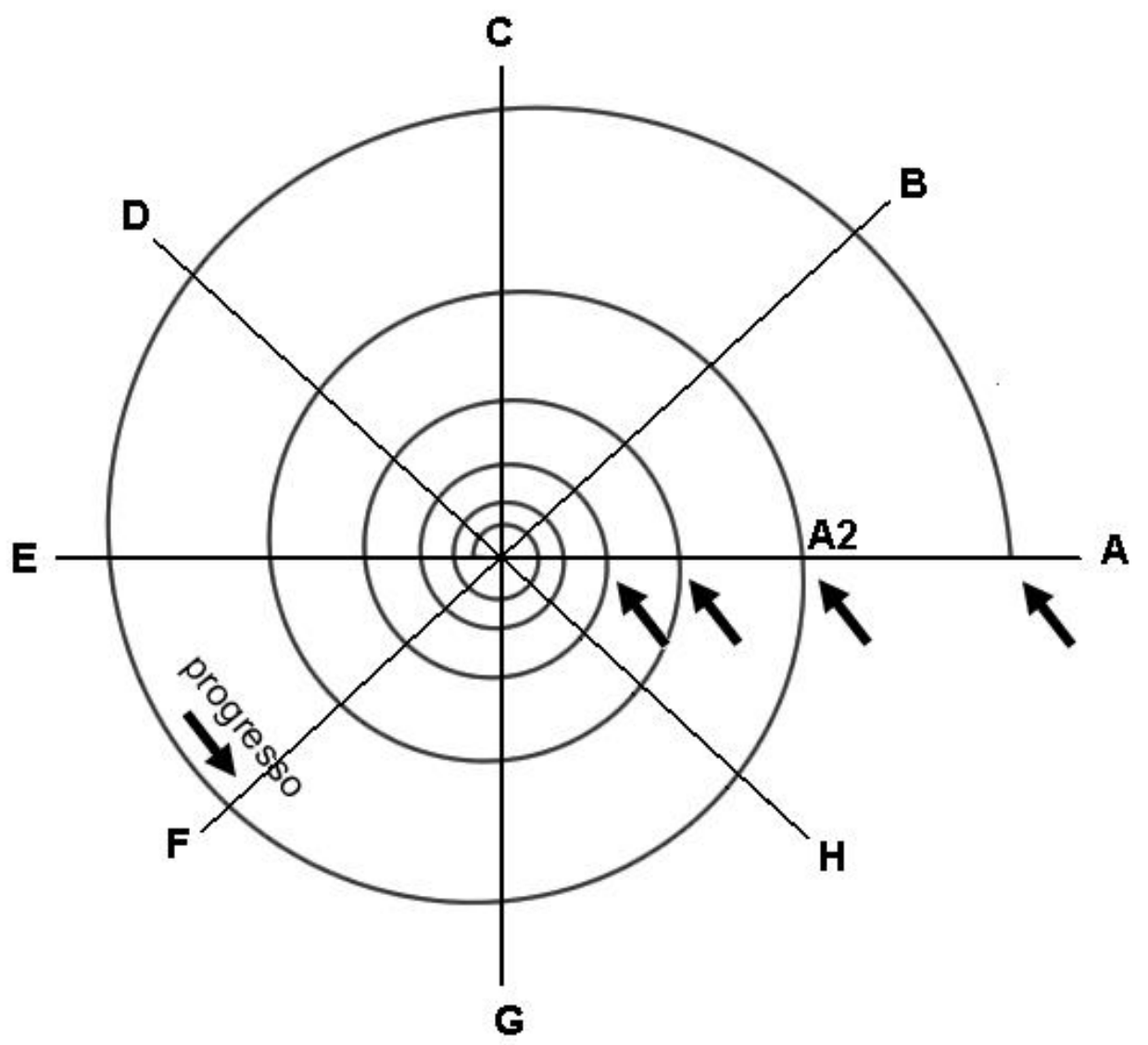

Figura 15. Esquema geral da espiral de projetos

\subsection{ENGENHARIA SIMULTÂNEA}

Ao longo dos diversos casos monocoluna, sempre se analisa sua viabilidade em diversos sentidos, abordando desde arquitetura naval e comportamento em ondas até sua construção e instalação, para isso, a filosofia da Engenharia Simultânea faz com que se poupe tempo de retrabalho, de acordo com K.J. Sharma, B. Bowonder [8]. A troca de informações entre os colaboradores é constante, o projeto considera todas as fases da "vida" de um produto, incluindo manufatura, operação, manutenção, disposição final, desde o seu projeto de concepção. Aplicando essas filosofias de projeto, os tempos de produção e de projeto podem ser reduzidos e a 
qualidade do produto melhorada, proporcionando assim um produto com qualidade superior e custo menor, que pode ser introduzido no mercado mais rapidamente.

$\mathrm{O}$ aumento na produtividade e a melhoria da qualidade usando a filosofia da Engenharia Simultânea têm se confirmado nas indústrias eletrônica, aeronáutica e automobilística, e o resultado da utilização desses métodos nesse projeto conceitual se mostrou altamente útil, pois diminuiu retrabalho e fez com que o projeto atingisse esferas que não eram muito exploradas anteriormente, como por exemplo, a otimização de blocos estruturais visando construção em estaleiros brasileiros.

\subsection{FLUXOGRAMA DE GERAÇÃO DE CASOS}

Para a análise das dimensões principais da plataforma monocoluna foi necessário o desenvolvimento de uma planilha numérica que incorporasse todos os fatores referentes a este estudo, tendo em vista que devido ao alto grau de comprometimento entre as variáveis do empreendimento, torna-se inviável a análise em separado de cada um dos itens. Cada caso foi gerado a partir de uma planilha base que através das formulações apresenta estimativa do comportamento inicial dessa plataforma, em seguida essa tem sua análise hidrodinâmica validada, e então parte-se para a estabilidade, seguida pela amarração e assim sucessivamente, através da metodologia de espiral de projetos apresentada no item 4.1 (Figura 16). 


\section{Processo de geração de cascos utilizando a espiral de projetos}

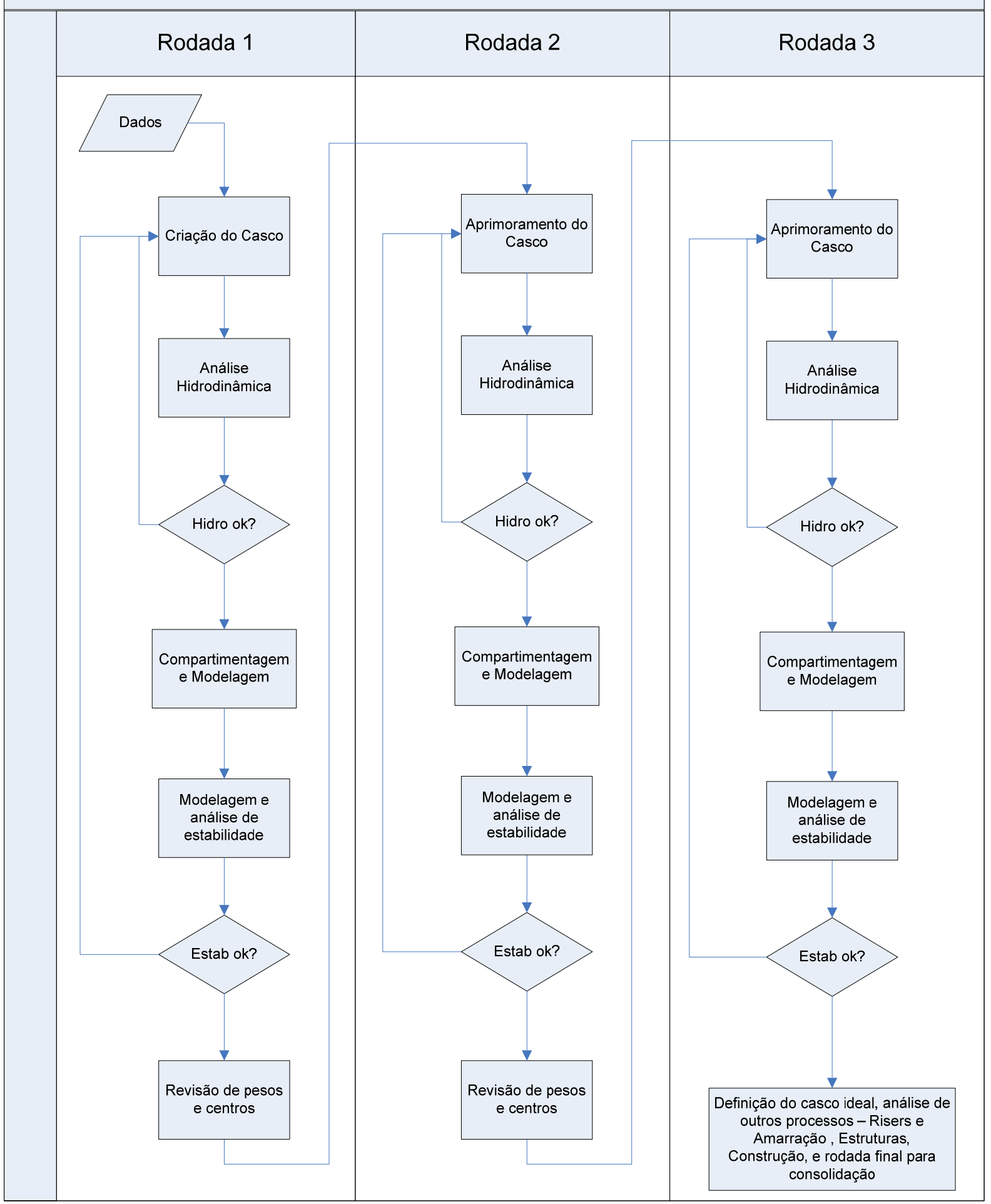

Figura 16. Fluxograma de dimensionamento 


\subsection{SÍNTESE DO CAPÍTULO}

Com a utilização de metodologias de gerenciamento de projetos e a organização das atividades de forma rigorosa por meio de atividades encadeadas foi possível criar um mecanismo de geração de casos de monocoluna que se provou muito eficiente, pois era capaz de gerar e analisar um casco para um determinado campo de operação em muito pouco tempo. Para que fosse feita a análise de viabilidade de uma monocoluna a um campo específico era necessário apenas um dia. Isso fez com que muitos casos fossem gerados e inúmeras análises de estabilidade fossem realizadas, o que foi fundamental no entendimento do comportamento da plataforma não só no que diz respeito a estabilidade estática e avariada, mas também com relação a seu comportamento em ondas, características estruturais e assim por diante 


\section{ESTABILIDADE DE PLATAFORMAS FLUTUANTES}

\subsection{ESTABILIDADE ESTÁTICA}

Estabilidade estática define-se por: dada uma perturbação no casco, diz-se que ele está em equilíbrio estável quando, ao ser deslocado de sua posição inicial, retorna à mesma. Se o corpo não retornar ao ser deslocado da posição inicial, o corpo pode estar em equilíbrio instável ou indiferente (Figura 17).

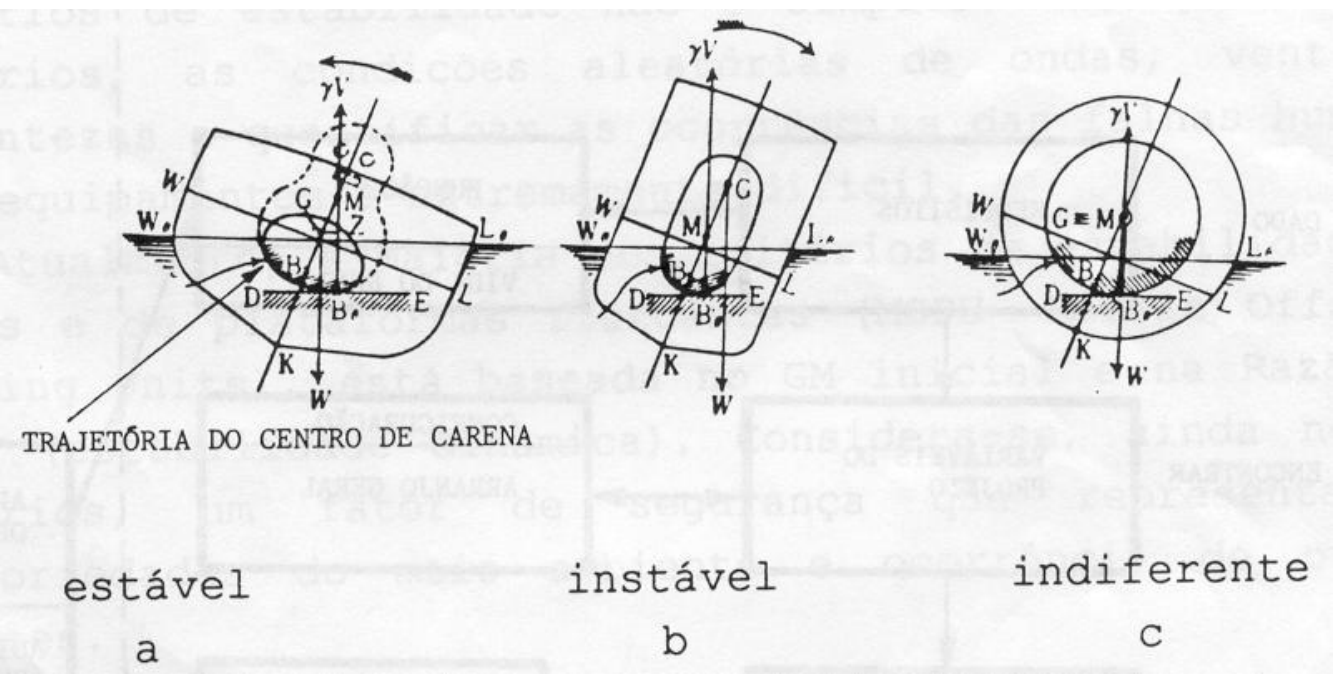

Figura 17. Equilíbrios estável, instável e indiferente (modificado de [6])

\subsection{CRITÉRIOS DE GM}

A análise de estabilidade inicial começa com a simulação de um teste de inclinação, e para cada ângulo de inclinação, é preciso obter o braço de endireitamento. Com o braço (GZ) e o ângulo de inclinação, é possível traçar a curva $G Z$ versus inclinação. Na Figura 18 e na Figura 19, apresenta-se os esquemas do teste de inclinação e 
como se obtém o braço GZ. Para pequenas inclinações (até $7^{\circ}$ ), GZ=GM sen $\alpha$, onde $\alpha$ é o ângulo de inclinação do casco.

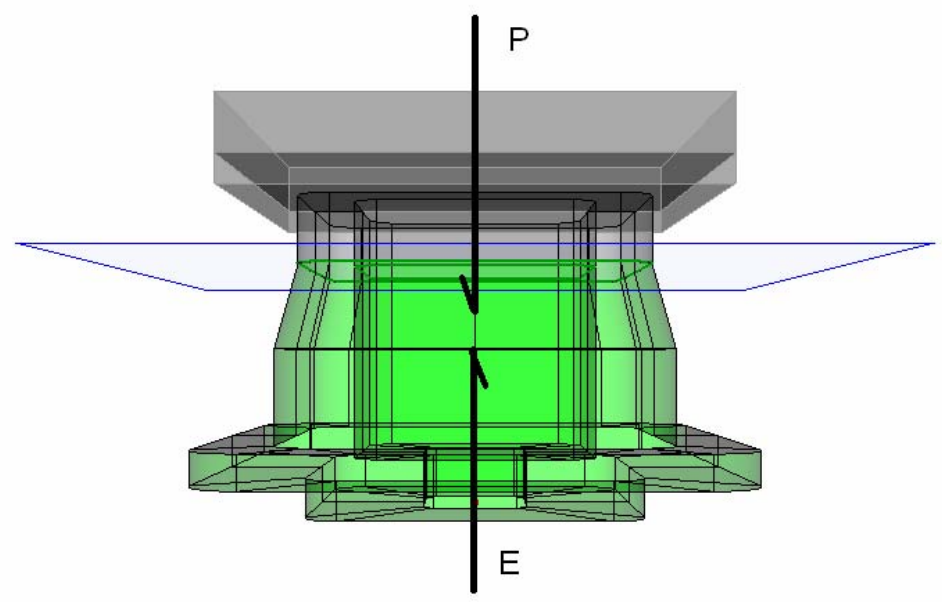

Figura 18. Força peso e empuxo agindo na plataforma a $0^{\circ}$ (não há braço GZ)

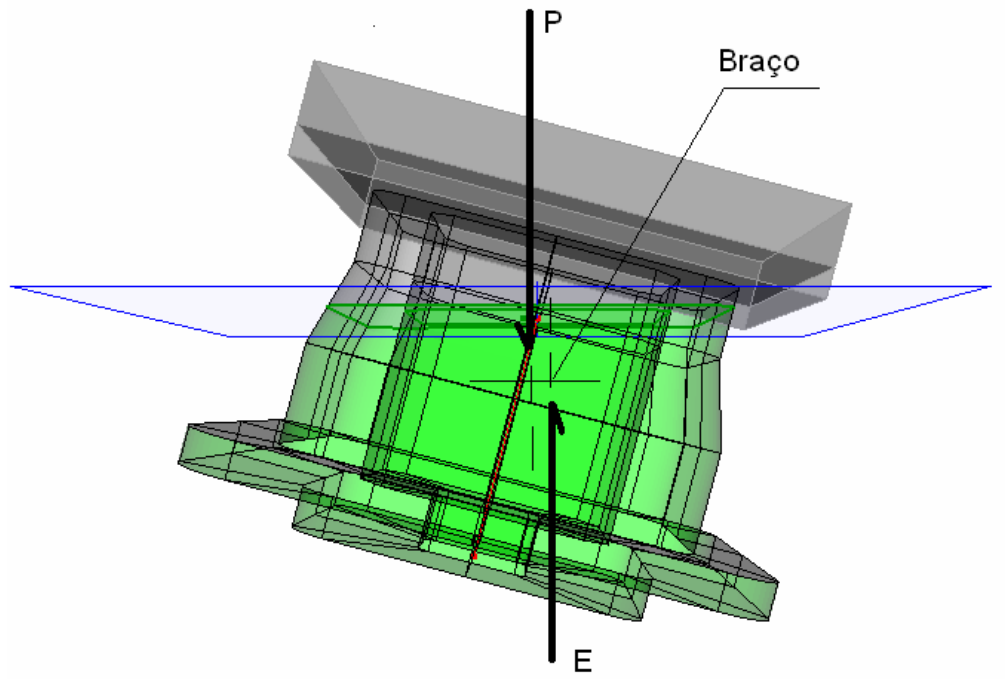

Figura 19. Força peso e empuxo agindo na plataforma a $7^{\circ}$

\subsection{ESTABILIDADE DINÂMICA}

Atualmente, a maioria dos critérios de estabilidade está baseada no GM inicial e na razão de áreas (estabilidade dinâmica), que está apresentada no item 4.4. Considera-se nestes critérios um fator de segurança que representa as 
aleatoriedades do meio ambiente. Com as simulações de ocorrências considerando as probabilidades, pode-se calcular o risco em que as embarcações emborcam (Figura 20).

\section{FREQUENCIA}

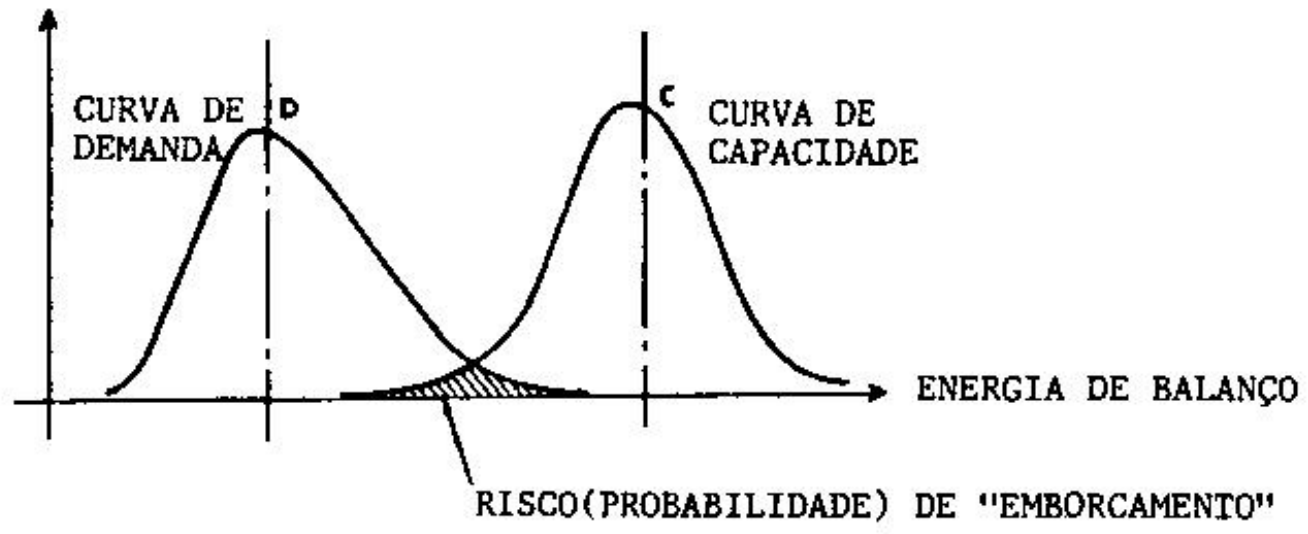

Figura 20. Risco de emborcamento (modificado de [6])

\subsection{CRITÉRIOS DE ÁREA}

Para a análise dos critérios de área é preciso traçar a curva de estabilidade intacta do sistema naval (curva GZ X $\theta$ ) obtida através de cálculos geométricos da parte imersa do corpo flutuante. Esta curva representa o trabalho (energia) realizado para inclinar o navio até o ângulo $\theta$. A Figura 21 exemplifica a curva que representa o trabalho necessário ao corpo flutuante que este incline de um certo ângulo (a área sobre o gráfico desde o ângulo $\theta \mathrm{A}$ até $\theta \mathrm{B}$ ). 


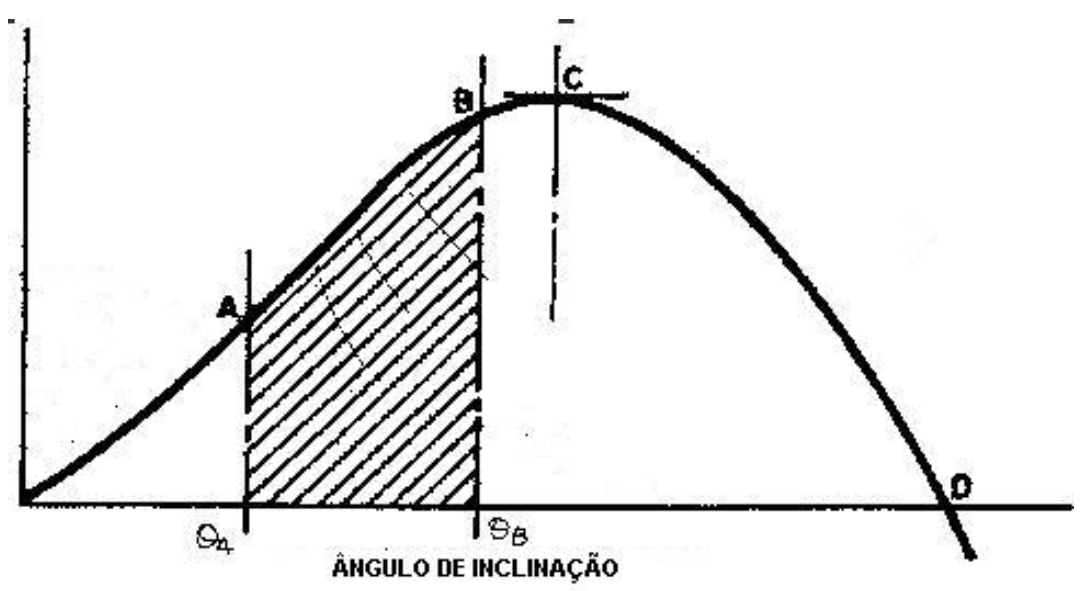

Figura 21. Energia de restauração e momento emborcador (modificado de [6])

Momento emborcador é gerado pelo conjunto força do vento e resistência da água, em contrapartida surge o momento restaurador, já que a plataforma em equilíbrio estável tende a retomar sua condição inicial. A Figura 22 ilustra os momentos emborcador e restaurador.

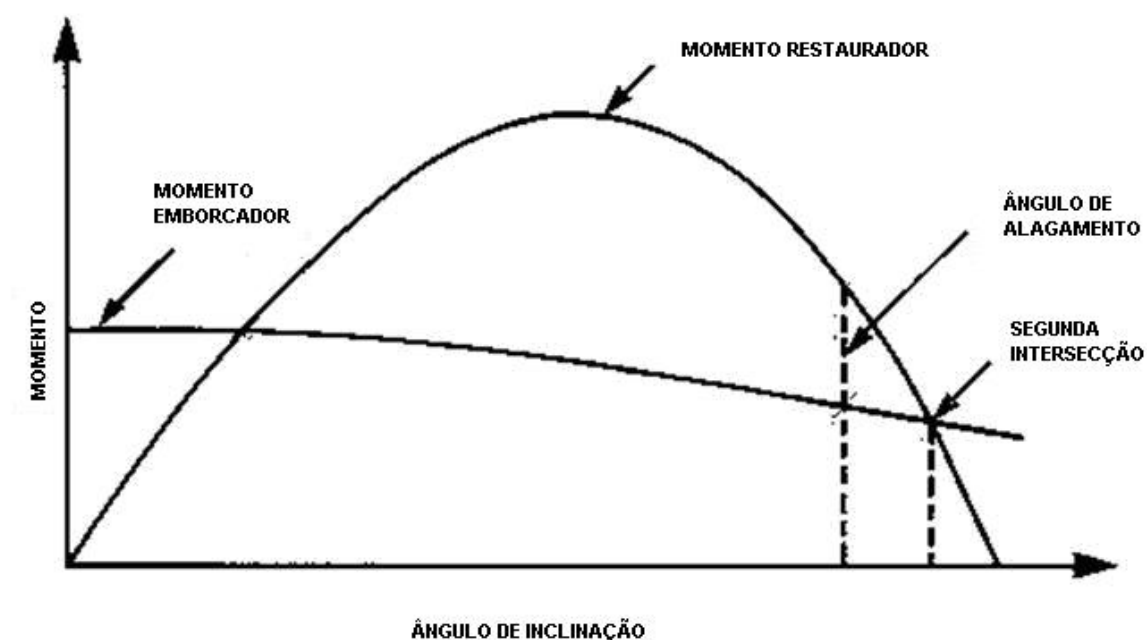

Figura 22. Momento restaurador vs emborcador (modificado de [6])

Um gráfico similar pode ser apresentado como esquema ilustrativo (Figura 23): 


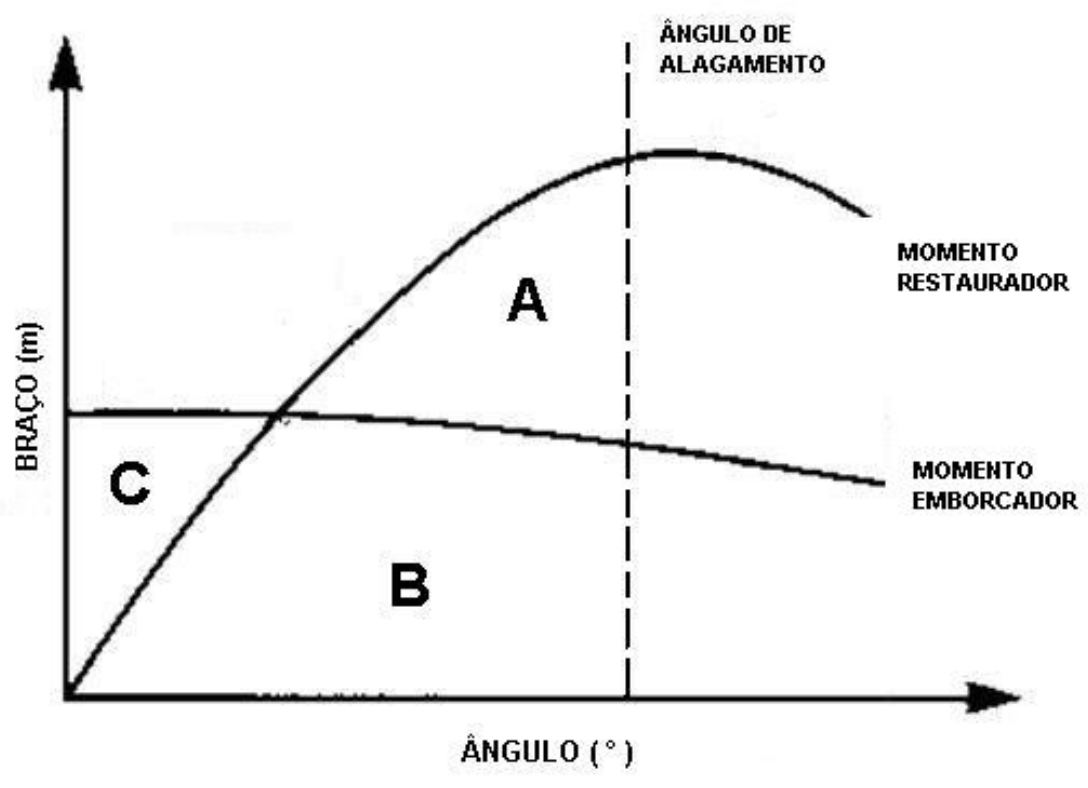

Figura 23. Critério estabilidade Intacta

Nesse gráfico de estabilidade (Figura 23) as áreas $A+B$ devem ser maiores que $B+C$ vezes um coeficiente $k$, que deve valer no mínimo 1,3 para semi-submersíveis. Isso porque a energia de restauração da plataforma deve ser no mínimo 1,3 vezes maior que a energia de emborcamento, ou seja:

$$
(A+B) \geq 1,3 \times(B+C)
$$

Já no critério de estabilidade avariada o fator $k$ vale 1,0 , a área de $A+B$ deve ser no mínimo igual à área $B+C$, ou seja:

$$
(A+B) \geq 1,0 \times(B+C)
$$

Isso representa que a energia que a plataforma tem para retornar a posição original é maior ou igual à energia que o vento impõe na plataforma para que a mesmo emborque. As áreas citadas são definidas pelas curvas de momento e pelo downflooding angle, que é o ângulo onde ocorre o toque do primeiro ponto da plataforma na água e começa o alagamento da mesma.

A razão de área mostra a energia que a plataforma tem para restaurar e a energia que o vento provoca na plataforma para essa emborcar $A$ razão de área é justamente o resultado de:

$$
(A+B) /(B+C)
$$


Quanto maior essa razão, maior a estabilidade da plataforma, ou seja, maior a chance dela retornar a posição original quando provocada por uma força.

\subsection{CRITÉRIOS DE ESTABILIDADE VIGENTES}

As entidades estatutárias são órgãos legislativos cujas regras, critérios e procedimentos que devem ser atendidos por força de lei, certificam as embarcações. No âmbito marítimo internacional, essas entidades estão agrupadas da seguinte forma:

País de registro: Toda embarcação é registrada num país, denominado "bandeira" dessa embarcação, cujos regulamentos devem ser atendidos.

Área de operação: São entidades governamentais responsáveis pela fiscalização das embarcações operando em suas águas territoriais e visam basicamente segurança, tráfego e poluição.

Acordos internacionais: acordos efetuados entre países que registram plataformas ou abrigam atividades offshore. A principal é a International Maritime Organization (IMO), braço da ONU, que elabora e revisa regulamentos específicos para embarcações moveis engajadas em atividades petrolíferas, e da qual o Brasil é signatário.

Sociedades Classificadoras: entidades privadas e independentes que podem classificar e certificar certo projeto, a construção e operação de embarcações e sistemas navais. Têm a função de avalista para seguradoras e controle de qualidade para o armador. Dentre as entidades estatutárias e sociedades classificadoras, são estas cujos critérios podem ser usados para análise de estabilidade no sentido de adequação das plataformas aos padrões internacionais: DNV, IMO - MODU, ABS, NMD.

Em linhas gerais, os critérios de classificação são semelhantes e não abrangem novos conceitos, notam-se também diferenças entre os critérios como, por exemplo, a ABS difere da DNV no sentido de que não fixa ângulos máximos de inclinação para avaliação de estabilidade intacta e avariada, limitando-se a restringir a inclinação à integridade das regiões impermeáveis a alagamento ou impermeáveis a 
chuva. Contudo, ao submeter os sistemas flutuantes a uma combinação dessas sociedades, se garante a estabilidade dos sistemas convencionais.

O IMO-MODU tem regras claras e simples, que formam a base das regras das sociedades classificadoras, que direcionam os regulamentos segundo parâmetros indicativos dos riscos operacionais da seguinte maneira:

Local de operação irrestrito: Prevê a operação da unidade em qualquer local dentro das áreas petrolíferas comumente exploradas. Considera que o risco é maior do que em locais de operação restritos, pois engloba regiões com condições ambientais severas como Mar do Norte e Golfo do México.

Local de operação restrito: Prevê a operação apenas em uma região pré definida, como por exemplo, a Bacia de Campos, e considera o risco especifico da região, limitado a um patamar mínimo.

Está implícito nas regras que condições operacionais permanentes e transitórias, e os calados a elas associados implicam em níveis de risco e critérios diferenciados, calados nos quais a unidade passa a maior parte da sua vida, conseqüentemente estando sujeita a maior risco, são chamados de "calado ou condição permanente"; calados que a unidade atinge ao passar de uma condição a outra ou na instalação, e por isso o risco é menor, já que o tempo de exposição às intempéries da natureza é menor, são chamados de "calado ou condição temporária".

\subsection{DESCRIÇÃO GERAL DOS CRITÉRIOS}

Nesse capitulo está apresentada uma visão geral dos critérios de estabilidade, entretanto os critérios de estabilidade podem ser encontrados em sua íntegra nas referências [2], [3], [4] e [5].

Inicialmente apresenta-se o critério de estabilidade intacta, que é a analise da estabilidade da embarcação apenas sob a ação das intempéries naturais, sem danos, avarias ou alagamentos.

Em linhas gerais, os critérios para SS são enunciados a seguir:

- Todas as unidades devem ser capazes de passar por tempestade severas num período de tempo coerente com as condições climáticas do local. 
- Deve ser possível passar por períodos de tempestade sem que se tenha que realocar consumíveis sólidos ou outras cargas variáveis.

- Todos os procedimentos devem ser descritos no manual de estabilidade da plataforma.

- Pode ser aceitável que se tenha que realocar consumíveis para passar por tempestades severas, enquanto o VCG máximo não for excedido sob as seguintes condições:

o Num local onde as condições geográficas e climáticas sejam notoriamente brandas,

- Num local onde a plataforma esteja apta a carregar peso extra no convés por um curto período de tempo em que as condições climáticas sejam notoriamente conhecidas e brandas.

Essas regiões e condições climáticas devem ser apresentadas no manual de estabilidade.

Um critério de estabilidade alternativo (exceção) pode ser aceito se o nível de segurança for mantido e se a plataforma tiver uma boa reserva de estabilidade inicial. Para que esse critério alternativo seja aceito, as seguintes afirmativas são necessárias:

- Condições ambientais com ventos reais (incluindo rajadas) e ondas apropriadas para o serviço da unidade em vários modos de operação.

- A análise de resposta dinâmica da unidade deve incluir resultados de testes feitos em túnel de vento, tanques de prova, e simulação não-linear quando apropriado. Qualquer espectro de onda ou de vento usado deve abranger freqüências suficientes para assegurar que as condições de movimento críticas serão obtidas.

- A susceptibilidade ao emborcamento, deve considerar a energia de restauração da unidade e a inclinação estática devido a vento médio de operação e a resposta dinâmica máxima.

- Margem de segurança deve ser adequada para compensar incertezas.

Até esse ponto, é possível observar que as normas são flexíveis, ou seja, deve se analisar caso a caso a condição da plataforma, já os dois itens seguintes, são mais específicos e mostram o que já foi comentado no item 3.4. 
- A área sob a curva de momento restaurador no gráfico de momento versus ângulo de inclinação deve ser $30 \%$ maior que área sob a curva de momento de emborcamento, no mesmo ângulo limite.

- A curva de momento restaurador deve ser positiva até a segunda intersecção."

Com o cumprimento desses itens, referentes à SS, a estabilidade intacta de uma monocoluna pode ser satisfeita.

Em seguida, são apresentados os critérios para estabilidade em avaria, que é a análise da estabilidade da embarcação após ter sofrido avaria com conseqüente alagamento ou inundação, sujeito ainda às intempéries da natureza.

Em linhas gerais, os critérios são descritos da seguinte maneira.

A plataforma deve ter borda livre suficiente e ser subdividida por anteparas estanques de forma que exista suficiente estabilidade e flutuabilidade para que a instalação agüente um vento de 50 nós $(25,8 \mathrm{~m} / \mathrm{s})$, aplicado em qualquer direção na plataforma em calado de operação ou trânsito, levando em consideração as seguintes hipóteses:

- O ângulo de inclinação da plataforma depois da avaria deve ser de no máximo $17^{\circ}$.

- Qualquer abertura (na qual o alagamento progressivo possa ser iniciado) abaixo da linha d'água final deve ser estanque; qualquer abertura na região compreendida até 4 metros acima da linha d'água final deve ser resistente a chuva.

- A curva de momento restaurador, depois da avaria descrita acima, deve ter, desde a primeira intersecção com a curva de momento emborcador, de acordo com os critérios de descritos no item anterior, até a segunda intersecção, uma extensão de no mínimo $7^{\circ}$. Neste intervalo, a curva de momento restaurador deve ser no mínimo duas vezes maior que o momento emborcador, sendo ambos medidos no mesmo ângulo.

- A unidade deve possuir flutuabilidade e estabilidade suficiente em qualquer calado de operação ou trânsito, de modo a resistir ao alagamento total ou parcial de qualquer compartimento estanque, levando em consideração os seguintes pontos: 
o O ângulo de inclinação da plataforma após inundação de um tanque não pode ser maior que $25^{\circ}$.

o Qualquer abertura abaixo da linha d'água final deve poder ser tornada estanque.

o Deve existir reserva de estabilidade de no mínimo $7^{\circ}$ além do ângulo de inclinação calculados.

Essas afirmativas são diretas e devem ser respeitadas para que uma SS assim como uma monocoluna apresente reserva de estabilidade em caso de avarias, entretanto, na pratica, é preciso observar que as premissas diferem quando se compara as sociedades classificadoras. A tabela 1 apresenta um resumo ilustrativo dos fatores utilizados para definir essas afirmativas, e evidencia que existem variações entre as sociedades classificadoras entre si e também quando comparadas a órgãos regulamentadores como o Norwegian Maritime Directorate (NMD). 
Tabela 1 - Comparação dos fatores constituintes dos critérios

\begin{tabular}{|c|c|c|c|c|c|}
\hline & Unidade & IMO-MODU & DNV & $\mathrm{ABS}$ & NMD \\
\hline \multicolumn{6}{|l|}{ INTACTA } \\
\hline Velocidade do & nós & 67 & 67 & 67 & 67 \\
\hline Calados & - & operaçẫo/trânsito & operaçẫo/trânsito & operaçẫo/trânsito & operaçẫo/trân sito \\
\hline $\begin{array}{c}\text { GM mín Normal/ } \\
\text { Temporário }\end{array}$ & metros & $1,0,0,30$ & $1,0,0,30$ & \begin{tabular}{|l|}
$1,0 / 0,30$ \\
\end{tabular} & $1,0,0,30$ \\
\hline Curva GZ $\times \theta$ & non & $\begin{array}{c}\text { sempre positiva de } \\
0 \text { até } \theta_{2}\end{array}$ & $\begin{array}{c}\text { sempre positiva de } \\
0 \text { até } \theta_{2}\end{array}$ & $\begin{array}{c}\text { sempre positiva de } \\
0 \text { até } \theta_{2}\end{array}$ & $\begin{array}{c}\text { sempre positiva de } \\
0 \text { até } \theta_{2}\end{array}$ \\
\hline Razẫo de áreas & - & 1,3 & 1,3 & \begin{tabular}{|l|}
1,3 \\
\end{tabular} & \begin{tabular}{|c|}
1,3 \\
\end{tabular} \\
\hline $\begin{array}{c}\text { Intervalo } \\
\text { considerado }\end{array}$ & - & 0 até $\theta_{\text {lim }}$ & $\begin{array}{c}0 \text { até } \theta_{2} \text { podendo } \\
\text { ultrapassar qdf }\end{array}$ & 0 até $\theta_{\mathrm{im}}$ & $\begin{array}{c}0 \text { até } \theta_{2} \text { podendo } \\
\text { ultrapassar qdf }\end{array}$ \\
\hline$\theta_{0} \operatorname{máx}$ & graus & - & - & - & 17 \\
\hline$\theta_{1} \operatorname{máx}$ & graus & - & - & - & 30 \\
\hline \multicolumn{6}{|l|}{ AVARIADA } \\
\hline Velocidade do & nós & 50 & 50 & 50 & 50 \\
\hline Calados & - & operaçẫo/trânsito & operação/trânsito & operaçẫo/trânsito & operaçẫo/trânsito \\
\hline Razẫo de áreas & - & - & 1 & - & 1 \\
\hline $\begin{array}{c}\text { Intervalo } \\
\text { considerado }\end{array}$ & - & - & $\begin{array}{l}0 \text { até } \theta_{2} \text { podendo } \\
\text { ultrapassar qdf }\end{array}$ & - & $\begin{array}{l}0 \text { até } \theta_{2} \text { podendo } \\
\text { ultrapassar qdf }\end{array}$ \\
\hline$\theta_{0} \operatorname{máx}$ & graus & - & 15 & - & - \\
\hline$\theta_{1} \max$ & graus & 17 & - & $\theta_{1}<\theta_{d f}$ & 17 \\
\hline $\begin{array}{c}\text { Faixa de } \\
\text { estabilidade } \\
\text { positiva mín. }\end{array}$ & graus & $\begin{array}{c}7 \text { além de } \theta_{1} \text { até } \\
\theta_{\lim }\end{array}$ & - & $\begin{array}{c}7 \text { além de } \theta_{1} \text { até } \\
\theta_{\lim }\end{array}$ & $\begin{array}{c}10,0 \text { além de } \theta_{1} \\
\text { até } \theta_{2}\end{array}$ \\
\hline $\mathrm{GZ}$ & metros & - & - & - & $\begin{array}{l}\text { Deve atingir } 2,5 \mathrm{~m} \\
\text { ou mais no } \\
\text { intervalo } \theta_{0} \text { a } \theta_{\text {lim. }} \text {. } \\
\text { Parte desse valor, } \\
\text { pelo menos } 1,0 \mathrm{~m} \\
\text { deve ser devido ao } \\
\text { ganho por imersão } \\
\text { de volumes } \\
\text { anteriormente } \\
\text { emersos da coluna }\end{array}$ \\
\hline GZNWHL & - & $>2,0$ & - & $>2,0$ & $\begin{array}{c}\text { em } \theta d f,>2,0 \text { (novo } \\
G Z \text { após o } \\
\text { alagamento) }\end{array}$ \\
\hline \multicolumn{6}{|l|}{ ALAGAMENTO } \\
\hline Velocidade do & nós & 0 (sem vento) & - & - & - \\
\hline Calados & - & operaçẫo/trânsito & - & - & - \\
\hline$\theta_{0} \operatorname{máx}$ & graus & 25 & - & - & - \\
\hline $\begin{array}{c}\text { Faixa de } \\
\text { estabilidade } \\
\text { positiva mín. }\end{array}$ & graus & 7 além de $\theta_{0}$ & - & - & - \\
\hline
\end{tabular}

Na tabela, $\theta$ representa um ângulo de inclinação da plataforma definido em [2], [3], [4] e [5].

Um dos critérios que compõe o grupo de critérios de estabilidade avariada é a definição de extensão de avaria, esse assunto merece atenção especial no caso 
monocoluna, já que as criticas aos critérios de estabilidade em sua aplicabilidade as monocolunas se dão nessa definição.

Definir extensão de avaria em estabilidade avariada é dizer qual o tamanho da avaria gerada pelo hipotético abalroamento da unidade, e quais seus efeitos gerados na estabilidade da unidade.

De acordo com as normas, foram resumidos de [2], [3], [4] e [5] alguns critérios de avaria úteis para a análise da monocoluna:

- Somente as colunas, casco e contraventamentos na parte periférica da unidade devem ser assumidos avariados, e a avaria deve ser considerada na parte exposta desses elementos.

- A extensão horizontal dos danos deve ser considerada 1/8 (um oitavo) do perímetro da coluna.

- Colunas e contraventamentos devem ser considerados inundados por avaria com extensão vertical de $3 \mathrm{~m}$, ocorrendo em qualquer local compreendido entre $5 \mathrm{~m}$ acima e $3 \mathrm{~m}$ abaixo dos calados operacionais especificados no manual de estabilidade da plataforma. Quando existir antepara estanque nessa região, deve-se considerar que a avaria deve ter afetado os dois compartimentos (acima e abaixo da antepara em questão). Distâncias menores que essas citadas podem ser consideradas, levando em conta as condições de operação da plataforma. Entretanto, a região avariada deve ter no mínimo 1,5 $\mathrm{m}$ acima e abaixo do calado considerado.

- A penetração horizontal da avaria deve ser de 1,5 m."

- Quando operando em condição de trânsito, partes submersas do casco devem se submeter a todas as condições de avarias aqui descritas.

- Todas as tubulações, dutos de ventilação e túneis dentro da região de avaria definida, devem ser considerados avariados. Meios de fechar a passagem de água ao redor das avarias devem ser fornecidos de forma a prevenir o alagamento de outros espaços que deveriam estar intactos.

Uma SS, ao cumprir todos esses itens, tem sua estabilidade validada, entretanto nem todas monocolunas podem ter extensão horizontal dos danos de 1/8 (um oitavo) do perímetro da coluna, e é exatamente essa cláusula que faz com que o critério tenha que ser reavaliado para monocolunas. 


\subsection{MOTIVADORES PARA REGULAMENTAÇÃO}

Ao longo dos anos, nota-se que o grande motivador das regulamentações foram os acidentes. Em seguida são apresentados dois acidentes importantes, o primeiro (Alexander Kielland) por ter sido um acidente que fez com que as regulamentações fossem estreitadas para plataformas do tipo SS e o segundo (P-36) por ter se tratado do acidente da maior plataforma em operação do mundo em seu tempo.

Alexander Kielland era uma plataforma semi-submersível pentagonal (cinco colunas) que em 1980, operava no campo de Ekofisk - Noruega para Phillips petróleo. Por volta das 18:30 horas do dia 27 de março de 1980, um dos contraventamentos horizontais principais que suportavam uma das cinco colunas, falhou. Essa falha foi atribuída a uma fratura que se originou a partir de um furo usado para posicionar a plataforma em seu local de operação. Após a falha do primeiro contraventamento, houve uma sucessão de rupturas, o que fez com que a unidade se inclinasse em um ângulo de 35 graus, parcialmente submergindo o convés e o grupo das acomodações. Esse acidente suscitou o interesse das autoridades internacionais para a segurança das unidades offshore, e obrigou que as plataformas passassem a ter margens de segurança maiores, estimulando o desenvolvimento de novos critérios de estabilidade e revisão dos vigentes.

A P-36 foi a maior plataforma de produção de petróleo no mundo antes de seu afundamento em março de 2001. A plataforma era da estatal brasileira Petrobras e custou 350 milhões de dólares, foi construída na Itália em 1995 como uma base semi-submersa de exploração petrolífera. A P-36 era operada pela Petrobras no campo de Roncador, distante $130 \mathrm{~km}$ da costa brasileira, produzindo 84 mil barris de petróleo por dia.

No madrugada do dia 15 de março de 2001 ocorreram duas explosões na coluna da plataforma, a primeira às 00:22h e a segunda às 00:39h. Segundo a Petrobras, das 175 pessoas que estavam no local no momento do acidente, 11 morreram. Depois das explosões, a plataforma tombou em 16 graus, o suficiente para permitir alagamento que levou ao seu afundamento.

Times de resgate tentaram salvar a plataforma durante o fim de semana seguinte, injetando nitrogênio e ar comprimido nos tanques para tentar remover a água 
acumulada, mas abandonaram as tentativas devido a condições climáticas adversas.

A plataforma afundou no dia 20 de março, em uma profundidade de $1200 \mathrm{~m}$ e com estimados 1500 toneladas cúbicas de óleo ainda a bordo. Segundo a agência nacional de petróleo (ANP - www.anp.gov.br), por meio do relatório da investigação conjunta apresentado em julho de 2001, as causas das explosões na P-36 estiveram relacionados à não-conformidades quanto a procedimentos operacionais, de manutenção e de projeto. O relatório indicou que as explosões e o afundamento da P-36 ocorreram por uma série de causas, sendo que nenhuma delas, isoladamente, seria suficiente para provocar o acidente. Ações tomadas após as explosões e o alagamento da P-36 também foram consideradas fora da conformidade de procedimentos operacionais, mas a comissão não pôde concluir se o afundamento da plataforma poderia ter sido evitado. O exame dessas causas levou o grupo de trabalho, a partir de uma metodologia de investigação predefinida, a classificar as que foram mais criticas e determinantes. A investigação levou a ANP acelerar a elaboração de um novo modelo de segurança operacional nas atividades de offshore, através de uma consultoria contratada junto a ABS, e a partir desse trabalho, tornou-se clara a necessidade de revisão das normas de estabilidade e análise critica da aplicabilidade dos critérios para cada tipo específico de plataforma.

\subsection{SÍNTESE DO CAPÍTULO}

Além de esse capítulo apresentar os conceitos de estabilidade para unidades flutuantes em geral e mostrar normas vigentes de forma sucinta, é nesse ponto do texto que se observa que os acidentes que presenciamos em nosso cotidiano, têm influência nos critérios de estabilidade e em sua constante revisão, pois quando esses ocorrem, provocam revisões nas normas vigentes. É importante ressaltar que esses critérios devem ser revistos e atualizados não somente após acidente, mas também quando existem alterações devido a inovações ou a forma de operação. 


\section{METODOLOGIA PARA ANÁLISE DE ESTABILIDADE - MONOCOLUNAS}

Para se entender a análise de estabilidade das monocolunas é preciso antes apresentar alguns conceitos básicos de estabilidade e hidrodinâmica utilizados no dimensionamento e definição dos apêndices, para que depois seja enunciado o método de análise de estabilidade adotado.

\subsection{CONCEITOS BÁSICOS DE ESTABILIDADE}

Para esclarecer a linha de estudo para concepção das dimensões do casco, apresenta-se primeiramente a fórmula da altura metacêntrica.

$$
\begin{aligned}
& \mathrm{GM}=\mathrm{KB}+\mathrm{BM}-\mathrm{KG} \\
& \mathrm{BM}=\frac{\mathrm{I}_{\mathrm{WL}}}{\nabla}
\end{aligned}
$$

Onde:

KB é o centro de carena, isto é, ponto onde se aplica a força resultante do campo de pressão hidrostático, força de empuxo;

$I_{\text {wl }}$ é a inércia de área de linha d'água;

$\nabla$ é o deslocamento em metros cúbicos;

GM (altura metacêntrica) é o parâmetro de estabilidade inicial de uma embarcação e simplificadamente, GM positivo significa que a embarcação é estável inicialmente. Este parâmetro depende do equilíbrio entre as posições do CG e da movimentação do centro de carena $B$.

Seguem abaixo, as expressões para o cálculo dos períodos naturais $(\mathrm{Tn})$ referentes a este sistema oceânico. 


$$
\begin{aligned}
& \operatorname{Tn}_{\text {heave }}=\sqrt{\frac{\mathrm{m}}{\mathrm{K}}}=\sqrt{\frac{\mathrm{m}+\mathrm{m}_{\mathrm{a}}}{\rho^{*} \mathrm{~A}_{\mathrm{wl}}{ }^{*} \mathrm{~g}}} \\
& \operatorname{Tn}_{\text {roll/pitch }}=\sqrt{\frac{\mathrm{I}}{\mathrm{K}}}=\sqrt{\frac{\mathrm{I}+\mathrm{I}_{\mathrm{ad}}}{\mathrm{GM}^{*} \nabla^{*} \mathrm{~g}}}
\end{aligned}
$$

Onde:

$\rho$ é a densidade da água;

$A_{w l}$ é a área da linha d'água;

g é a aceleração da gravidade;

m é a massa o sistema;

l é a inércia de massa do sistema;

$\mathrm{l}_{\mathrm{ad}}$ é a Inércia de massa adicional hidrodinâmica;

$\mathrm{m}_{\mathrm{a}}$ é a massa adicional do sistema hidrodinâmico.

Os denominadores em ambas as fórmulas de período natural representam a restauração hidrostática respectivas para cada movimento.

Logo, para deslocar o período natural de modo a obter movimento necessário para utilização de SCRs, é preciso trabalhar com todos estes parâmetros apresentados. Com uma melhor observação das fórmulas, nota-se que para se obter uma melhor estabilidade estática inicial, maior $\mathrm{GM}$, tem como conseqüência um período natural em roll/pitch menor e também a diminuição do período natural em heave para alguns casos, para o aumento da área de linha d'água e/ou redução do deslocamento. Assim, devem-se ponderar os dados para que se tenha a melhor combinação entre estabilidade e períodos naturais.

A interdependência dos diversos parâmetros, como deslocamento, $K G, I_{w l}, T n, K B$, calado, diâmetro do corpo, e todos os outros intrínsecos a estes, como posicionamento dos equipamentos, peso da estrutura, risers e amarração, dificulta a análise em separado de qualquer variável do sistema.

Pode-se concluir que o projeto de um casco depende de vários parâmetros e também da forma de construção e de instalação. Para dimensionamento inicial, há necessidade de se considerar as principais funcionalidades do casco da forma mais sintética possível, sem com isso perdermos os efeitos no casco como um todo. 
Para descrever a interdependência dos parâmetros de projeto para o caso completo, esta será mostrada através de um modelo simplificado (Figura 24) onde é apresentada apenas uma forma de correlação entre algumas variáveis de projeto.

Por exemplo, podemos mencionar a variação do calado (d), dada a altura do CG em relação à linha d'água (h). Dada a simplificação para o corpo da plataforma, tornando este um cilindro com diâmetro (D), têm-se:

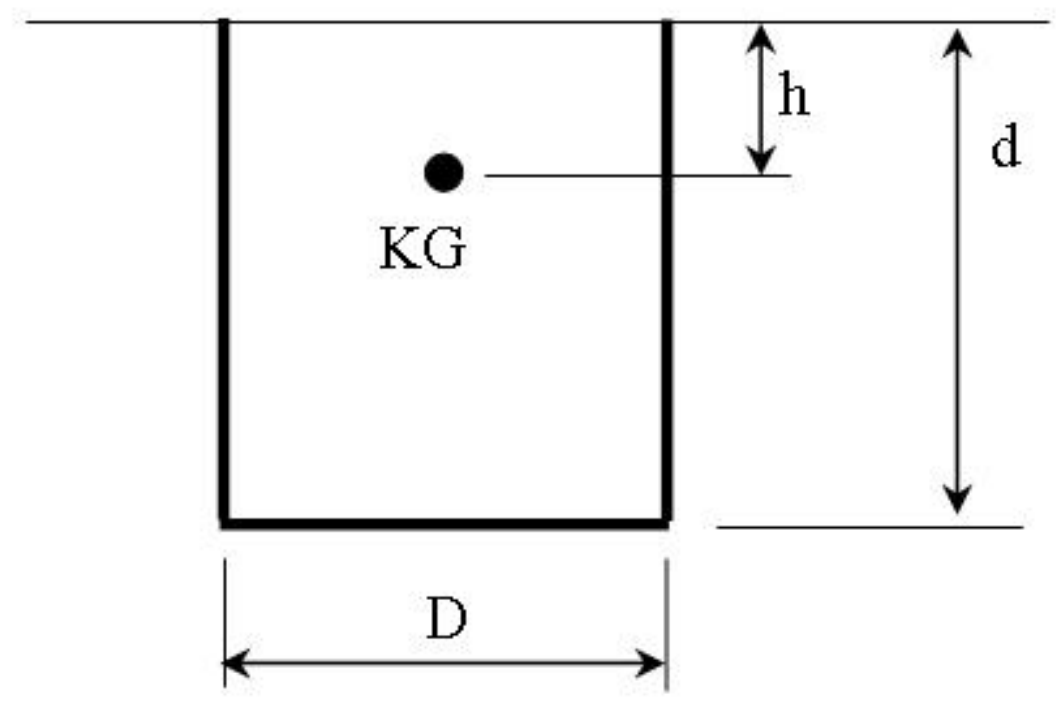

Figura 24. Modelo simplificado

$$
\begin{gathered}
\nabla=\frac{\pi^{*} D^{2}}{4} * d \\
K B=\frac{1}{2} * d \\
I_{w l}=\frac{\pi^{*}\left(\frac{D}{2}\right)^{4}}{4} \\
B M=\frac{I_{w l}}{\nabla}=\frac{D^{2}}{16 * d}
\end{gathered}
$$


Nesse modelo simplificado é pré-suposto que o KG do sistema só sofra influência dos pesos dos conveses, isto é, o peso da estrutura e lastro não seja significativo. Logo:

$$
K G=-h+d
$$

Supondo que o KG esteja na linha d'água, se dividir o calado e o diâmetro por dois, obtém-se:

$$
G M^{\prime}=\frac{K B}{2}+\frac{B M}{2}-\frac{K G}{2}=\frac{G M}{2}
$$

Ao admitir que o KG esteja deslocado de "h", a relação entre o GM' e o GM dependerá da proporção entre "h" e "d".

Demonstra-se assim, que mesmo para uma simplificação, a relação entre todas as variáveis não é fácil de determinar. Dessa maneira, foi desenvolvida uma planilha com um algoritmo que correlaciona as variáveis para que o dimensionamento inicial fosse gerado. Resumidamente, segue abaixo uma explicação breve a respeito das variáveis mencionadas.

Deslocamento: além de ser um fator limitante construtivamente, este afeta em muito o GM e o período natural em roll. Um dos objetivos é minimizar esta variável. O deslocamento provoca também uma variação do KG, devido à variação da quantidade de lastro necessária na plataforma

Área de linha d'água: esta é dada pela área da estrutura externa (área do pescoço) menos a área de estrutura interna (abertura para passagem dos risers). Com o aumento desta variável, o KB e o BM aumentam, pois o volume deslocado na parte superior aumenta e a inércia de linha d’água também. Isto provoca um aumento do $\mathrm{GM}$, isto é, da estabilidade, mas ao mesmo tempo provoca uma queda no período natural de heave, pois a restauração em heave aumenta. Além disto, quanto menor o diâmetro do pescoço, menor será a influência dos ventos e ondas no movimento da plataforma, pois a área projetada na direção do campo de pressões destes dois fatores ambientais será menor, logo a resultante do campo de pressões atuante será menor.

Assim, tanto o deslocamento como a área da linha d'água são de grande importância na otimização do movimento da plataforma. Regra geral, o período natural de roll obtido nos casos monocoluna é maior que os períodos naturais de roll 
das plataformas existentes em operação, logo, o deslocamento pode ser aumentado até que o GM fosse ótimo, entretanto existem outras restrições de projeto: calado e o custo estrutural. Quanto ao calado, existem dois problemas: a limitação física dos estaleiros, onde a profundidade dos diques limita-se em torno de $40 \mathrm{~m}$ no máximo, outro fator é a busca por um novo tipo de plataforma, diferentes das SPAR já que essas plataformas apresentam pequenas amplitudes de movimento, mas possuem problemas com relação aos risers, pois em determinadas freqüências de onda, estes começam a se chocar nas paredes internas do moonpool da plataforma.

Devido a todos estes motivos que o estudo do formato da plataforma, da otimização da saia externa e o estudo das dimensões do moonpool foi fundamental no projeto, pois com a otimização destes é possível encontrar uma plataforma com boa estabilidade e que se comporte bem no mar, sem apresentar grande calado e deslocamento. 


\subsection{FLUXOGRAMA PARA ANÁLISE DE ESTABILIDADE DE MONOCOLUNAS}

Para se entender o processo de análise de estabilidade para a família monocoluna, foi criado o fluxograma apresentado na Figura 25.

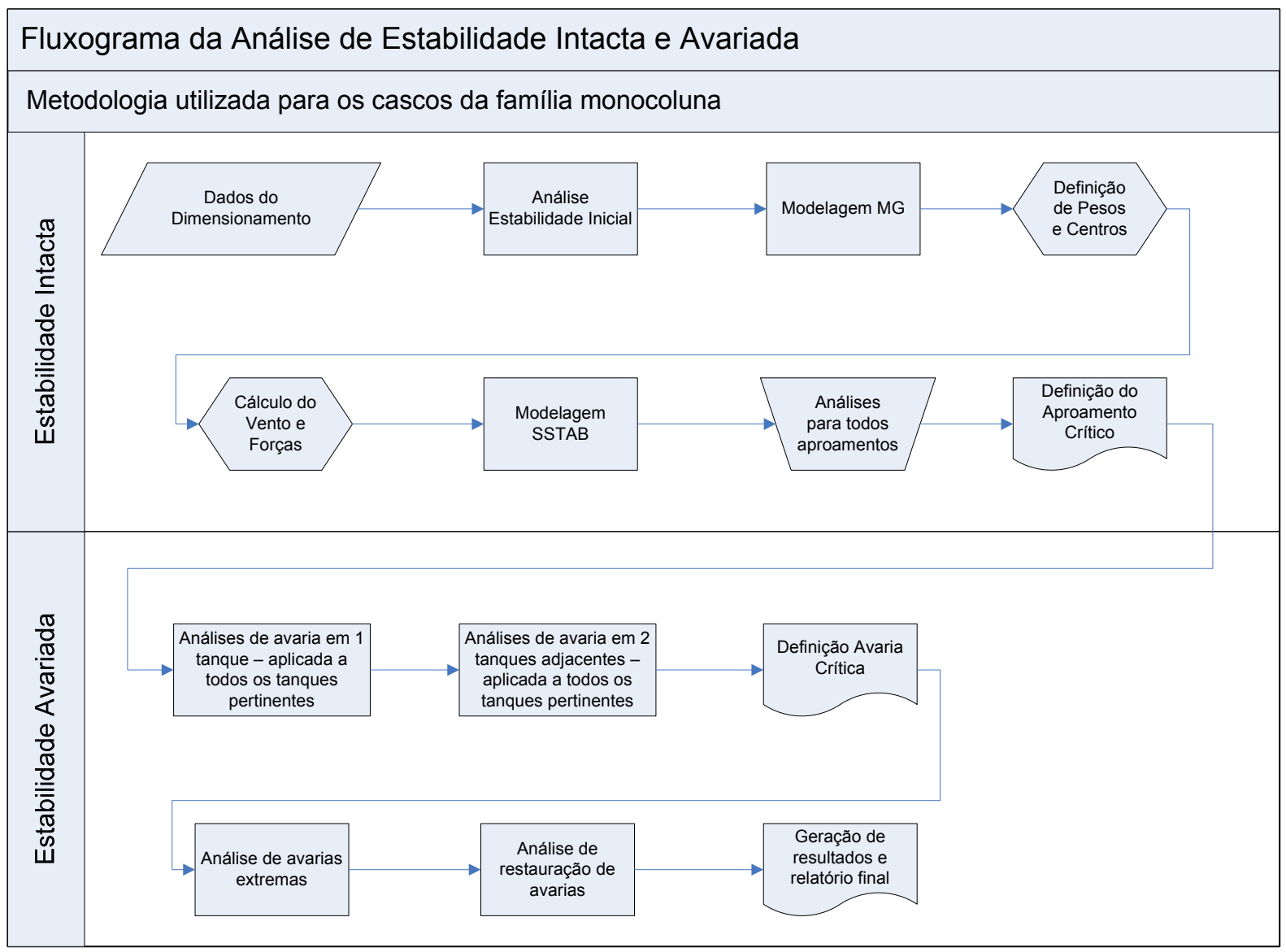

Figura 25. Processo de análise de estabilidade

Esse fluxograma é composto por diversas atividades, que dependem de diversos fatores que são descritos de forma sucinta a seguir. Para que se defina a estabilidade inicial da plataforma é criada uma planilha que por meio das formulações apresentadas em 5.1 apresenta as características da unidade, caso essas características estejam de acordo com o desejado para o campo de operação proposto, é feita a modelagem do caso no Mesh Generator (MG), que é o programa de modelagem utilizado pela Petrobras. Esse modelo, juntamente com a definição de pesos e centros da unidade mais o cálculo de vento e forças, que pode ser feito por meio de ensaio em tanques de prova com modelo emborcado ou mesmo por 
meio de formulações, dá os parâmetros necessários para que se faça a modelagem do modelo de estabilidade no Sstab, que é descrito em 5.3. A análise de estabilidade deve ser feita em diversos aproamentos, para que se defina o aproamento crítico, como visto em 5.4, e também em diversos calados, como apresentado em 5.5.

Passando para a análise de estabilidade avariada, testa-se avaria em todos os tanques, um a um, e em seguida, para manter o caráter conservador do estudo, testa-se avaria em dois tanques adjacentes, combinando-os até que todos os tanques sejam testados. Todas essas análises geram resultados que quando comparados apresentam a avaria crítica, que deve atender as normas de estabilidade. Essa etapa do procedimento de análise fez com que uma característica importante da monocoluna viesse à tona, a reserva de estabilidade e capacidade de restauração de inclinação, que está mais bem descrita em 5.6.

Indo um pouco além do que é comumente analisado, ao notar a reserva de estabilidade da monocoluna, foram estudados alguns casos extremos de avaria, que ajudam a comprovar a reserva de estabilidade da unidade devido a sua geometria, esses estudos estão apresentados no mesmo 5.6. Seguindo essa linha de pesquisa, a monocoluna foi comparada com a SSBR, que é uma plataforma conceitual desenvolvida pela Petrobras, e essa comparação está apresentada em 5.7.

Vale ressaltar que esse procedimento completo é feito inúmeras vezes já que é parte integrante da metodologia de geração de casos da monocoluna, apresentada em 3.3, compondo uma parte de cada iteração da espiral de projetos.

\subsection{PROGRAMA UTILIZADO PARA ANÁLISES - SSTAB}

Em todas as análises de estabilidade, assim como na metodologia apresentada para monocoluna (Figura 25) foi utilizado o programa Sstab, que foi desenvolvido pelo CENPES (Centro de pesquisa da Petrobras) e pelo Tecgraf (Grupo de Tecnologia em Computação gráfica da PUC-Rio). Atualmente é o programa de estabilidade naval oficial da Petrobras e é utilizado em todos os sistemas flutuantes instalados na Bacia de Campos. 
O Sstab não particulariza ou restringe o modelo geométrico a um tipo especial de sistema flutuante, podendo ser usado em modelos de navios, plataformas semisubmersíveis ou mesmo sistemas compostos por mais de um casco, adequando com tranqüilidade os novos conceitos testados. O Sstab trata os corpos e compartimentos modelados como se estivessem rigidamente conectados, fazendo com que os movimentos que os compartimentos experimentam sejam descritos por seis graus de liberdade (três deslocamentos e três rotações).

O Sstab permite que se modelem os corpos com subdivisões em compartimentos, que podem ser classificados de acordo com o seguinte fluxograma extraído de [7].

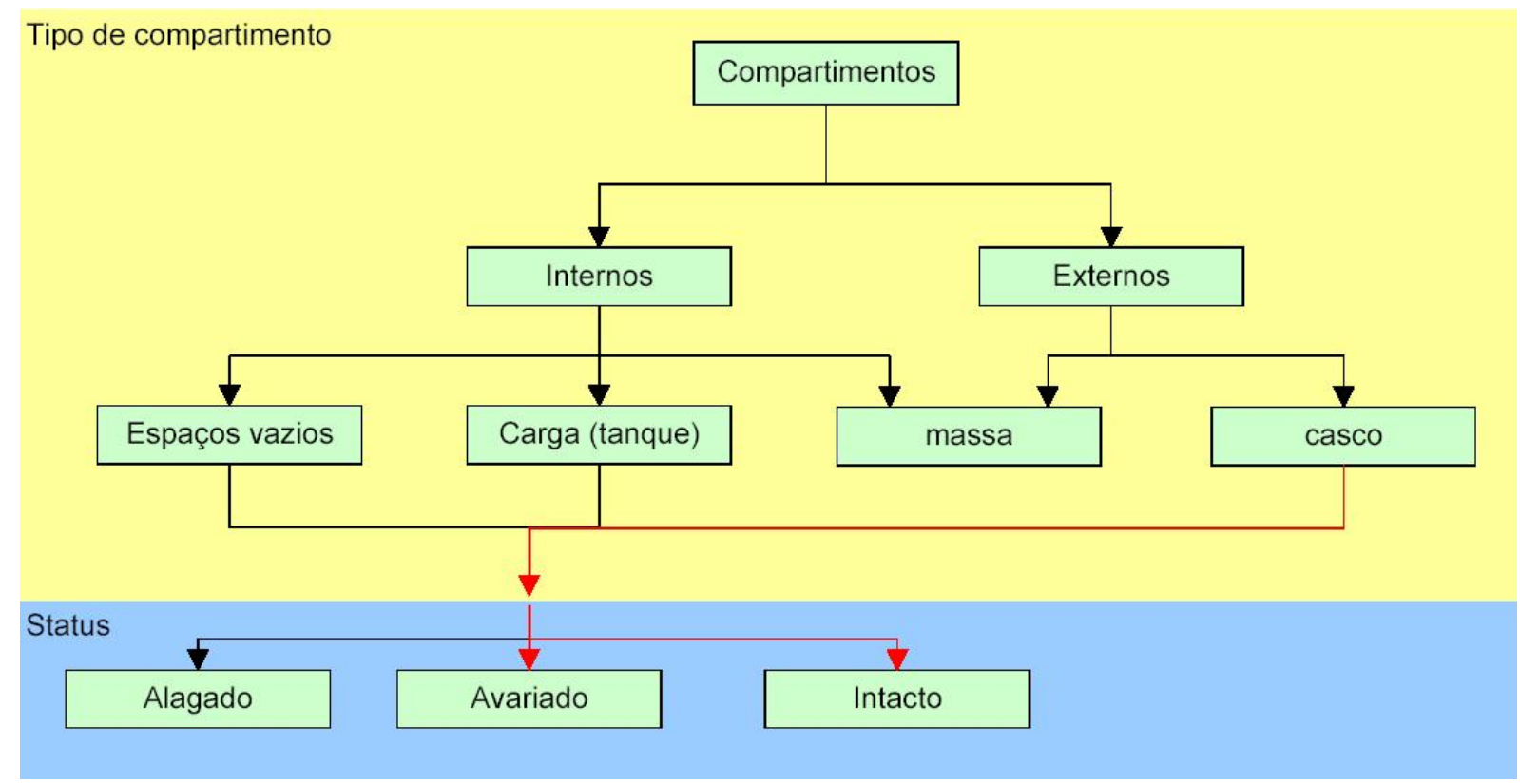

Figura 26. Classificação dos compartimentos no Sstab (modificado de [7])

Cada compartimento tem sua fronteira definida individualmente, o que fornece ao programa a funcionalidade de diversas combinações de testes de estabilidade, sejam os tanques intactos, alagados ou avariados, dando também a possibilidade de modelagem de diversos tipos de convés, e casco.

Como ao longo do projeto monocoluna foram testados inúmeros cascos, utilizando o conceito de engenharia simultânea, houve a motivação de utilizar o Sstab para testes iniciais dos cascos, facilitando o processo de decisão dos candidatos, dessa maneira se desenvolveu uma interface do programa de modelagem básica para o Sstab, o MG, de forma que houvesse a parametrização das planilhas com o software, gerando modelos a serem analisados automaticamente, e isso deu ao 
grupo de projetos a capacidade de gerar um casco válido em horas ao invés de dias, como era comum até então.

Nesse processo foram notadas falhas no programa Sstab, que era sempre corrigido e aprimorado quando elas surgiam, o que fez com que a USP participasse ativamente do processo de validação do Sstab como um sistema apto a verificar a estabilidade de plataformas de petróleo. A partir do trabalho monocoluna também foi gerada uma nova ferramenta no Sstab que define carregamento ótimo para otimização de GM. É preciso destacar que o programa tem um ponto fraco ao observarmos que o mesmo faz todas as análises estaticamente, dessa maneira, as análises dinâmicas ficam muito aproximadas. Isso pode ser notado no cálculo de efeito de superfície livre que o programa faz, o que leva os modelos a ter característica extremamente conservadora em prol da segurança, que pode acarretar na não otimização do casco.

\subsection{APROAMENTO CRÍTICO}

A monocoluna, por ter corpo imerso com simetria radial, apresenta diferenças na análise de sua estabilidade quando comparada com navios, que têm corpos mais esbeltos. Ao analisar a estabilidade de um navio, nota-se claramente a presença de um eixo crítico, já nas monocolunas isso não ocorre, o que provoca um número de análises maiores, já que todos os azimutes têm que ser checados. Dessa maneira, partindo de um sistema de coordenadas definido, e com a incidência do vento determinada pelas normas e calculada de acordo com cada incidência no convés, é possível determinar em qual ângulo de incidência a plataforma apresenta menor GM e razão de áreas, esse azimute é definido como crítico para as análises da plataforma, mesmo assim, ao se definir o casco, os ângulos de $0^{\circ}$ a $360^{\circ} \mathrm{em}$ intervalos de $45^{\circ}$ são novamente testados. A Figura 27 apresentada a seguir, é uma forma de visualização desenvolvida pelo grupo de projetos da monocoluna, e apresenta as análises realizadas para um dado casco, em cada aproamento. 


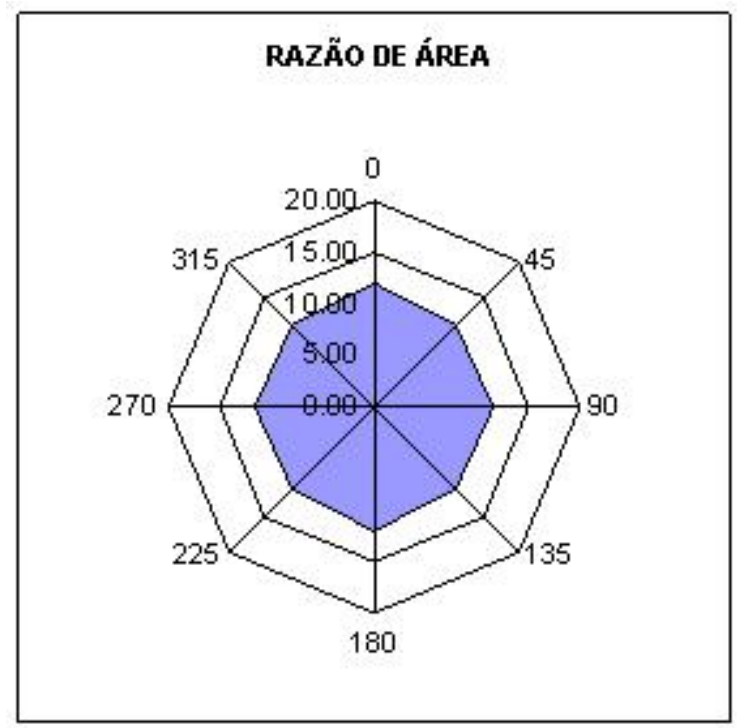

Figura 27. Razão de área para diferentes aproamentos

Essa característica da unidade pode ocasionar maior dificuldade na análise da estabilidade, pois faz com que o número de iterações seja maior para as análises, porém essa mesma característica proporciona a unidade um potencial de restauração de inclinação muito grande, já que pequenas inclinações aumentam muito a linha d’água e conseqüentemente sua inércia.

\subsection{CALADOS PARA ANÁLISE DE ESTABILIDADE DA MONOCOLUNA}

Os calados comumente considerados nas análises de estabilidade de monocolunas são os seguintes:

Calado de operação - calado em que a plataforma passa a maior parte da sua vida útil é o calado onde a operação rotineira se dá (Figura 28).

Calado de Pull In - calado onde será feita toda a operação de pull in, ou seja, acoplamento dos risers. Regra geral é um calado crítico, pois a plataforma fica mais emergida que o normal, o que gera menor estabilidade, isso adicionado ao acúmulo de tensões localizadas em decorrência das tarefas de acoplamento de risers, pode gerar falta de estabilidade. Deve ser considerada condição de calado antes da colocação do primeiro riser, condição mais crítica, pois apresenta menor GM. Na 
medida em que os risers são instalados, é retirado lastro da plataforma, para manutenção do calado (Figura 30).

Calado de transporte - calado em que a plataforma será transportada até seu campo de operação. Normalmente não é muito restritivo, já que se pode lastrear a plataforma de maneira adequada ao transporte, e as condições climáticas, quando transportada, são boas. Nesta condição não se aplicam os pesos de risers, amarração, variáveis e consumíveis (Figura 32).

Calado de reparo - calado onde são executadas tarefas de recuperação da plataforma após algum tipo de acidente ou corrosão. Normalmente é um calado que proporciona pouca estabilidade, já que a plataforma deve ficar mais emergida que o normal para que as inspeções e reparo sejam executados. A diferença de altura em relação ao calado operacional possibilita condições para o reparo de uma eventual avaria. Para variar do calado de operação para o de reparo não há a necessidade de desconexão de risers nem retirada de líquidos ou consumíveis da planta (Figura 29). Calado de operação parcial - como a operação de pull-in pode demorar algum tempo, existe a possibilidade da unidade entrar em operação sem contar com sua capacidade total. Apenas uma parcela do peso de risers deve ser considerada, pois isso gera uma grande diferença de tensões e na plataforma, o que implica em uma condição crítica para a estabilidade, com acumulo de carregamentos em um extremo da plataforma, tendo que utilizar lastro para compensar os ângulos de trim e banda. É importante ser realizado dessa maneira para que se mantenha o caráter conservador da análise (Figura 31).

Calado de Acabamento - necessário para se executar o acabamento da unidade em algum cais de estaleiro ou canteiro de obras (Figura 33). 
Tabela 2 - Figuras dos calados para análise de estabilidade

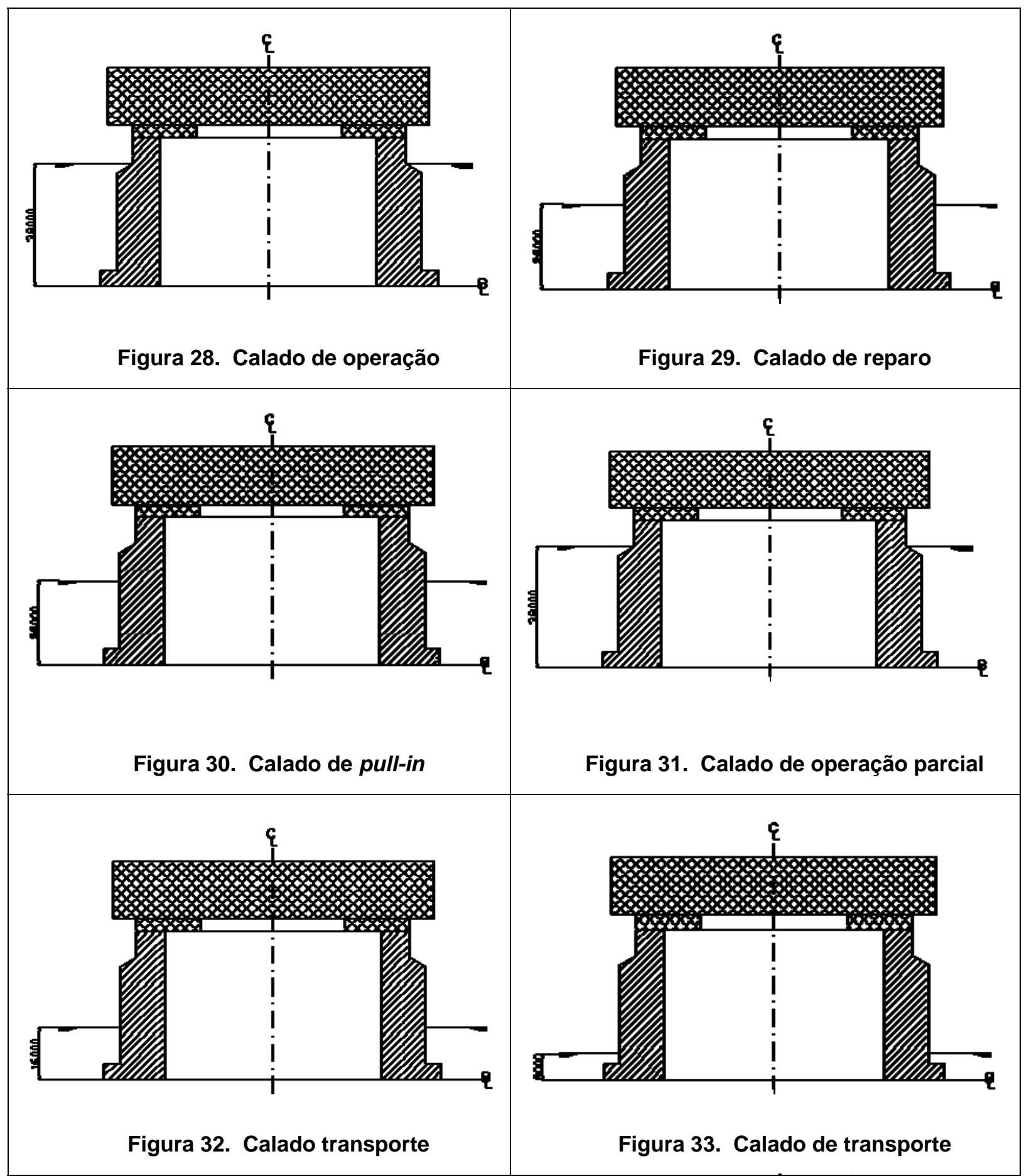




\subsection{COMPENSAÇÃO DE AVARIAS}

Uma característica da monocoluna é a reserva de estabilidade para casos de avaria; por ter grande quantidade de lastro e formato singular, a monocoluna tem a possibilidade de compensar a inclinação causada por uma avaria com a retirada de lastro inferior à região avariada ou incremento de lastro em região oposta, gerando momento restaurador. A seguir são apresentados exemplos de compensação de avarias em um dos casos da família monocoluna. A Figura 34 apresenta a avaria requerida pela norma (um tanque avariado) com inclinação de nove graus (esquerda) e após a compensação de avaria com lastro (direita).
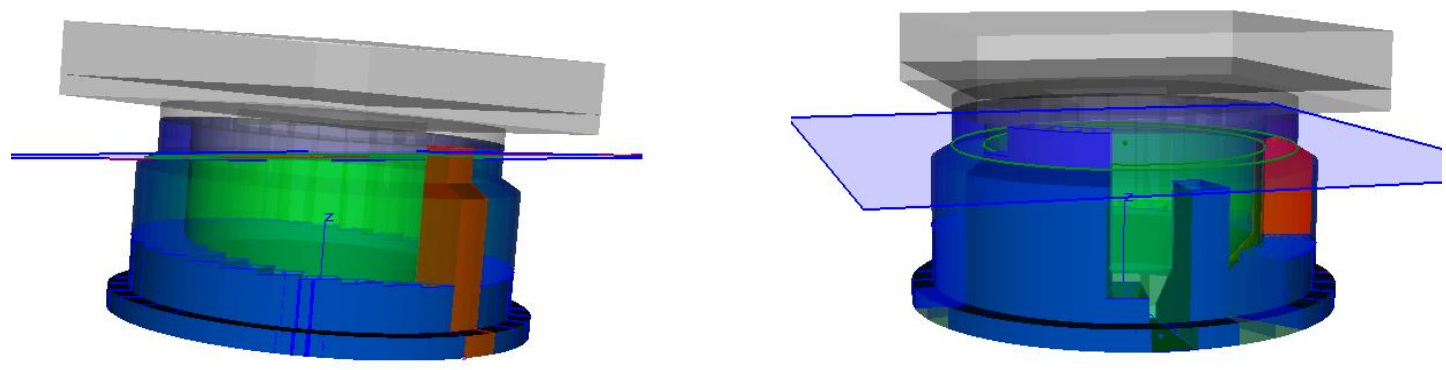

Figura 34. Plataforma com um tanque avariado / após compensação

A Figura 35 apresenta a avaria requerida pela Petrobras (dois tanques avariados), com inclinação de 11 graus (esquerda) e após a compensação de avaria com lastro (direita).
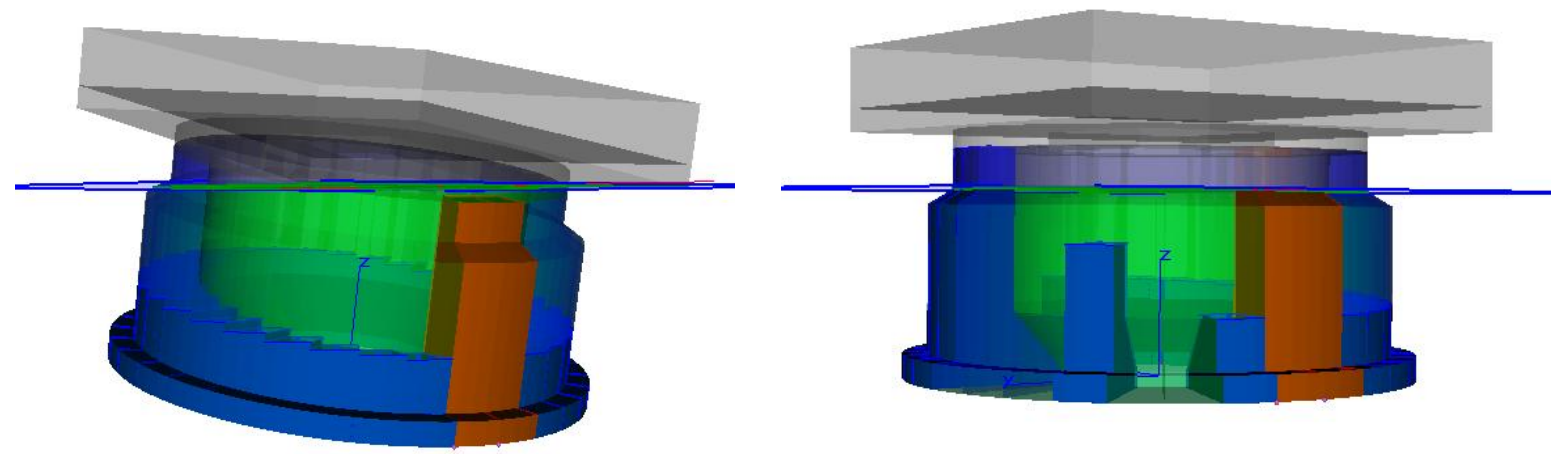

Figura 35. Plataforma com dois tanques avariados lapós compensação 
A Figura 36 apresenta uma avaria extrema, onde há uma simulação de avaria em um quarto da plataforma (8 tanques) com inclinação total de 31 graus (esquerda) e após a compensação de avaria com lastro (direita).
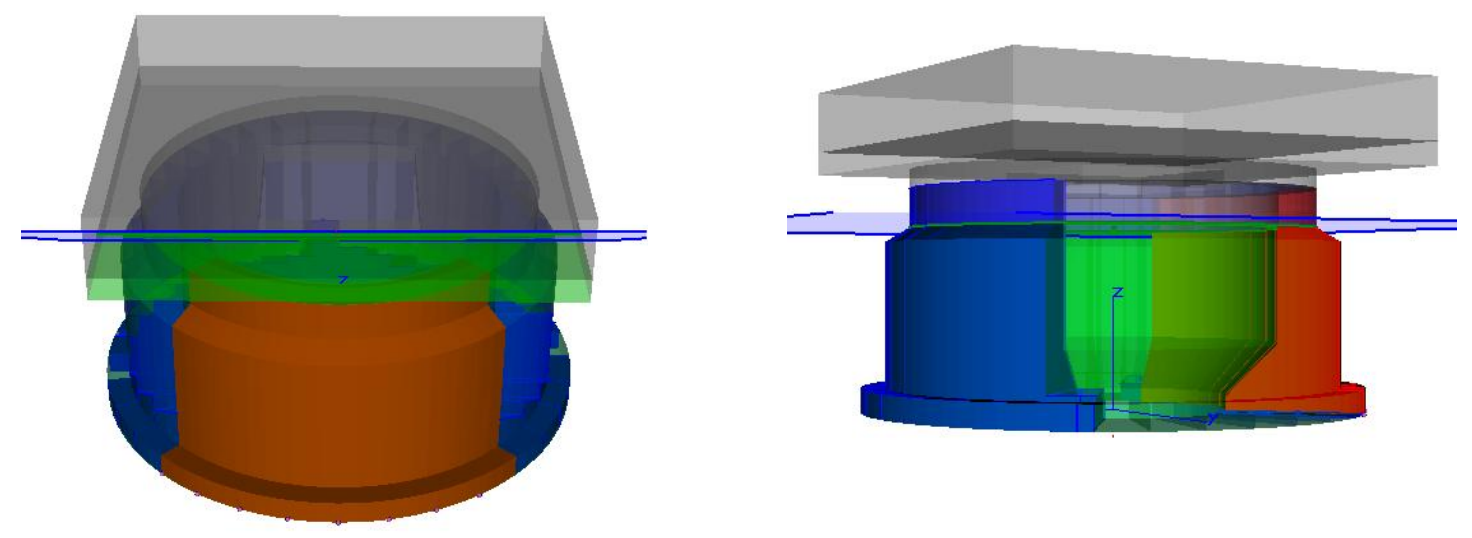

Figura 36. Plataforma com oito tanques avariados I após compensação

\subsection{COMPARAÇÃO MONOCOLUNA COM SSBR}

Ainda com o intuito de corroborar a eficácia da metodologia de análise, foi feita uma comparação entre a um dos casos da monocoluna e um projeto de SS da Petrobras feito para ter baixo custo de construção. Essa comparação se fez com base em premissas de carga de convés e campos de operação, idênticas para ambas.

O objetivo dessa comparação é apresentar de maneira resumida as diferenças entre a monocoluna e a SSBR, ressaltando que os resultados aqui apresentados representam o desenvolvimento de um projeto conceitual, adequado para avaliações de viabilidade técnica e econômica, no caso de aplicações práticas para a unidade, análises complementares deverão ser realizadas.

As características principais das unidades estão apresentadas nas tabelas 3 e 4: 
Tabela 3 - Dimensões principais - monocoluna

\begin{tabular}{|c|c|}
\hline Deslocamento $(\mathrm{t})$ & 135.000 \\
\hline Diâmetro na linha d'água $(\mathrm{m})$ & 85,0 \\
\hline Diâmetro do corpo principal $(\mathrm{m})$ & 95,0 \\
\hline Diâmetro da saia $(\mathrm{m})$ & 105,0 \\
\hline Largura do Moonpool (m) & 67,5 \\
\hline Calado operação (m) & 38,0 \\
\hline Air-Gap de operação (m) & 12,0 \\
\hline
\end{tabular}

Tabela 4 - Dimensões principais - SSBR

\begin{tabular}{|c|c|}
\hline Deslocamento $(\mathrm{t})$ & 95.000 \\
\hline LComprimento total $(\mathrm{m})$ & 96,0 \\
\hline Flutuador $(\mathrm{m})$ & $21,6 \times 6,0$ \\
\hline Coluna $(\mathrm{m})$ & $21,6 \times 21,6$ \\
\hline Calado operação $(\mathrm{m})$ & 35,0 \\
\hline Air-Gap de operação $(\mathrm{m})$ & 12,0 \\
\hline
\end{tabular}

Em seguida são apresentadas as condições de carregamento no calado operacional para as duas unidades (tabelas 5 e 6) por meio do resumo de pesos e centros $(P \& C)$ : 
Tabela 5 - Resumo P\&C monocoluna

\begin{tabular}{|c|c|c|c|c|}
\hline $\begin{array}{l}\text { Condição de Operação } \\
\text { Sumário de Pesos e Centros }\end{array}$ & $\begin{array}{l}\text { Peso } \\
\text { (ton) }\end{array}$ & $\begin{array}{r}\text { LCG } \\
(\mathrm{m})\end{array}$ & $\begin{array}{l}\text { TCG } \\
(\mathrm{m}) \\
\end{array}$ & $\begin{array}{l}\text { VCG } \\
(\mathrm{m})\end{array}$ \\
\hline Grupo 0 - Estruturas do Casco Inferior & 18292,32 & 0,00 & 0,00 & 20,04 \\
\hline Grupo 1 - Equipamentos do Casco Inferior & 2884,00 & 0,18 & 0,23 & 14,27 \\
\hline Grupo 2 - Equipamentos e Estrutura de Convés & 31667,05 & 0,71 & 1,54 & 58,16 \\
\hline Grupo 3 - Variáveis & 6135,02 & 2,10 & 0,96 & $\overline{55,30}$ \\
\hline Grupo 4 - Consumíveis & 2670,00 & 0,00 & 0,00 & 27,37 \\
\hline Grupo 5 - Linhas de Amarração e Risers & 10705,41 & 0,87 & 18,56 & 3,02 \\
\hline Grupo 6 - Lastro & 62646,20 & $-0,72$ & $-4,05$ & 8,71 \\
\hline & & & & \\
\hline SUB-TOTAL & 135000,00 & 0,00 & 0,00 & 24,00 \\
\hline
\end{tabular}


Tabela 6 - Resumo P\&C SSBR

\begin{tabular}{|c|c|c|c|c|}
\hline $\begin{array}{l}\text { Condição de Transporte } \\
\text { Sumário de Pesos e Centros }\end{array}$ & $\begin{array}{l}\text { Peso } \\
\text { (ton) }\end{array}$ & $\begin{array}{l}\text { LCG } \\
(\mathrm{m})\end{array}$ & $\begin{array}{l}\text { TCG } \\
(\mathrm{m})\end{array}$ & $\begin{array}{l}\text { VCG } \\
(\mathrm{m})\end{array}$ \\
\hline Estrutura Convés & 12359 & 0.00 & 0.00 & 35.20 \\
\hline Estrutura Casco & 14394 & 0.00 & 0.00 & 35.20 \\
\hline Estrutura do Casco - miscelaneous & 2014 & 0.00 & 0.00 & 35.20 \\
\hline Equipamentos do Casco & 1560 & 0.00 & 0.00 & 35.20 \\
\hline Planta + Utilidades & 17726 & 0.00 & 0.00 & 35.20 \\
\hline Margem & 4044 & 0.00 & 0.00 & 35.20 \\
\hline Diesel & 3000 & 0.00 & 0.00 & 35.20 \\
\hline Água & 3000 & 0.00 & 0.00 & 35.20 \\
\hline Líquidos na planta/casco & 4320 & 0.00 & 0.00 & 35.20 \\
\hline Químicos & 200 & 0.00 & 0.00 & 35.20 \\
\hline Tripulação & 160 & 0.00 & 0.00 & 35.20 \\
\hline Incrustração & $\overline{713}$ & 0.00 & 0.00 & 35.20 \\
\hline Risers + Umbilicais & 12126 & 0.00 & 0.00 & 35.20 \\
\hline Ancoragem & 3792 & 0.00 & 0.00 & 35.20 \\
\hline Reserva & 1000 & 0.00 & 0.00 & 35.20 \\
\hline Lastro & 14601 & 0.00 & 0.00 & 4.12 \\
\hline & & & & \\
\hline
\end{tabular}

Com as características apresentadas, é possível calcular a estabilidade das duas unidades, ambas apresentam boa estabilidade intacta, mas é na comparação em avarias extremas que as unidades se diferenciam, como apresentado na Figura 37, que mostra as plataformas após avarias similares. 

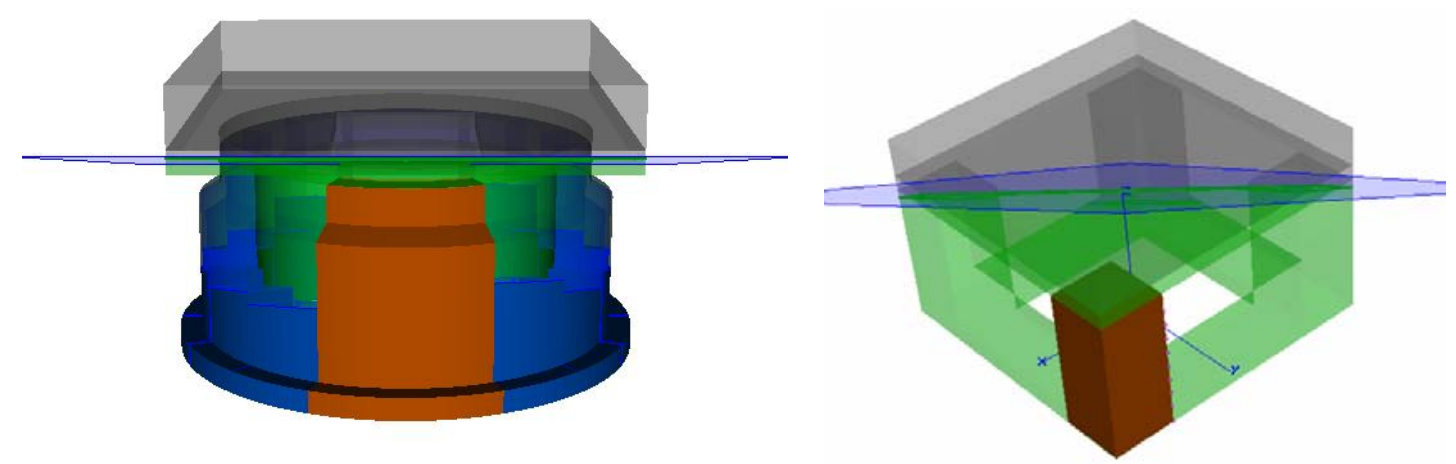

Figura 37. Comparação entre Monocoluna (A) e SSBR (B)

A Monocoluna, apresentada na Figura 37A possui as seguintes características:

- Avaria da fileira completa

- Inclinação $12,87^{\circ}$

- Comprimento de avaria: aproximadamente $37 \mathrm{~m}$

A SSBR, apresentada na Figura 37B, possui as seguintes características:

- Avaria da coluna inteira

- Inclinação 38,96

- Comprimento de avaria: aproximadamente $30 \mathrm{~m}$

Aplicando o mesmo volume de água embarcada na SSBR na monocoluna, a mesma inclina apenas $15,6^{\circ}$, como ilustra a Figura 38.

- Avaria de volume equivalente ao volume embarcado na SSBR

- Inclinação $15,6^{\circ}$

- Comprimento de avaria: aproximadamente $37 \mathrm{~m}$

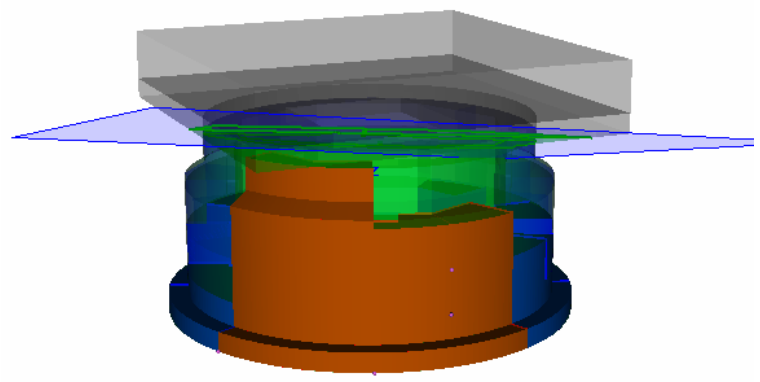

Figura 38. Monocoluna - avaria extrema

Caso haja o embarque de 5000 toneladas de água nos tanques da coluna da SSBR, essa inclina $12^{\circ}$, fazendo o topo do deckbox tocar a água (downflooding point). Com 
a mesma carga, a unidade monocoluna inclina $10^{\circ}$, precisando de aproximadamente 8500 toneladas de água para que se atinja o topo do deckbox (downflooding point). A monocoluna apresenta ainda a possibilidade de restaurar ângulos de inclinação devido à avaria, como apresentado no item 4,5, já no caso da SSBR, essa compensação de avaria não é igualmente possível devido à ausência de grande volume de lastro.

\subsection{SÍNTESE DO CAPÍTULO}

A metodologia de análise de estabilidade na família monocoluna parte obrigatoriamente do dimensionamento e a partir daí segue, utilizando o conceito de Espiral de Projeto, no refinamento das análises. Para se analisar a estabilidade de monocolunas é preciso definir diversas forças, pesos e centros, além de ter que repetir as análises para cada condição e aproamentos a fim de achar as condições críticas. O programa utilizado para análise de estabilidade de monocolunas foi o Sstab.

O conceito monocoluna apresenta reserva de estabilidade, principalmente por ter a peculiaridade de ser capaz de restaurar inclinação mesmo após avarias extremas, por meio de rearranjo de lastros.

Essa característica fez a monocoluna superar o conceito SSBR apresentado em comparação feita com o mesmo software utilizado para todas as análises de estabilidade feitas pelo grupo de projetos, o Sstab. 


\section{ESTUDO DE CASO - MONOGOM}

Esse capítulo tem como objetivo apresentar as análises de estabilidade de um caso específico de monocoluna que foi batizado de MonoGOM por ser um projeto destinado ao Golfo do México (Em Inglês "Gulf of Mexico").

Essa análise é importante pois além de mostrar a eficiência de estabilidade do caso específico MonoGOM, ela também serve de exemplo para ilustrar como todos os outros casos da família monocoluna foram analisados.

As análises de estabilidade intacta foram repetidas para 19 diferentes condições de carregamento, em nove diferentes calados, e estas análises podem ser encontradas na íntegra em [9].

\subsection{SISTEMA DE COORDENADAS}

A Figura 39 apresenta o sistema de coordenadas adotado no caso MonoGOM.
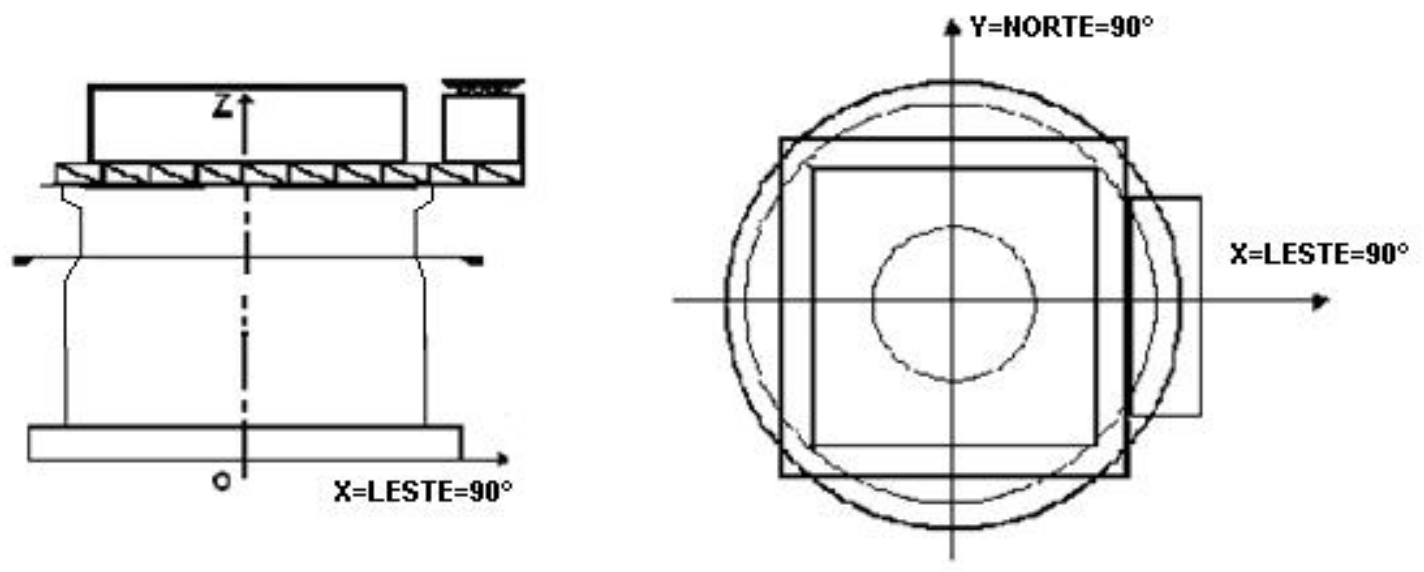

Figura 39. Sistema de coordenadas

Nesse capítulo nota-se mais uma vez que o conceito de azimute crítico vem à tona por repetidas vezes, nesse caso o azimute crítico está calculado a partir do zero grau sempre no sentido horário. 


\subsection{CARACTERÍSTICAS GERAIS}

A tabela 7, Figura 40 e Figura 41 apresentam as dimensões principais da unidade.

Tabela 7 - Dimensões principais

\begin{tabular}{|c|c|}
\hline Boca Máxima $(\mathrm{m})$ & 118.8 \\
\hline Boca na linha d'água $(\mathrm{m})$ & 87.1 \\
\hline Altura $(\mathrm{m})$ & 58.0 \\
\hline Calado $(\mathrm{m})$ & De 28.7 até 47.9 \\
\hline Air Gap $(\mathrm{m})$ & De 10.1 até 29.3 \\
\hline Deslocamento $(\mathrm{t})$ & De 207,000 até 299,500 \\
\hline GM (com efeito de sup. livre) $(\mathrm{m})$ & De 2.8 até 15.2 \\
\hline Numero de risers SCR & 6 \\
\hline Numero de umbilicais & 3 \\
\hline Numero de SCR para exportação & 1 \\
\hline Numero de linhas de amarração & 13 \\
\hline
\end{tabular}




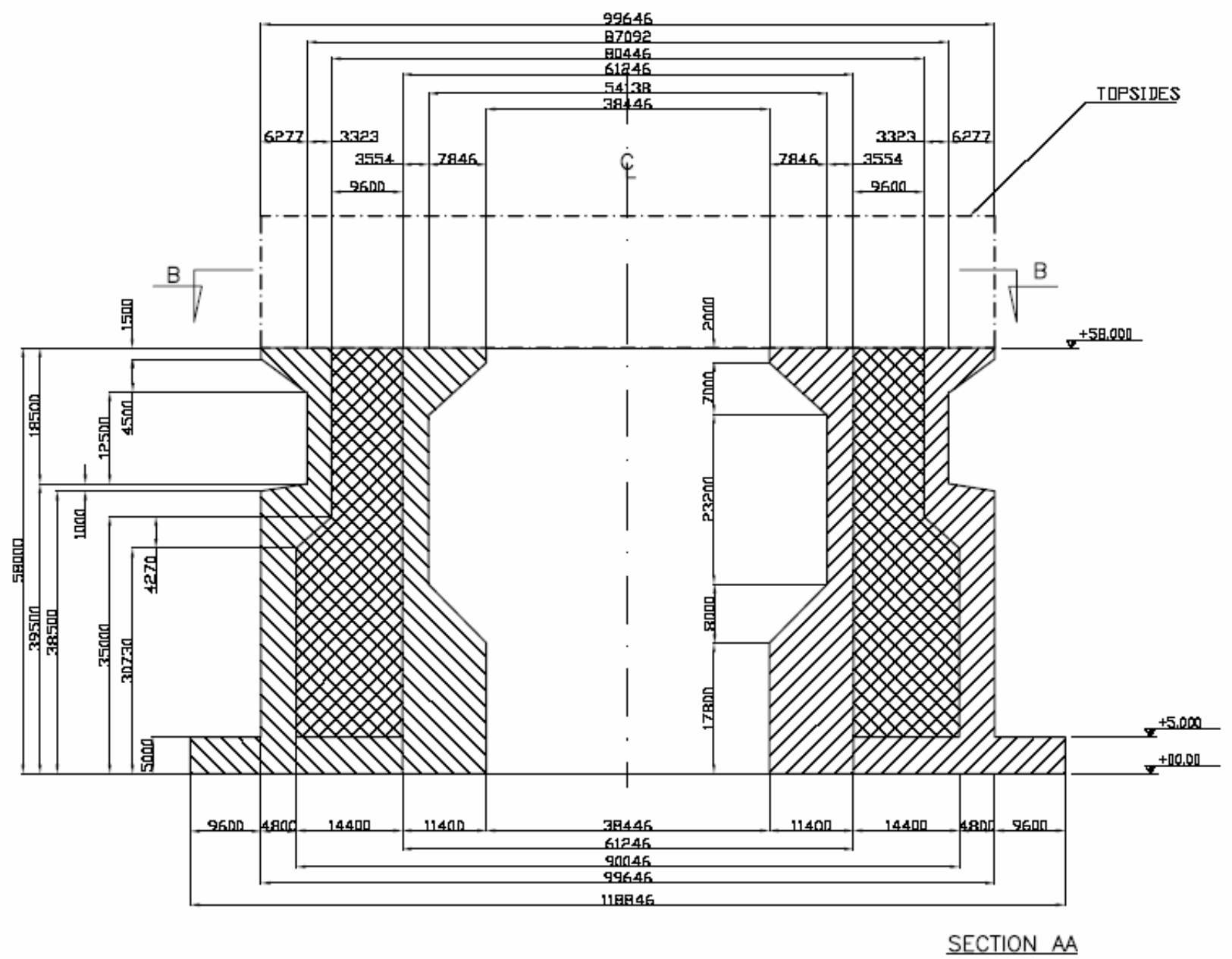

Figura 40. Dimensões Gerais vista frontal 


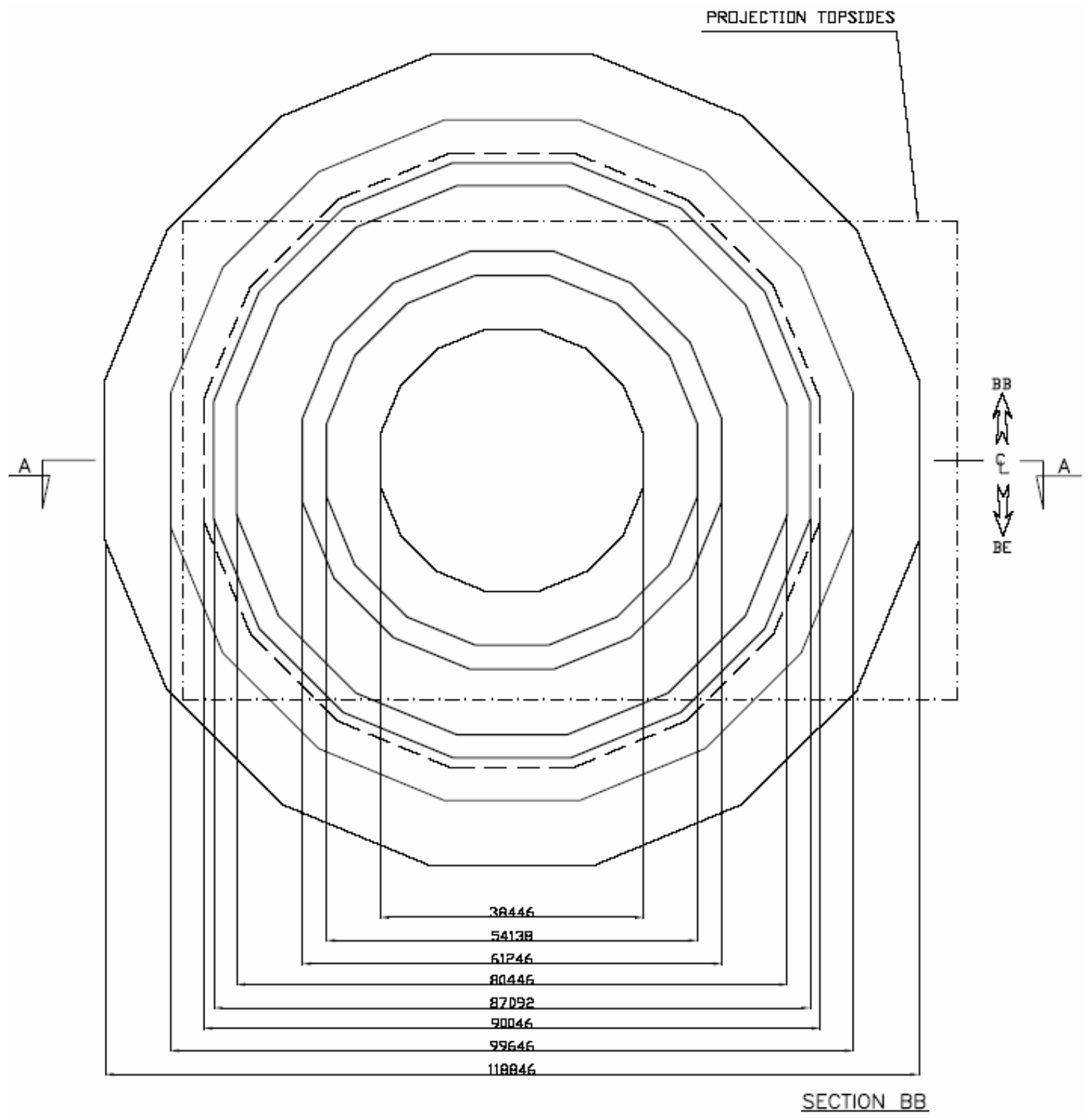

Figura 41. Dimensões Gerais vista Topo

\subsection{CONDIÇÕES DE CARREGAMENTO}

Várias condições de carregamento foram consideradas para que se cubram diversas possibilidades de operação. As condições de carregamento em uma análise de estabilidade têm como objetivo apresentar os itens que contribuem com as principais forças de carregamento, explicitando peso e posição na plataforma por meio de suas 
coordenadas geométricas. As condições de carregamento de forma completa podem ser verificadas em [9].

\subsection{PONTOS DE ALAGAMENTO}

Para análise de estabilidade deve ser definido um ou mais pontos de alagamento, que representam o ponto onde, hipoteticamente, ocorrerá embarque de água a uma dada inclinação. Para esse caso, apenas um ponto de alagamento foi definido, representando o ponto onde sairiam os respiros dos tanques de lastro, localizado no centro da plataforma, 0,8 $\mathrm{m}$ acima da linha d'água (Figura 42), e mesmo que essa altura seja inferior a alturas praticadas em unidades em operação, reitera-se que a análise tem caráter conservador.

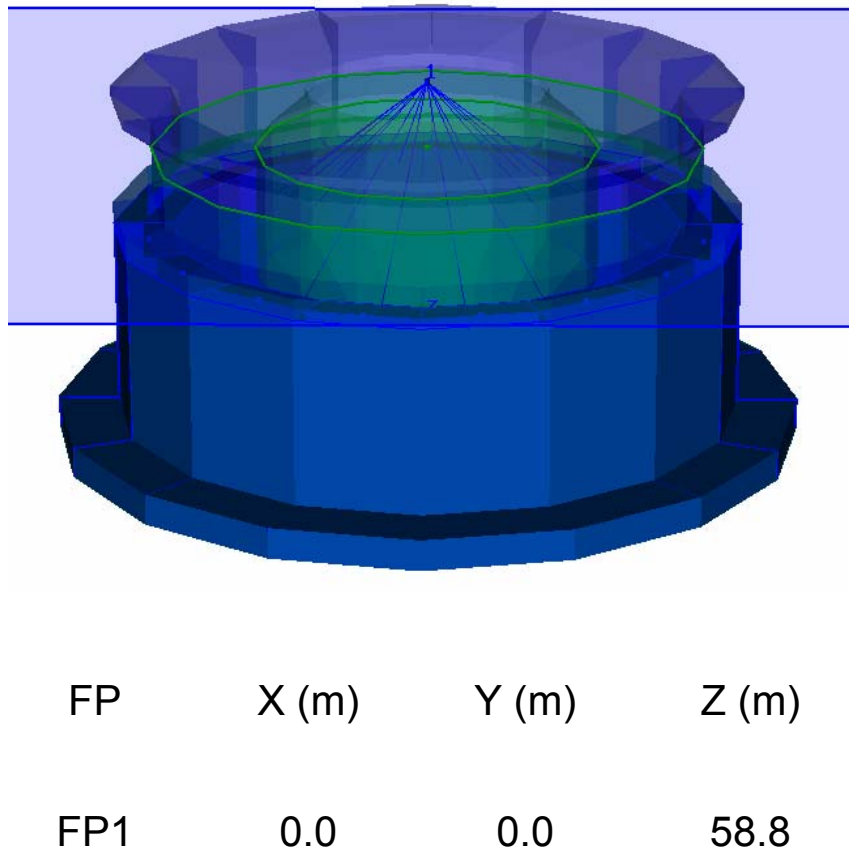

Figura 42. Posição do ponto de alagamento. 


\subsection{COMPARTIMENTAGEM}

A compartimentagem do casco da MonoGOM foi gerada de forma a facilitar a construção e acesso aos tanques na operação, e dessa maneira, os tanques foram subdivididos verticalmente, sem anteparas horizontais. Os tanques foram segregados em cinco classes: tanques de lastro externo (16 tanques), tanques de lastro interno (8 tanques), tanques de resíduos (2 tanques) e tanques de consumíveis - água e diesel (4 tanques). Essa unidade apresenta sistema que impede que os tanques de óleo sejam divididos por uma antepara simples, e sim por uma faixa de tanque de lastro, viabilizando o esvaziamento de um tanque de óleo sem necessidade de esvaziamento de seu adjacente. A Figura 43 e a Figura 44 mostram o modelo de compartimentagem.

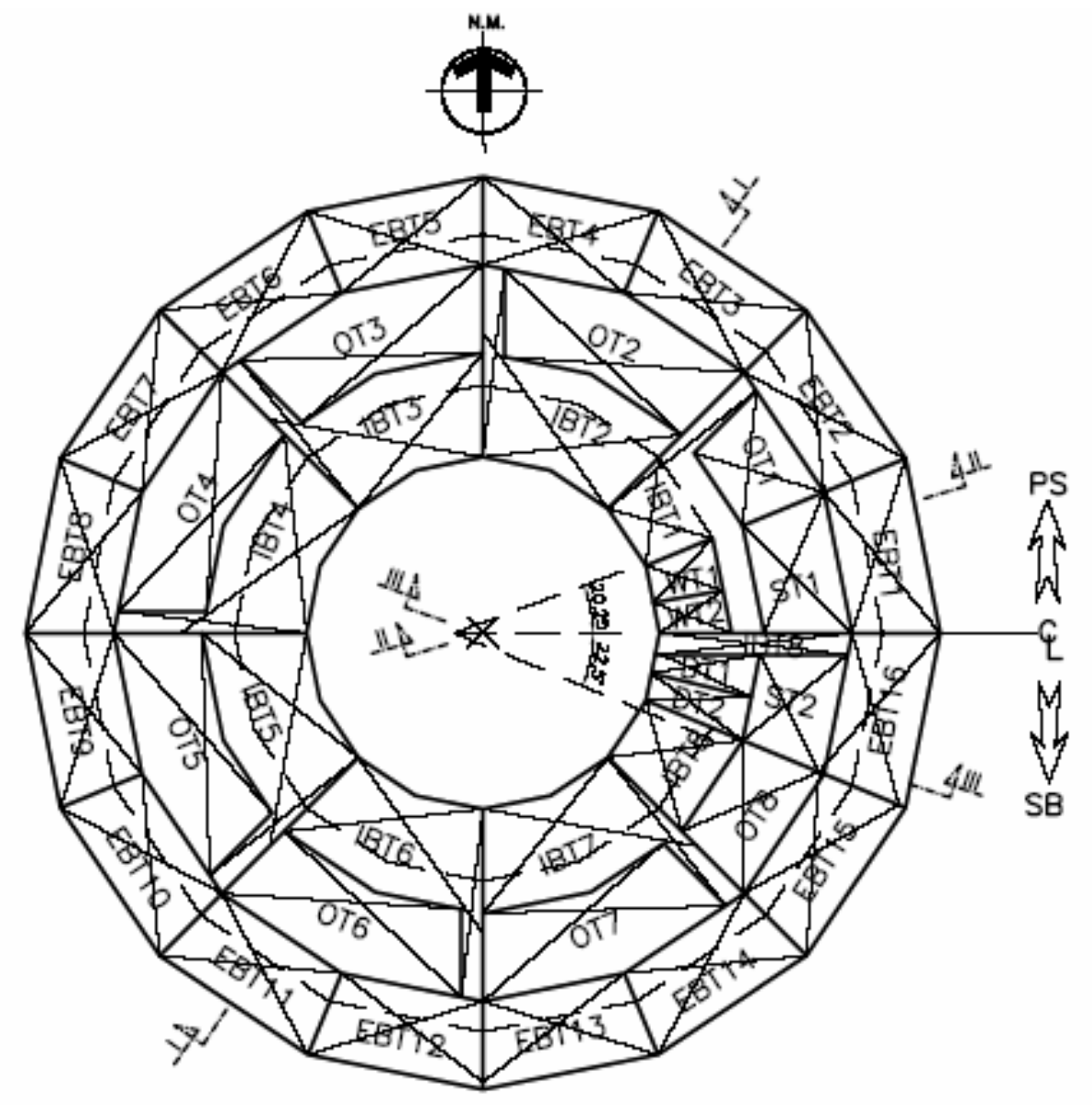

\section{SECTION A}

Figura 43. Arranjo dos tanques linha d'água 


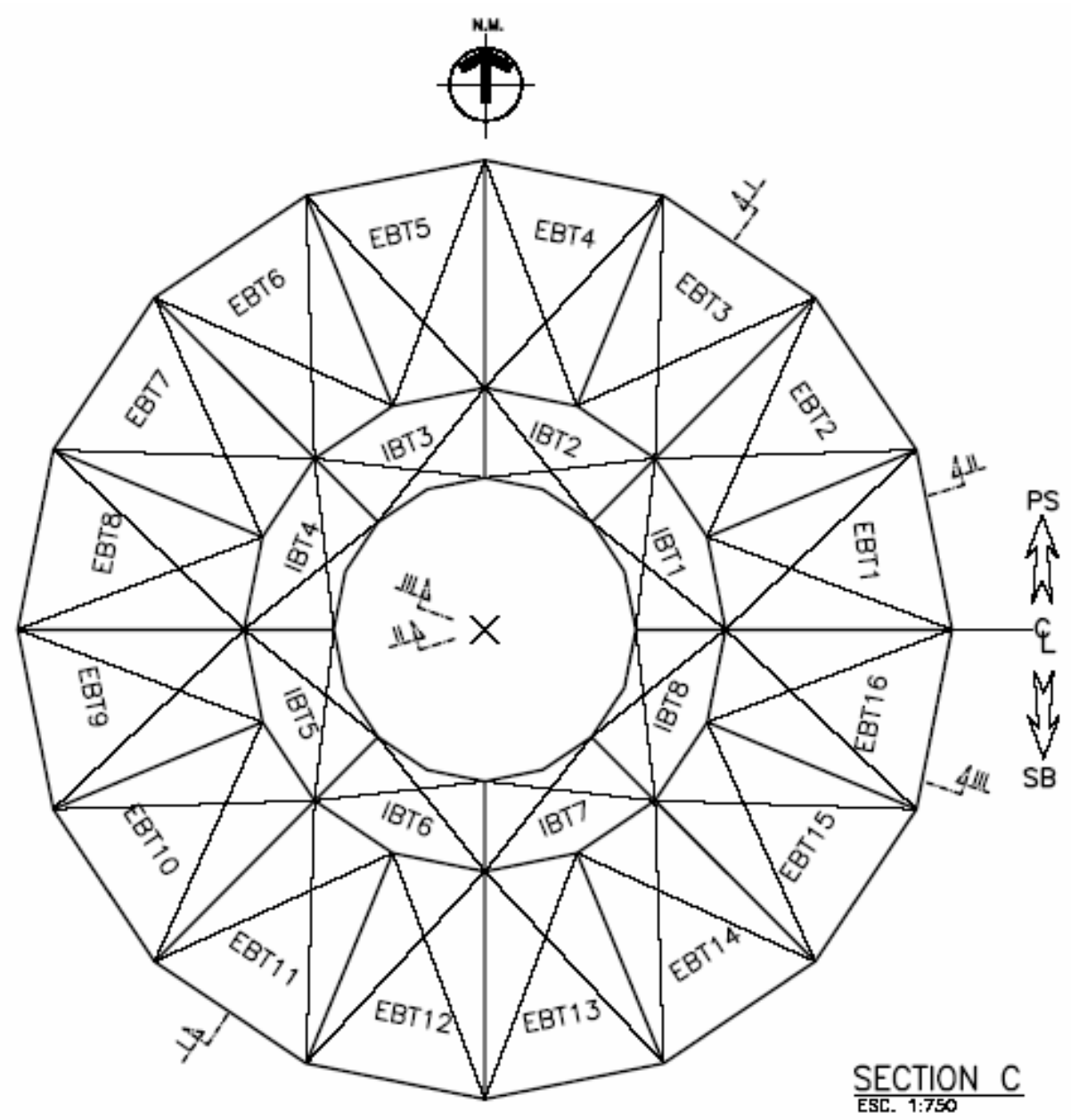

Figura 44. Arranjo dos tanques base

\subsection{INFLUÊNCIA DO VENTO}

O objetivo dessa análise é avaliar a ação do vento na superestrutura da plataforma já que essa tem parte da coluna emersa e também tem os módulos do convés, bem como sua estrutura expostos ao vento, o que gera momento emborcador. A Figura 45 apresenta o modelo empregado nas análises. 


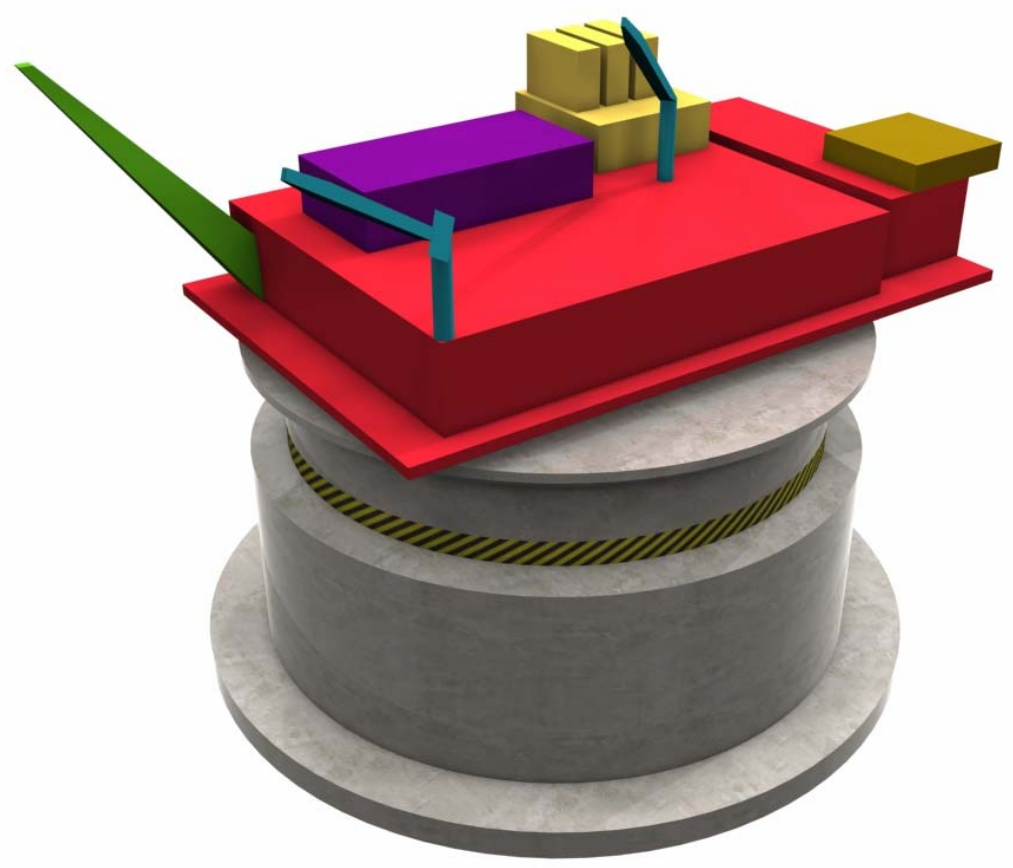

Figura 45. Modelo empregado para análise de influência do vento

O cálculo foi realizado para 7 diferentes calados $(3,6 \mathrm{~m} ; 7,0 \mathrm{~m} ; 21,7 \mathrm{~m} ; 28,7 \mathrm{~m} ; 39,5 \mathrm{~m}$; 47,9m; e 53m) e para 3 azimutes críticos* $\left(0^{\circ} ; 270^{\circ} ; 315^{\circ}\right.$ - sistema de coordenadas utilizado para o cálculo de momento emborcador tem $90^{\circ}$ de defasagem do apresentado no sistema de coordenadas), considerando 8 ângulos de inclinação $\left(0^{\circ}\right.$, $5^{\circ}, 10^{\circ}, 15^{\circ}, 20^{\circ}, 25^{\circ}, 30^{\circ}, 35^{\circ}$ e $\left.40^{\circ}\right)$.

Para os azimutes de $45^{\circ}, 135^{\circ}$ e $225^{\circ}$ a influência do vento foi considerada similar a $315^{\circ}$. O azimute $90^{\circ}$ foi considerado similar a seu oposto $270^{\circ}$, da mesma maneira, $0^{\circ}$ similar a $180^{\circ}$. Essa aproximação é possível, pois as áreas afetadas pelo vento são similares, além do fato de que os azimutes analisados apresentam maiores coeficientes de arraste, o que implica em um coeficiente de arrasto maior que por sua vez implica em maior momento emborcador. A Figura 46 apresenta uma vista de topo do convés com um esquema das incidências do vento (com a incidência do vento e os azimutes da plataforma entre parêntesis). Os azimutes que foram extrapolados para análise de toda plataforma são os mais críticos. 


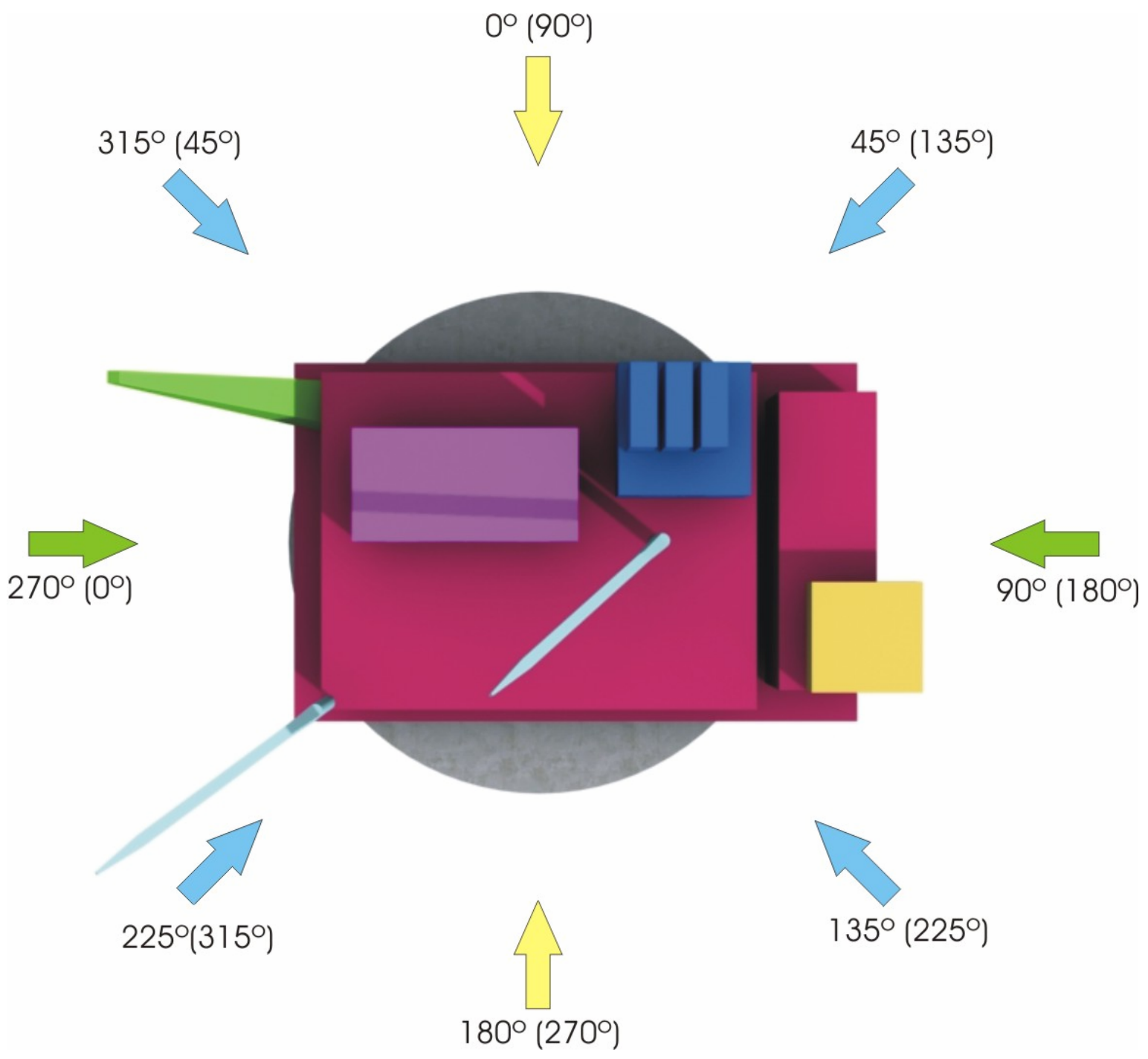

Figura 46. Incidência do vento com azimutes (entre parêntesis)

Todos os cálculos foram realizados seguindo [3] e [4].

As forças do vento foram calculadas utilizando a seguinte fórmula:

$$
F=0.610 C_{S} C_{H} V^{2} A(\mathrm{~N})
$$

Onde:

CS: Coeficiente de forma;

$\mathrm{CH}$ : Coeficiente de altura;

$\mathrm{V}$ : Velocidade do vento $(\mathrm{m} / \mathrm{s})$;

A: Área projetada de todas as superfícies expostas ao vento quando da plataforma inclinada ou sem trim nem banda $\left(\mathrm{m}^{2}\right)$.

A força de momento emborcador foi calculada pela seguinte formula:

$$
M=F^{*} d\left(\mathrm{~N}^{*} \mathrm{~m}\right)
$$


Onde:

$\mathrm{d}=$ distancia vertical do centro de pressão de todas as superfícies expostas ao vento até o centro de resistência lateral da parte submersa da plataforma(m).

Finalmente, o momento emborcador devido ao vento é calculado por:

$$
W H A=\frac{M}{g \Delta}(\mathrm{m})
$$

Onde:

$\Delta$ : Deslocamento da unidade em cada calado considerado $(\mathrm{kg})$;

g: aceleração da gravidade $\left(9.81 \mathrm{~m} / \mathrm{s}^{2}\right)$

Para os cálculos foi preciso determinar os coeficientes de altura e forma; os coeficientes de altura adotados seguem os valores da tabela 8:

\section{Tabela 8 - Coeficientes de altura}

\begin{tabular}{|c|c|c|}
\hline \multicolumn{3}{|c|}{$C_{H}(A B S)$} \\
\hline $\operatorname{Min}(\mathrm{m})$ & $\operatorname{Max}(\mathrm{m})$ & $\mathrm{C}_{\mathrm{H}}$ \\
\hline 0 & 15.3 & 1 \\
\hline 15.3 & 30.5 & 1.23 \\
\hline 30.5 & 46 & 1.4 \\
\hline 46 & 61 & 1.52 \\
\hline 61 & 76 & 1.62 \\
\hline 76 & 91.5 & 1.71 \\
\hline 91.5 & 106.5 & 1.78 \\
\hline
\end{tabular}

Os módulos de convés expostos foram agrupados em 6 grandes grupos. Sua posição, bem como seus coeficientes de forma estão apresentada na tabela 9:

Tabela 9 - Descrição dos grandes grupos e coeficientes de forma

\begin{tabular}{|l|l|r|l|}
\hline Modulo & Item & Cs & Cor \\
\hline Pescoço & Área exposta do casco & 1 & Cinza \\
\hline M 1 & Estrutura do deck & 1,3 & Vermelho \\
\hline M 2 & Helideck & 1,3 & Marrom \\
\hline M 3 & Flare & 1,5 & Verde \\
\hline M 4 & Compressão de Gas & 1,5 & Amarelo \\
\hline M 5 & Turbo Generator & 1,5 & Roxo \\
\hline M 6 & Guindastes & 1,5 & Azul \\
\hline
\end{tabular}

Para análise de estabilidade intacta, a velocidade do vento adotada foi de $51,5 \mathrm{~m} / \mathrm{s}$ (100 nós), e para análise de estabilidade avariada, a velocidade do vento adotada foi de $25,8 \mathrm{~m} / \mathrm{s}$ (50 nós), como regem as normas vigentes. 
O resultado de todas análises são diversas curvas de momento emborcador, elas estão apresentadas por completo em [9].

A Figura 47 apresenta uma curva de momento emborcador para análise de estabilidade intacta com calado de $53 \mathrm{~m}$ e azimute $270^{\circ}$, para fins ilustrativos:

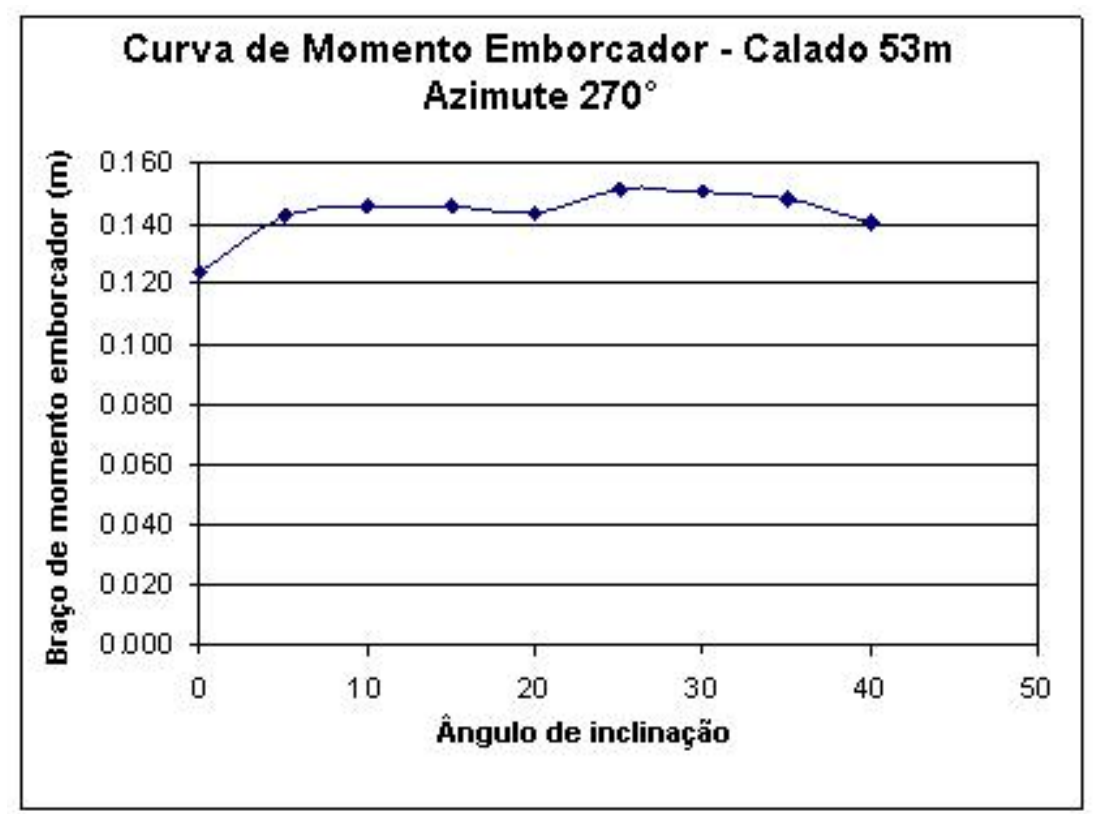

Figura 47. Curva de momento emborcador - estabilidade intacta

A Figura 48 apresenta curva de momento emborcador para análise de estabilidade avariada com calado de $47,87 \mathrm{~m}$ e azimute $0^{\circ}$, para fins ilustrativos:

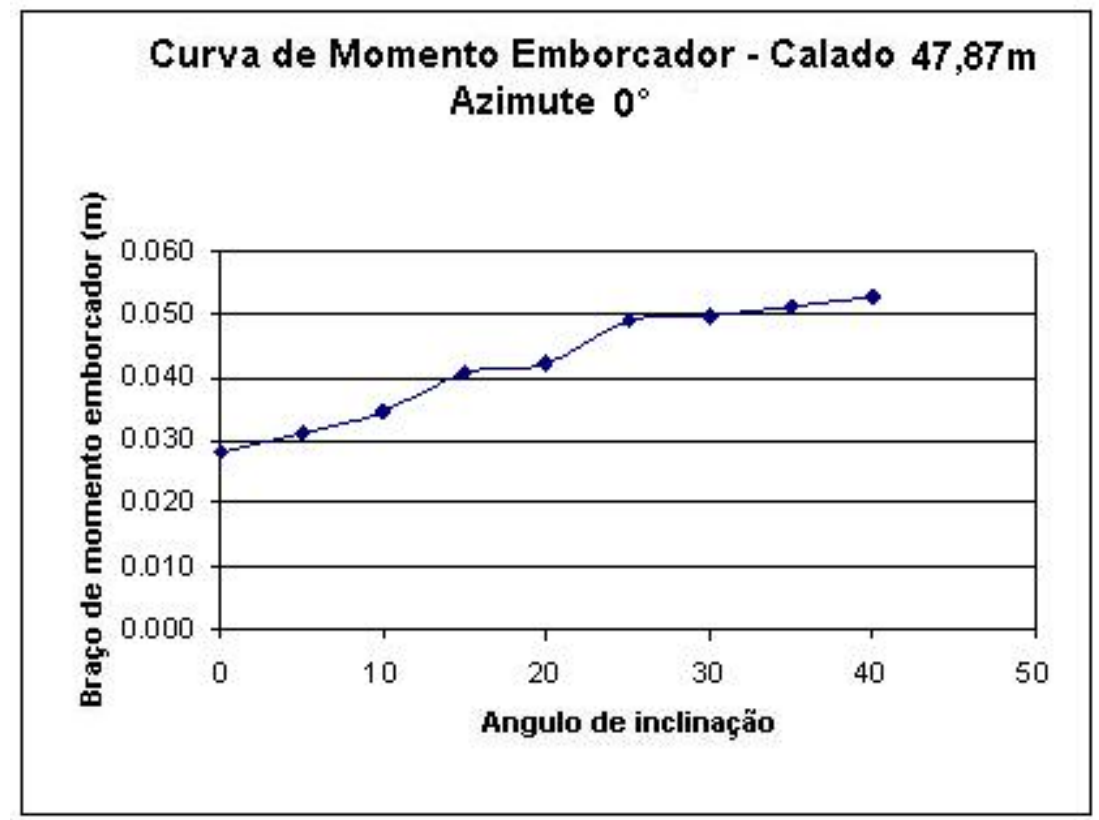

Figura 48. Curva de momento emborcador - estabilidade avariada 


\subsection{ESTABILIDADE INTACTA}

A estabilidade intacta desse caso específico foi testada e aprovada em diversas condições de carregamento e em diversos aproamentos. A plataforma apresenta grande reserva de estabilidade, com alturas metacêntricas bem altas, atingindo a faixa dos $20 \mathrm{~m}$, entretanto para mantermos o caráter conservador de validação dessa dissertação, a análise apresentada aqui é o caso mais restritivo da plataforma em relação à altura metacêntrica (que apresenta GM mais baixo, com efeito de superfície livre). A tabela 10 apresenta as características gerais da unidade. 
Tabela 10 - Respostas Monogom - Estabilidade Intacta

\begin{tabular}{|l|l|}
\hline Calado (m) & 39.50 \\
\hline Deslocamento (t) & 267671.30 \\
\hline GM $(\mathrm{m})$ & 3.50 \\
\hline GMFS (m) & 2.76 \\
\hline KG $(\mathrm{m})$ & 23.68 \\
\hline KGFS (m) & 24.36 \\
\hline Azimute crítico $\left(^{\circ}\right)$ & $135(\mathrm{SE})$ \\
\hline Razão de área & 11.14 \\
\hline Ângulo de equilíbrio $\left(^{\circ}\right)$ & 2.31 \\
\hline Faixa de estabilidade $\left(^{\circ}\right)$ & 37.69 \\
\hline Segunda intersecção $\left(^{\circ}\right)$ & $>40$ \\
\hline Ângulo de alagamento $\left(^{\circ}\right)$ & $>40$ \\
\hline
\end{tabular}

O ângulo de inclinação e a razão de área para cada azimute estão apresentados na tabela 11 e na Figura 49. 
Tabela 11 - Principais parâmetros de estabilidade

\begin{tabular}{|c|c|c|c|}
\hline Azimute $\left(^{\circ}\right)$ & Razão de área & Ângulo de equilíbrio & Faixa de estabilidade $\left(^{\circ}\right)$ \\
\hline 0 & 12,10 & 1,63 & 38,37 \\
\hline 45 & 11,25 & 2,30 & 37,70 \\
\hline 90 & 11,54 & 2,17 & 37,83 \\
\hline 135 & 11,14 & 2,31 & 37,69 \\
\hline 180 & 12,07 & 1,63 & 38,37 \\
\hline 225 & 11,23 & 2,30 & 37,70 \\
\hline 270 & 11,55 & 2,17 & 37,83 \\
\hline 315 & 11,18 & 2,31 & 37,69 \\
\hline
\end{tabular}
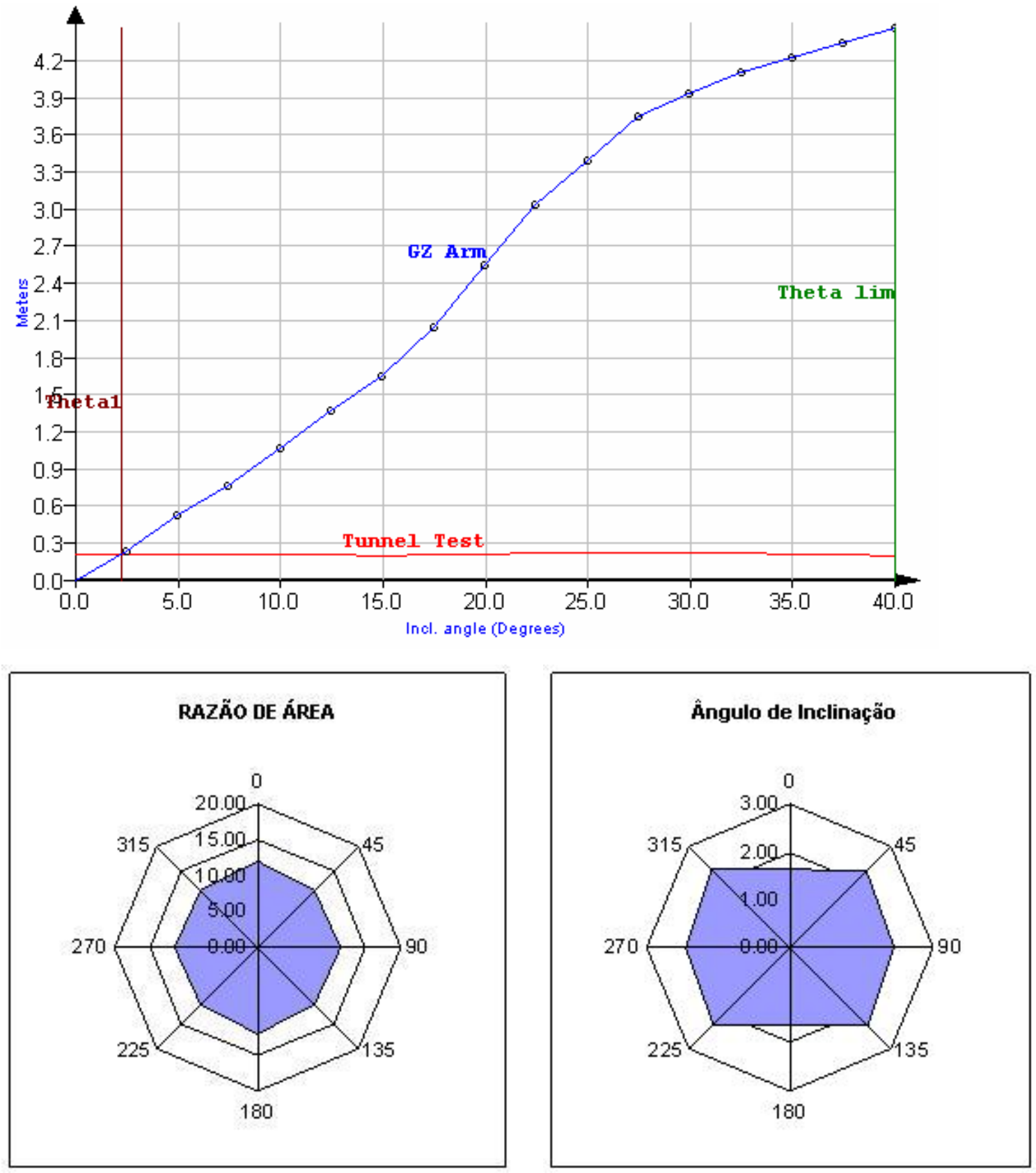

Figura 49. Curva de estabilidade intacta - aproamento $135^{\circ}$ (SE) 


\subsection{ESTABILIDADE AVARIADA}

Assim como na estabilidade intacta, ao analisarmos condições de possíveis avarias, tornam-se necessárias múltiplas análises, que cerceiem todas as possibilidades de abalroamento. Novamente a análise apresentada é o caso mais restritivo da plataforma apresentando menor GM com efeito de superfície livre.

A condição mais restritiva para a estabilidade desse caso é a de $90 \%$ de ocupação de óleo e calado de $39,5 \mathrm{~m}$. Nessa condição os tanques de lastro estão com pouquíssimo lastro, fazendo com que em caso de abalroamento o embarque de água seja maior, implicando em maior inclinação da plataforma.

A análise de estabilidade avariada foi realizada levando em consideração todos dos 16 tanques externos e 8 dos tanques internos de lastro, sempre considerando dois tanques adjacentes abalroados ao mesmo tempo. Os resultados dessa análise podem ser vistos na tabela 12, e a Figura 50 ilustra a plataforma após avaria.

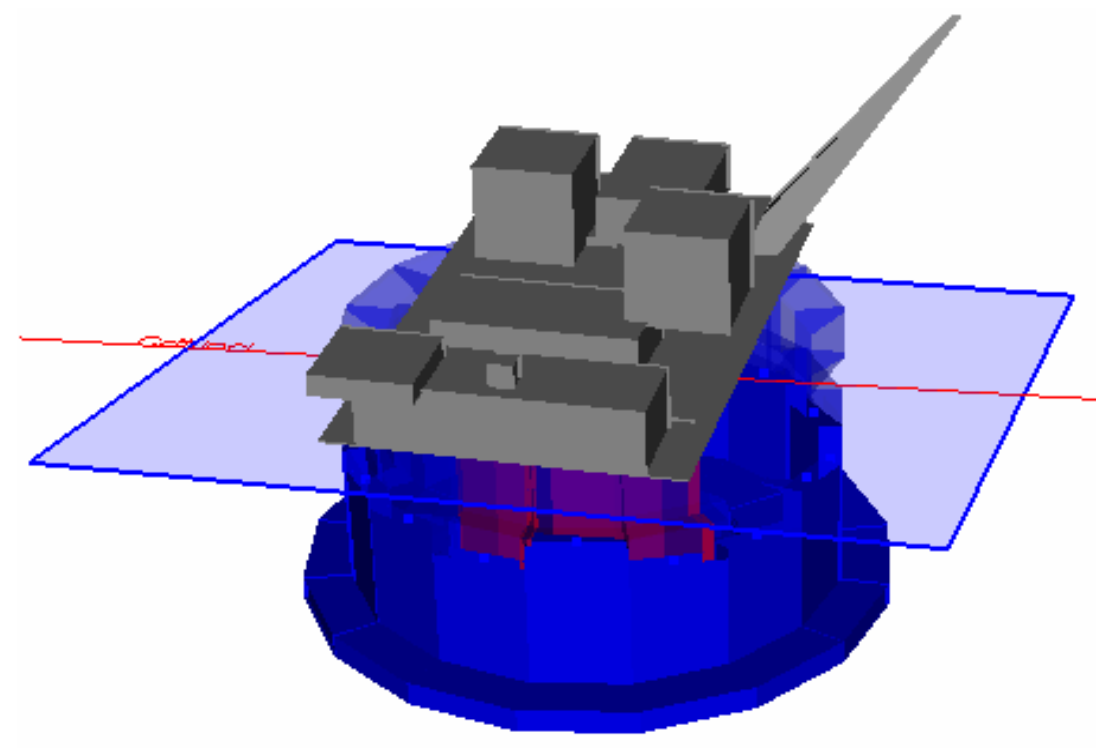

Figura 50. Plataforma após avaria 
Tabela 12 - Condição 90\% ocupação - Calado 39,5 m

\begin{tabular}{|c|c|c|c|}
\hline Calado $(\mathrm{m})$ & 43.73 & Ocupação & $90 \%$ \\
\hline Deslocamento (t) & $264.744,17$ & Razão de área & 38.20 \\
\hline GM $(\mathrm{m})$ & 7.59 & Angulo de equilíbrio $\left(^{\circ}\right)$ & 11.50 \\
\hline GMFS $(\mathrm{m})$ & 7.14 & Segunda intersecção $\left(^{\circ}\right)$ & $>40$ \\
\hline KG $(\mathrm{m})$ & 22.79 & Angulo de alagamento $\left(^{\circ}\right)$ & $>40$ \\
\hline KG FS $(\mathrm{m})$ & 23.23 & Faixa de estabilidade $\left(^{\circ}\right)$ & 28.50 \\
\hline Azimute crítico $\left({ }^{\circ}\right)$ & 355.12 & Tanques avariados & IBT8 e 1 \\
\hline
\end{tabular}

Obs.: Os valores de GM e KG apresentados são para a plataforma após a avaria. A tabela 13 apresenta detalhes da situação dos tanques após avaria e a Figura 51 apresenta a curva de estabilidade da plataforma avariada.

Tabela 13 - Características gerais dos tanques após avaria

\begin{tabular}{|c|c|c|c|c|c|c|c|}
\hline & $\begin{array}{l}\text { Tanques } \\
\text { avariados }\end{array}$ & Azimute & $\begin{array}{l}\text { Razão } \\
\text { área }\end{array}$ & $\begin{array}{l}\text { Angulo } \\
\text { Alagamento }\end{array}$ & Trim (") & $\begin{array}{l}\text { Angulo } \\
\text { Equilibrio }\end{array}$ & $\begin{array}{l}\text { Faixa de } \\
\text { estab. }\end{array}$ \\
\hline \multirow{16}{*}{ 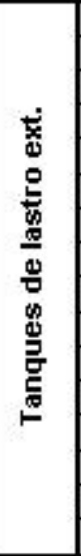 } & EBT1/EBT2 & 334.53 & 45.7 & $>40$ & 3.4 & 3.8 & 36.2 \\
\hline & EBT2:EBT3 & 315.11 & 43.7 & $>40$ & 4.3 & 4.7 & 35.3 \\
\hline & EBT3/EBT4 & 294.78 & 45.0 & $>40$ & 3.6 & 4.1 & 35.9 \\
\hline & EBT4/EBT5 & 267.07 & 45.2 & $>40$ & 4.0 & 4.4 & 35.6 \\
\hline & EBT5/EBT6 & 247.47 & 43.8 & $>40$ & 4.9 & 5.3 & 34.7 \\
\hline & EBT6IEBT7 & 235.89 & 48.3 & $>40$ & 2.4 & 2.9 & 37.1 \\
\hline & EBT7/EBT8 & 191.14 & 50.4 & $>40$ & 2.0 & 2.5 & 37.5 \\
\hline & EBT8IEBT9 & 190.08 & 47.9 & $>40$ & 2.1 & 2.6 & 37.4 \\
\hline & EB T9/EB T10 & 148.22 & 46.4 & $>40$ & 2.2 & 2.7 & 37.3 \\
\hline & EBT10EBT11 & 136.47 & 43.9 & $>40$ & 3.8 & 4.2 & 35.8 \\
\hline & EBT11EBT12 & 112.9 & 45.2 & $>40$ & 3.5 & 3.3 & 36.7 \\
\hline & EBT12/EBT13 & 89.96 & 44.5 & $>40$ & 3.5 & 3.9 & 36.1 \\
\hline & EBT13/EBT14 & 67.27 & 44.5 & $>40$ & 3.5 & 3.9 & 36.1 \\
\hline & ЕВТ14:ЕВT15 & 44.73 & 44.5 & $>40$ & 3.5 & 3.9 & 36.1 \\
\hline & EBT15/EBT16 & 21.3 & 45.1 & $>40$ & 3.8 & 4.1 & 35.9 \\
\hline & EBT16:EBT1 & 2.97 & 46.8 & $>40$ & 3.3 & 3.6 & 36.4 \\
\hline \multirow{8}{*}{ 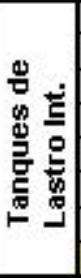 } & IBT1/BT2 & 310.61 & 36.6 & $>40$ & 11.1 & 11.4 & 28.6 \\
\hline & IBT2/BT3 & 264.87 & 36.9 & $>40$ & 11.0 & 11.4 & 28.6 \\
\hline & IBT3/BT4 & 219.55 & 36.0 & $>40$ & 11.1 & 11.4 & 28.6 \\
\hline & IBT4/1BT5 & 175.09 & 36.3 & $>40$ & 11.1 & 11.4 & 28.6 \\
\hline & IB T5/ABT6 & 130.55 & 36.1 & $>40$ & 11.1 & 11.4 & 28.6 \\
\hline & IBT6ABT? & 84.88 & 36.1 & $>40$ & 11.0 & 11.4 & 28.6 \\
\hline & IBT7/ABT8 & 39.42 & 37.1 & $>40$ & 11.1 & 11.5 & 28.5 \\
\hline & IBT8/BT1 & 355,12 & 38.2 & $>40$ & 112 & 11.5 & 28.5 \\
\hline
\end{tabular}




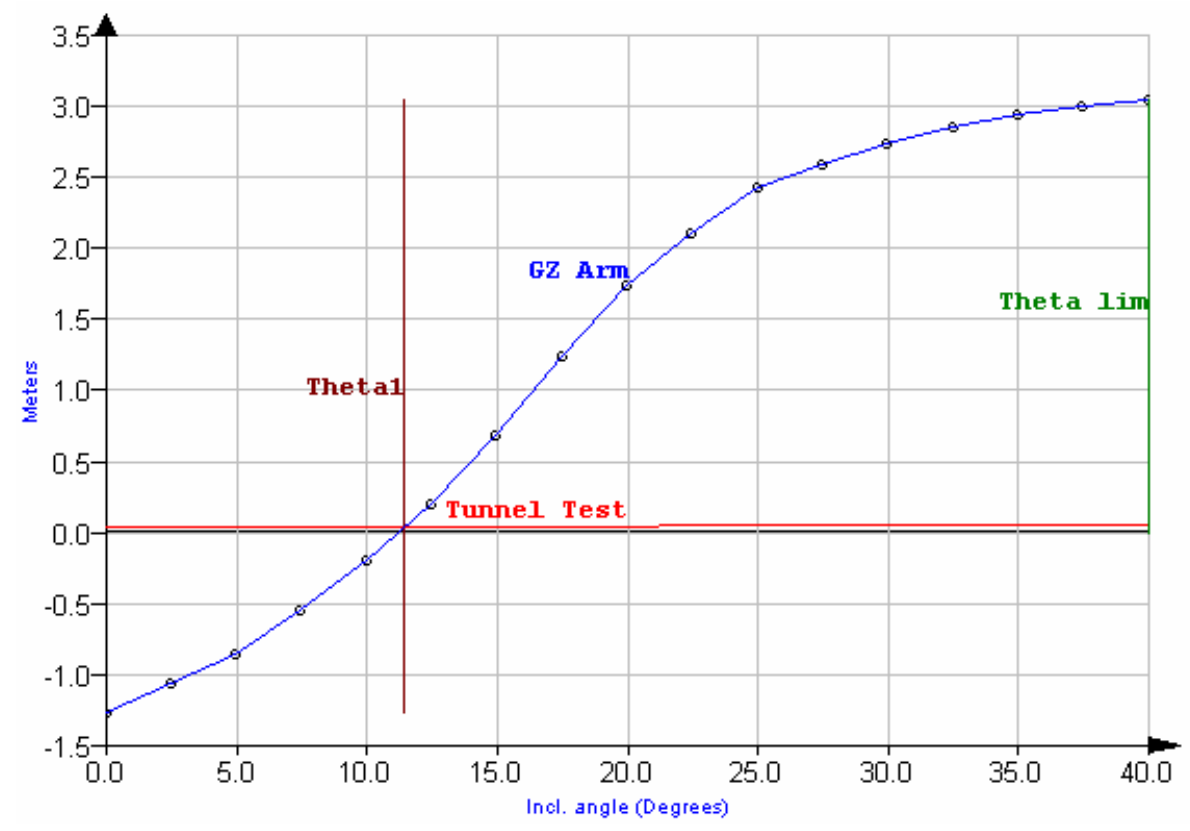

Figura 51. Curva de estabilidade calculada com unidade avariada

\subsection{ANÁLISE DE MÁXIMA ALTURA METACÊNTRICA}

A análise de máxima altura metacêntrica ou AVCG serve para definir o KG máximo no aproamento crítico que satisfaz as condições mínimas de estabilidade e razão de área da plataforma. Essa análise é fundamental na monocoluna pois essa não apresenta eixo crítico de estabilidade, dessa forma é necessário avaliar todas as características da unidade em aproamentos representativos, que simulem a operação da unidade, sujeita intempéries naturais. Dessa forma, a análise de AVCG foi realizada para 8 calados: $7.0 \mathrm{~m}, 15.0 \mathrm{~m}, 22.0 \mathrm{~m}, 28.0 \mathrm{~m}, 34.0 \mathrm{~m}, 40.0 \mathrm{~m}, 44.0 \mathrm{~m}$, $48.0 \mathrm{~m}$ e $53.0 \mathrm{~m}$. A análise foi feita considerando os requisitos de estabilidade intacta e avariada além do ângulo limite para ruptura dos flex joint. Outros aspectos como movimentos e ondas não foram considerados. O limite do flex joint para todos os calados foi definido em $12^{\circ}$.

O AVCG (incluindo o efeito de superfície livre) que atende as exigências de estabilidade intacta está apresentado na Figura 52. 


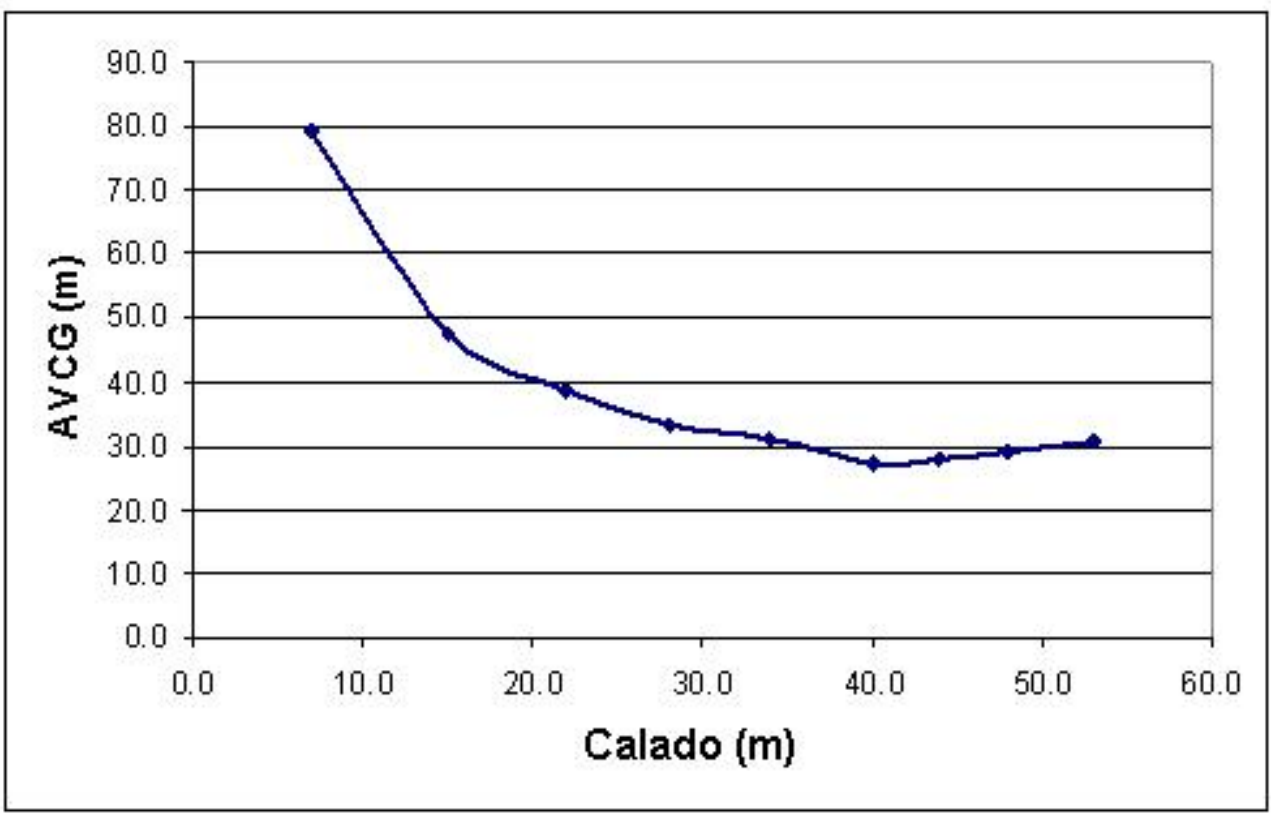

Figura 52. AVCG - estabilidade intacta

Os parâmetros que estabeleceram o AVCG foram: mínimo GM, primeiro ângulo de intersecção, faixa de estabilidade e a relação de área.

O efeito causado por um tanque danificado na unidade depende de seu carregamento, tendo em vista que a quantidade de água que o tanque incorpora ou perde variam. Dessa forma, as análises foram realizadas com o carregamento do tanque em $10 \%$, pois é condição mais crítica por dar a possibilidade de maior embarque de água. Os danos foram considerados de forma a afetar dois tanques adjacentes de lastro interno, e em outras análises dois externos. A tabela 14 e a Figura 53 apresentam o resultado para os tanques externos segundo [9], onde encontram-se também as análises completas. 
Tabela 14 - AVCG com tanques adjacentes externos avariados

\begin{tabular}{|r|r|r|r|r|r|r|r|r|r|}
\hline $\begin{array}{r}\text { calado } \\
\text { ocup. \% }\end{array}$ & $\mathbf{7 . 0} \mathbf{~ m}$ & $\mathbf{1 5 . 0} \mathbf{~ m}$ & $\mathbf{2 2 . 0} \mathbf{~ m}$ & $\mathbf{2 8 . 0} \mathbf{~ m}$ & $\mathbf{3 4 . 0} \mathbf{~ m}$ & $\mathbf{4 0 . 0} \mathbf{~ m}$ & $\mathbf{4 4 . 0} \mathbf{~ m}$ & $\mathbf{4 8 . 0} \mathbf{~ m}$ & $\mathbf{5 3 . 0} \mathbf{~ m}$ \\
\hline $\mathbf{0 . 0}$ & 70.95 & 39.97 & 31.83 & 27.50 & 25.59 & 23.42 & 21.25 & 19.92 & 18.40 \\
\hline $\mathbf{1 0 . 0}$ & 75.09 & 41.82 & 32.87 & 28.33 & 26.26 & 24.36 & 22.32 & 21.17 & 20.01 \\
\hline $\mathbf{2 0 . 0}$ & 79.48 & 43.70 & 33.91 & 29.17 & 26.93 & 25.24 & 23.35 & 22.36 & 21.56 \\
\hline $\mathbf{3 0 . 0}$ & 84.36 & 45.60 & 34.96 & 30.01 & 27.61 & 26.08 & 24.35 & 23.49 & 23.04 \\
\hline $\mathbf{4 0 . 0}$ & 73.65 & 47.57 & 36.03 & 30.88 & 28.31 & 26.89 & 25.33 & 24.58 & 24.50 \\
\hline $\mathbf{5 0 . 0}$ & 67.06 & 46.02 & 37.18 & 31.81 & 29.07 & 27.71 & 26.31 & 25.65 & 25.93 \\
\hline $\mathbf{6 0 . 0}$ & 61.35 & 44.05 & 37.36 & 32.81 & 29.87 & 28.54 & 27.30 & 26.70 & 27.35 \\
\hline $\mathbf{7 0 . 0}$ & 56.49 & 42.10 & 36.34 & 32.90 & 31.54 & 29.40 & 28.28 & 27.67 & 28.34 \\
\hline $\mathbf{8 0 . 0}$ & 52.40 & 40.27 & 35.38 & 32.17 & 30.26 & 30.23 & 29.22 & 28.63 & 29.43 \\
\hline $\mathbf{9 0 . 0}$ & 47.90 & 38.55 & 34.54 & 31.57 & 29.71 & 29.60 & 29.00 & 29.28 & 30.82 \\
\hline $\mathbf{1 0 0 . 0}$ & 42.90 & 36.68 & 33.69 & 31.00 & 29.20 & 29.08 & 28.44 & 28.47 & 29.91 \\
\hline
\end{tabular}

A Figura 53 mostra um gráfico tridimensional que apresenta os resultados obtidos para AVCG com dois tanques adjacentes de lastro externos avariados.

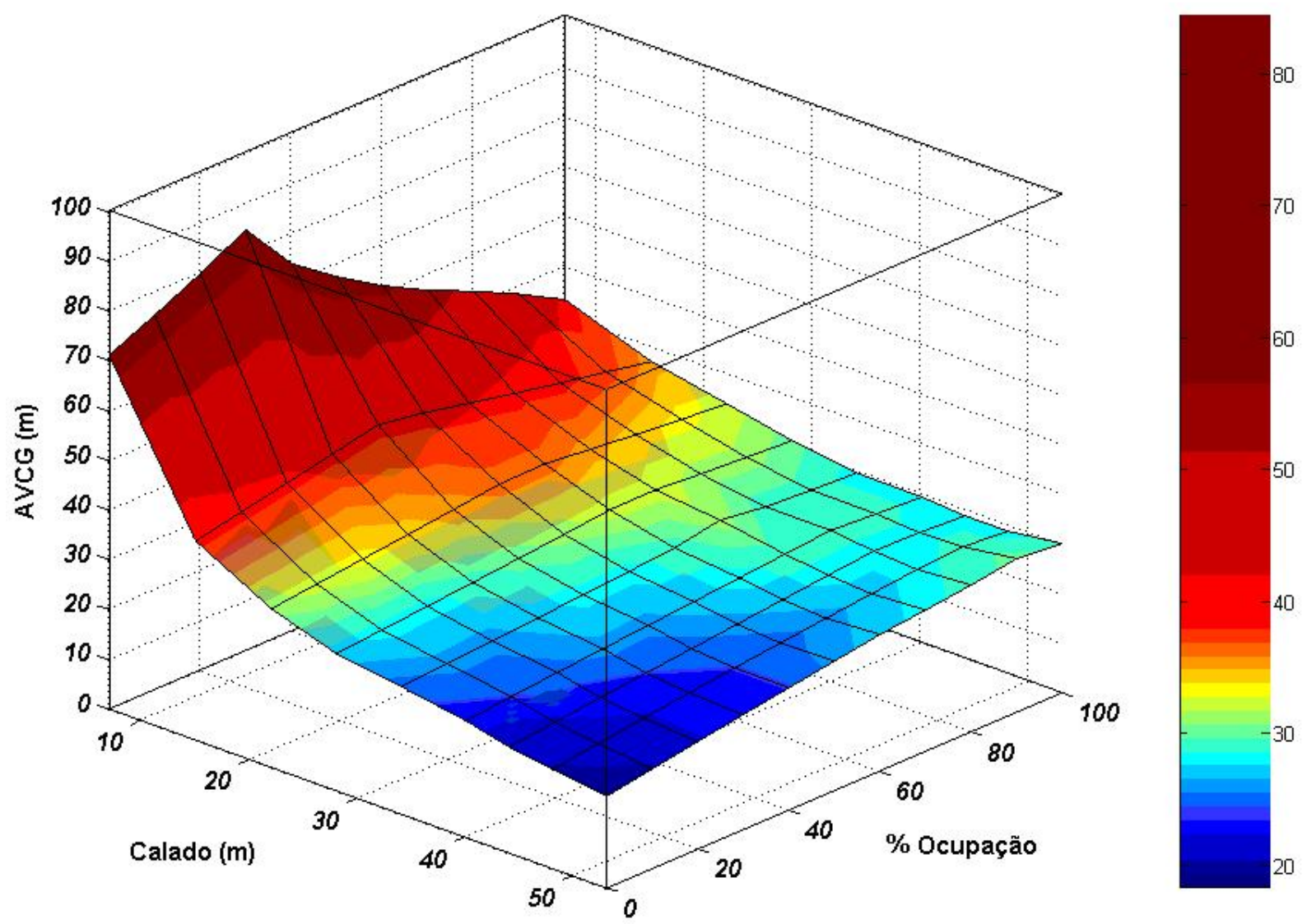

Figura 53. AVCG com dois tanques de lastro adjacentes externos avariados

O AVCG final para cada calado é o mínimo dentre as análises realizadas. Todas as análises [9] mostram que as cinco condições operacionais atendem às exigências da estabilidade, sendo que o ângulo máximo das inclinações é de $11.5^{\circ}$, 
conseqüentemente a unidade não alcança a inclinação necessária para rompimento dos flex-joint. A condição crítica tem dois tanques de lastro internos avariados. Apresenta-se a seguir os VCG de cada condição operacional e o AVCG variando com o calado.

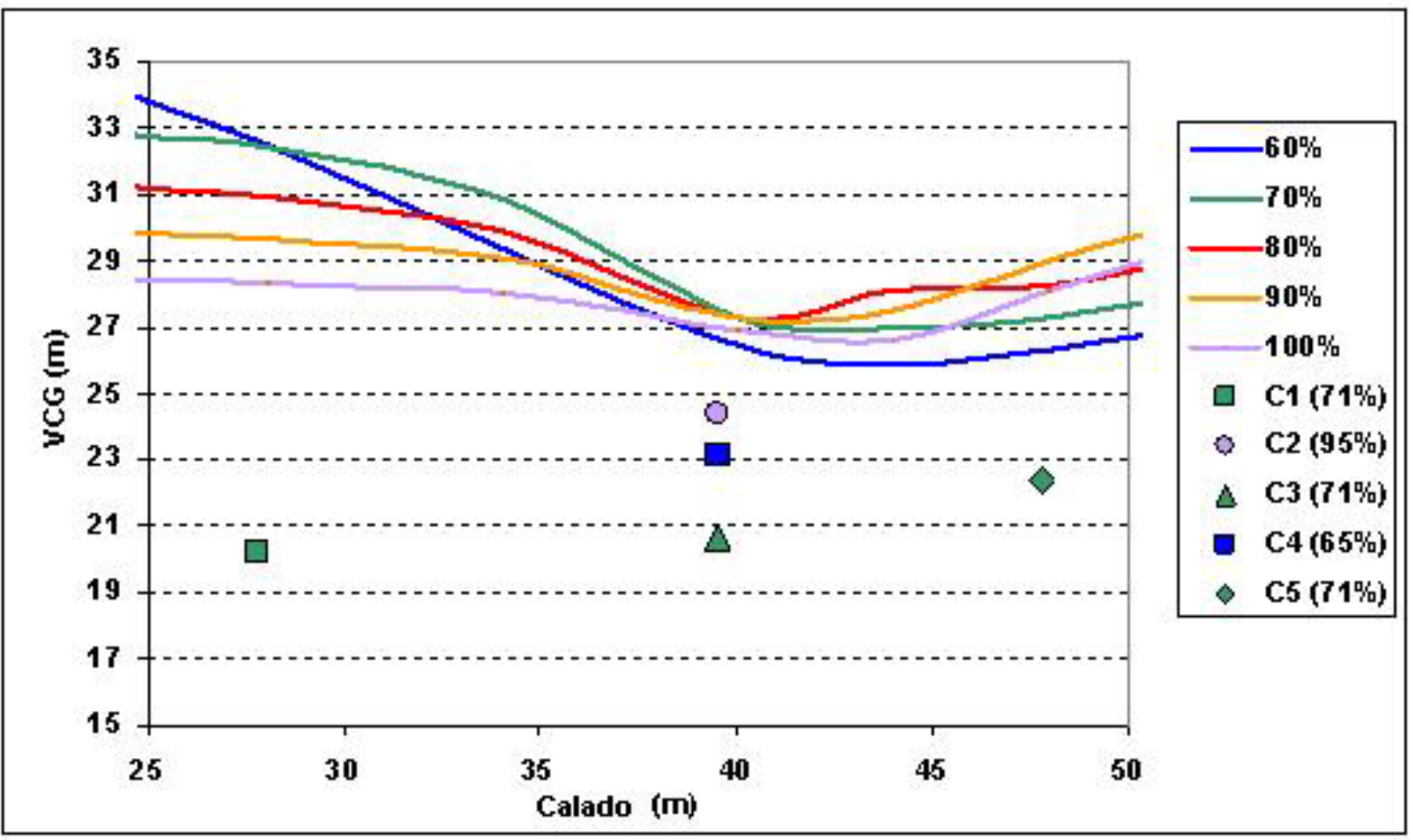

Figura 54. Comparação entre VCG em condição de operação e AVCG para avaria externa

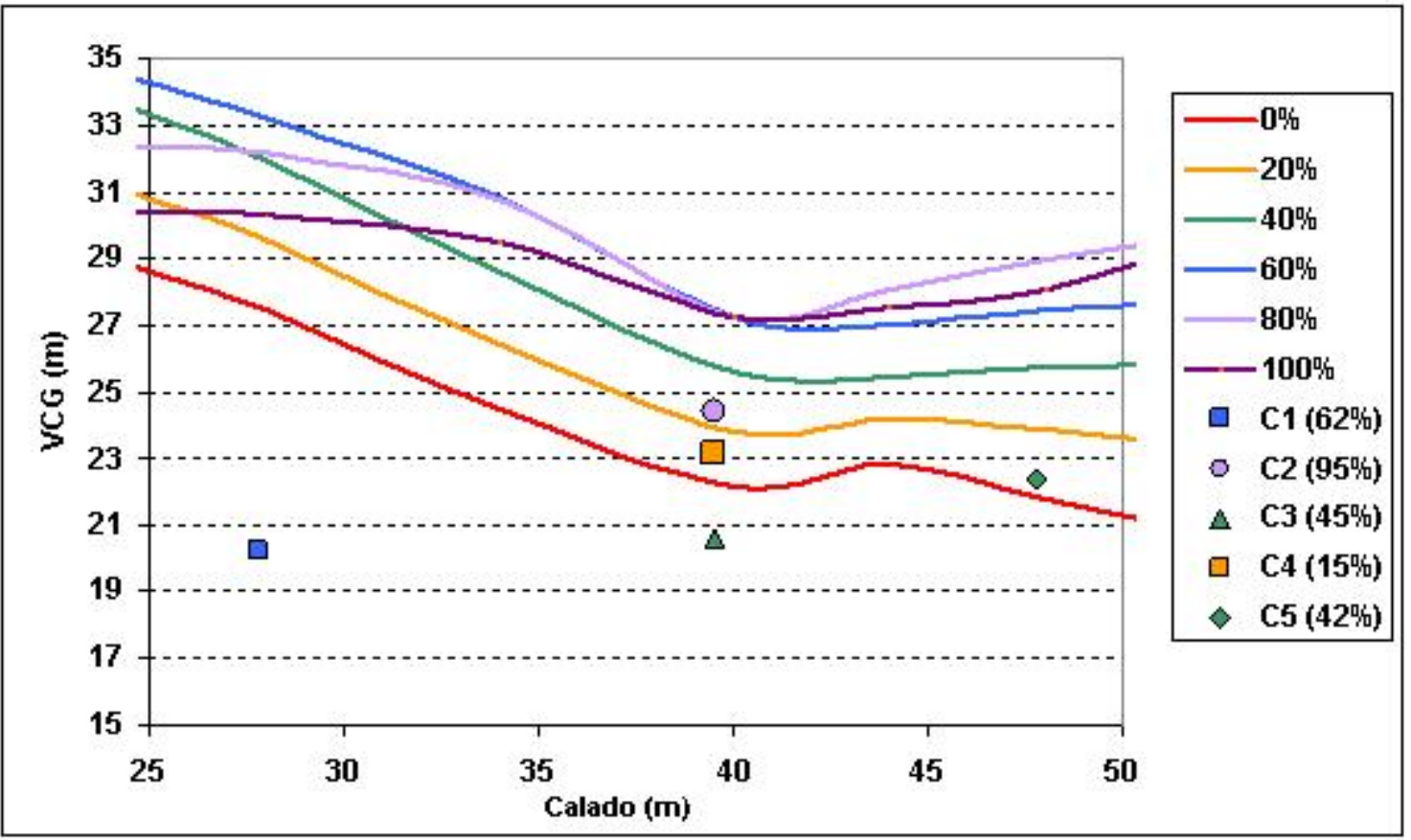

Figura 55. Comparação entre VCG em condição de operação e AVCG para avaria em tanque interno de lastro 
O carregamento dos tanques de lastro externos na condição operacional varia de $65 \%$ até $95 \%$, e em todas essas condições tem VCG claramente menor que as curvas de AVCG para condição de carregamento correspondente.

Ao analisarmos os tanques de lastro internos, que tem seu carregamento variando de $15 \%$ até $95 \%$. Nesse caso também todas as condições têm VCG menor que as curvas de AVCG para condição de carregamento correspondente, o que comprova a reserva de estabilidade da plataforma.

\subsection{ANÁLISE DE COMPENSAÇÃO DE AVARIAS}

Como já apresentado no capítulo 4, a plataforma, por ser da família monocoluna apresenta capacidade de compensação de avarias por meio de realocação de lastros.

A avaliação que segue foi realizada considerando 1 e 2 tanques adjacentes danificados numa condição em que os tanques de lastro internos estão com o mínimo de carga possível, o que é conservador já que proporciona efeitos mais danosos após a avaria.

A compensação da inclinação decorrente dos danos é realizada através do rearranjo do lastro, fazendo com que a unidade restaure sua posição inicial, sem mudar o calado inicial. Essa plataforma tem capacidade de voltar à condição sem inclinação mesmo com até 4 tanques adjacentes danificados.

A Figura 53 mostra a plataforma quando possui um tanque avariado e quando já teve seu rearranjo de lastros, trazendo-a a condição sem inclinação (even keel). 0 ângulo da inclinação causado pelo tanque danificado é $6.3^{\circ}$ (maior inclinação apresentada nas análises de avaria). 

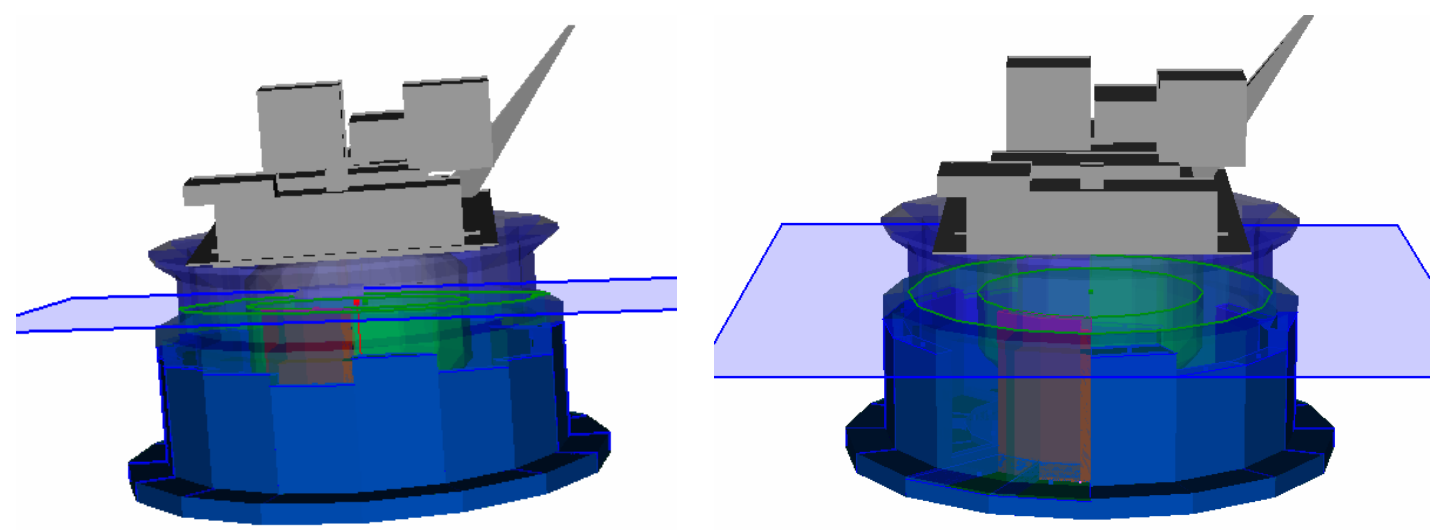

Figura 56. Compensação de avaria (1 tanque)

A tabela 15 apresenta a condição de carregamento dos tanques antes e depois da restauração da inclinação.

Tabela 15 - Condição de carregamento dos tanques - 1 tanque danificado

\begin{tabular}{|c|c|c|c|c|c|c|c|}
\hline & \multicolumn{3}{|c|}{ Condição Inicial } & \multicolumn{3}{|c|}{ Condição Final } & \multirow[b]{2}{*}{ Alteração no vol.(miz) } \\
\hline ID. & Altura (m) & Ocup $\%$ & Volume $\left(\mathrm{m}^{3}\right)$ & Altura (m) & Ocup $\%$ & Volume $\left(\mathrm{m}^{3}\right)$ & \\
\hline EBT1 & 35.51 & 72.1 & 5221.33 & 28.59 & 63.16 & 4574.26 & -647.07 \\
\hline EBT2 & 30.11 & 65 & 4707.15 & 30.11 & 65 & 4707.15 & 0 \\
\hline EBT3 & 29.9 & 64.75 & 4689.25 & 29.9 & 64.75 & 4689.25 & 0 \\
\hline EBT4 & 34.43 & 70.24 & 5086.69 & 34.43 & 70.24 & 5086.69 & 0 \\
\hline EBT5 & 27.72 & 62.1 & 4497.15 & 27.72 & 62.1 & 4497.15 & 0 \\
\hline EBT6 & 28.46 & 63 & 4562.31 & 28.46 & 63 & 4562.31 & 0 \\
\hline EBT7 & 29.28 & 64 & 4634.73 & 29.28 & 64 & 4634.73 & 0 \\
\hline EBT8 & 30.64 & 65.65 & 4754.03 & 30.64 & 65.65 & 4754.03 & 0 \\
\hline EBT9 & 40.27 & 81.07 & 5870.91 & 40.27 & 81.07 & 5870.91 & 0 \\
\hline EBT10 & 30.13 & 65.03 & 4709.04 & 30.13 & 65.03 & 4709.04 & 0 \\
\hline EBT12 & 32.58 & 68 & 4924.41 & 32.58 & 68 & 4924.41 & 0 \\
\hline EBT11 & 32.54 & 67.95 & 4920.78 & 32.54 & 67.95 & 4920.78 & 0 \\
\hline EBT13 & 32.5 & 67.9 & 4917.17 & 32.5 & 67.9 & 4917.17 & 0 \\
\hline EBT14 & 32.58 & 68 & 4924.4 & 32.58 & 68 & 4924.4 & 0 \\
\hline EBT15 & 32.58 & 68 & 4924.4 & 9.99 & 40.59 & 2939.77 & -1984.63 \\
\hline EBT16 & 30.11 & 65 & 4707.15 & 9.5 & 40 & 2896.71 & -1810.44 \\
\hline |BT1 & 6.37 & 15 & 1443.74 & 6.37 & 15 & 1443.74 & 0 \\
\hline |BT2 & 6.61 & 15 & 1503.64 & 6.61 & 15 & 1503.64 & 0 \\
\hline IBT3 & 6.61 & 15 & 1503.64 & 6.61 & 15 & 1503.64 & 0 \\
\hline IBT4 & 6.61 & 15 & 1503.64 & 0.08 & 0.17 & 17.4 & -1486.24 \\
\hline IBT5 & 6.61 & 15 & 1503.64 & 6.61 & 15 & 1503.64 & 0 \\
\hline IBT6 & 6.61 & 15 & 1503.64 & 6.61 & 15 & 1503.64 & 0 \\
\hline IBT7 & 6.61 & 15 & 1503.64 & 6.61 & 15 & 1503.64 & 0 \\
\hline IBT8 & & & Avariado & & & & \\
\hline
\end{tabular}

A Figura 57 mostra a plataforma quando possui dois tanques adjacentes avariados e quando já teve seu rearranjo de lastros, trazendo-a a condição even keel. O ângulo da inclinação causado pela avaria é de $11,5^{\circ}$ (maior inclinação apresentada nas análises de avaria de dois tanques). 

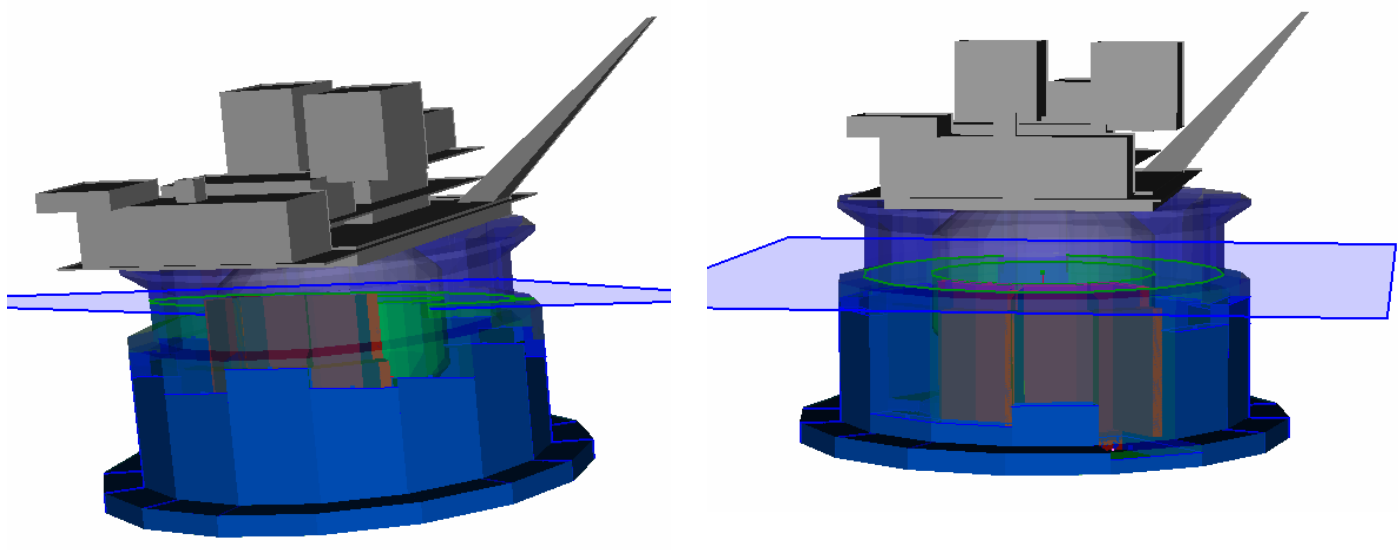

Figura 57. Compensação de avaria (2 tanques)

A tabela 16 apresenta a condição de carregamento dos tanques antes e depois da restauração da inclinação.

Tabela 16 - Condição de carregamento dos tanques - 2 tanques danificados

\begin{tabular}{|c|c|c|c|c|c|c|c|}
\hline & \multicolumn{3}{|c|}{ Condição Inicial } & \multicolumn{3}{|c|}{ Condição Final } & \multirow[b]{2}{*}{ Alteração no vol. $\left(\mathrm{m}^{3}\right)$} \\
\hline ID. & Altura (m) & Ocup $\%$ & Volume $\left(\mathrm{m}^{3}\right)$ & Altura (m) & Ocup\% & Volume (m) & \\
\hline EBT1 & 35.51 & 72.1 & 5221.33 & 14.17 & 45.67 & 3307.61 & -1913.72 \\
\hline EBT2 & 30.11 & 65 & 4707.15 & 3.27 & 22.61 & 1637.14 & -3070.01 \\
\hline EBT3 & 29.9 & 64.75 & 4689.25 & 29.9 & 64.75 & 4689.25 & 0 \\
\hline EBT4 & 34.43 & 70.24 & 5086.69 & 34.43 & 70.24 & 5086.69 & 0 \\
\hline EBT5 & 27.72 & 62.1 & 4497.15 & 27.72 & 62.1 & 4497.15 & 0 \\
\hline EBT6 & 28.46 & 63 & 4562.31 & 28.46 & 63 & 4562.31 & 0 \\
\hline EBT7 & 29.28 & 64 & 4634.73 & 29.28 & 64 & 4634.73 & 0 \\
\hline EBT8 & 30.64 & 65.65 & 4754.03 & 30.64 & 65.65 & 4754.03 & 0 \\
\hline EBT9 & 40.27 & 81.07 & 5870.91 & 40.27 & 81.07 & 5870.91 & 0 \\
\hline EBT10 & 30.13 & 65.03 & 4709.04 & 30.13 & 65.03 & 4709.04 & 0 \\
\hline EBT12 & 32.58 & 68 & 4924.41 & 32.58 & 68 & 4924.41 & 0 \\
\hline EBT11 & 32.54 & 67.95 & 4920.78 & 32.54 & 67.95 & 4920.78 & 0 \\
\hline EBT13 & 32.5 & 67.9 & 4917.17 & 32.5 & 67.9 & 4917.17 & 0 \\
\hline EBT14 & 32.58 & 68 & 4924.4 & 32.58 & 68 & 4924.4 & 0 \\
\hline EBT15 & 32.58 & 68 & 4924.4 & 9.54 & 40.06 & 2900.85 & -2023.55 \\
\hline EBT16 & 30.11 & 65 & 4707.15 & 9.5 & 40 & 2896.71 & -1810.44 \\
\hline IBT1 & \multicolumn{6}{|c|}{ Avariado } & \\
\hline IBT2 & 6.61 & 15 & 1503.64 & 6.61 & 15 & 1503.64 & 0 \\
\hline IBT3 & 6.61 & 15 & 1503.64 & 6.61 & 15 & 1503.64 & 0 \\
\hline IBT4 & 6.61 & 15 & 1503.64 & 0 & 0 & 0 & -1503.64 \\
\hline IBT5 & 6.61 & 15 & 1503.64 & 0 & 0 & 0 & -1503.64 \\
\hline IBT6 & 6.61 & 15 & 1503.64 & 6.61 & 15 & 1503.64 & 0 \\
\hline IBT7 & 6.61 & 15 & 1503.64 & 6.61 & 15 & 1503.64 & 0 \\
\hline IBT8 & \multicolumn{6}{|c|}{ riado } & \\
\hline
\end{tabular}




\subsection{ANÁLISE DE SUSCEPTIBILIDADE À ÁGUA}

A Figura 58 e a Figura 59 ilustram a vista 3D das áreas à prova d'água (watertight) e a prova de chuva (weathertight). Para definição dessas áreas foram utilizados os critérios da ABS [2], [3]. Para se definir a área watertight foi feito o cálculo da inclinação máxima em avaria, e para definição da área weathertight, se adiciona 7 graus ou 4 metros à região watertight.

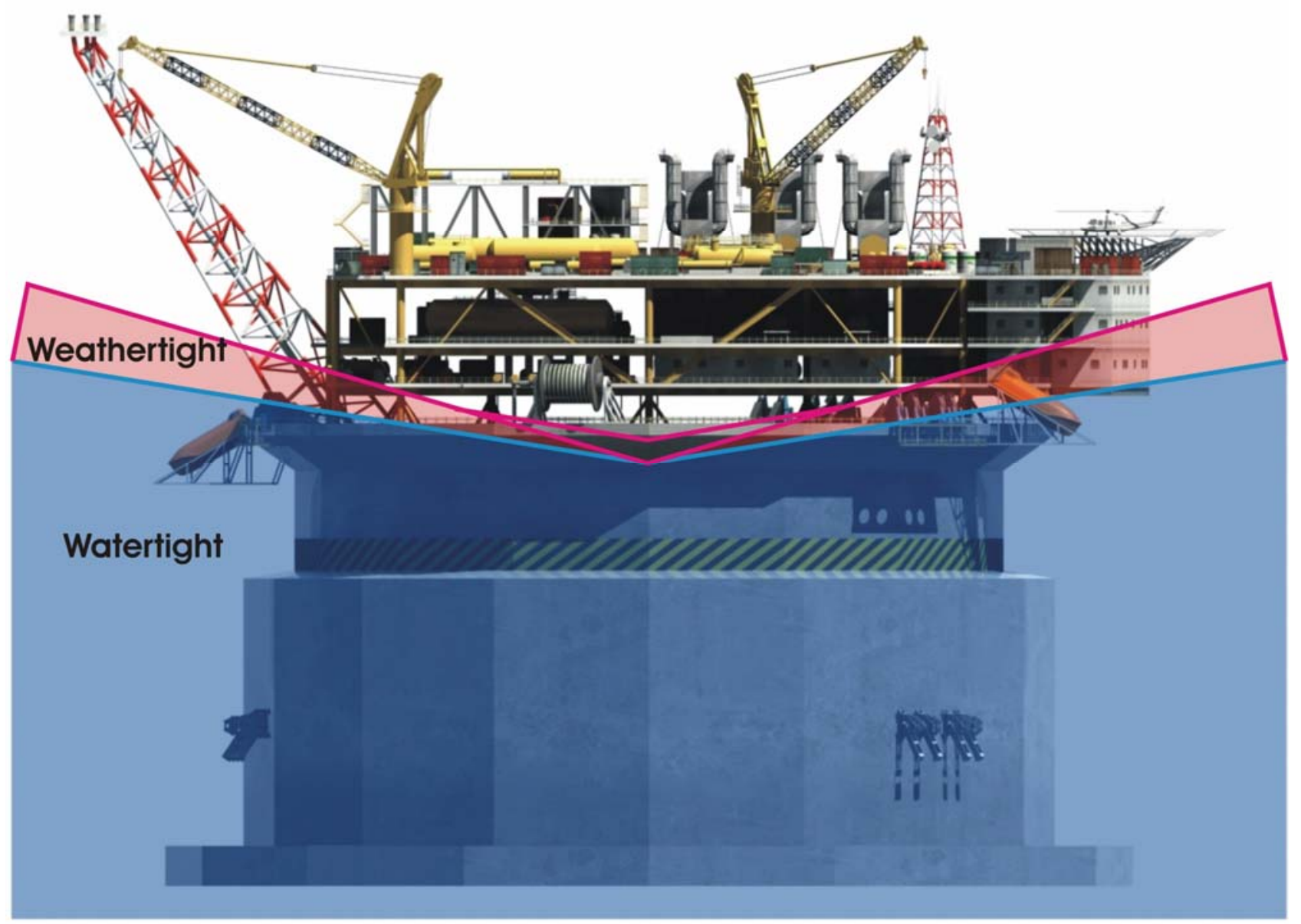

Figura 58. Esquema das áreas weathertight e watertight - Azimute $0^{\circ}$ e $180^{\circ}$ 


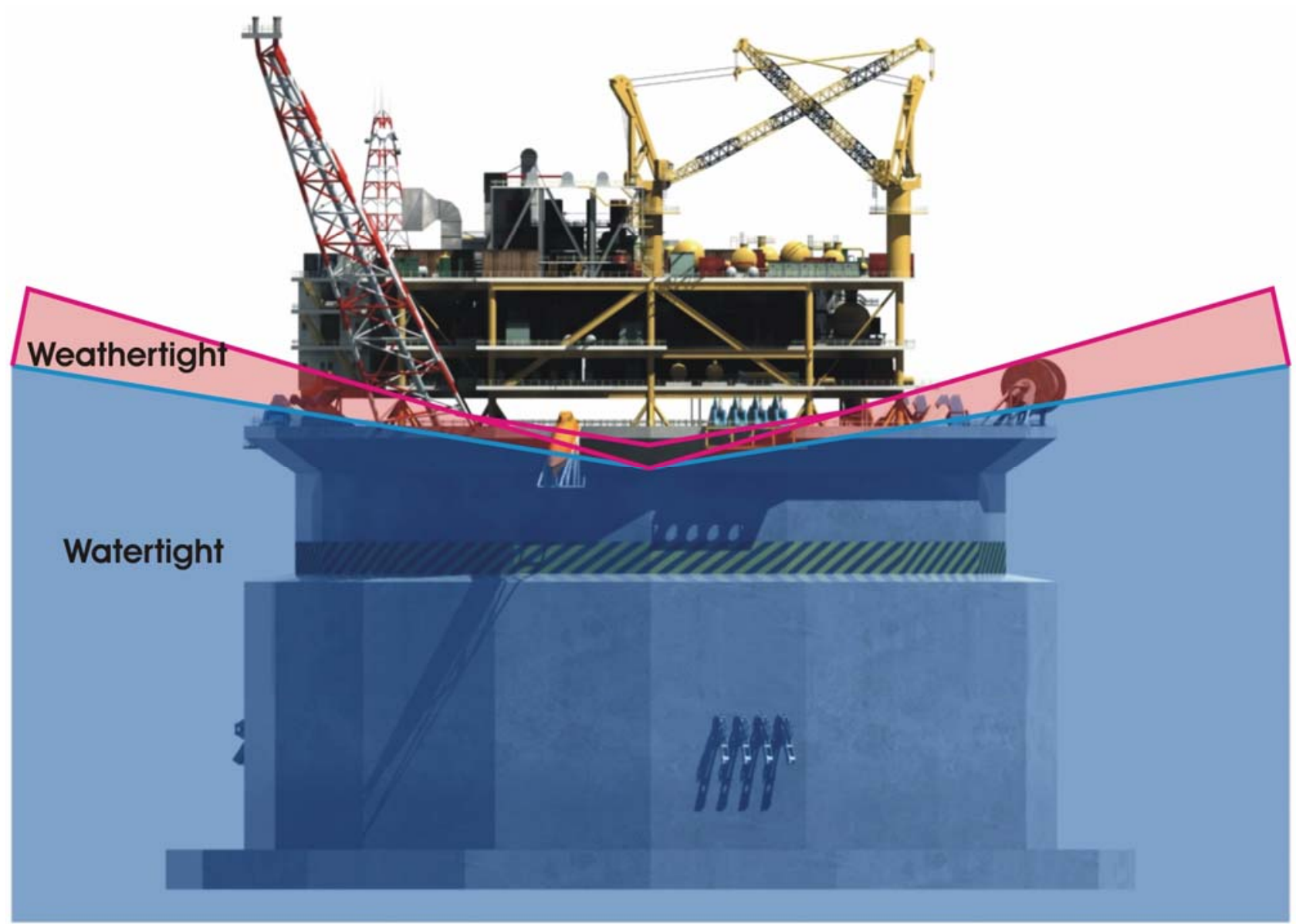

Figura 59. Esquema das areas weathertight e watertight - Azimute $90^{\circ}$ e $270^{\circ}$

\subsection{SÍNTESE DO CAPÍTULO}

Ao analisar um caso específico da família monocoluna, nota-se como é aplicada a metodologia de análise de forma prática, e dessa forma fica claro a profundidade até a qual cada tipo de análise chega. Apresentam-se resultados que comprovam a estabilidade do sistema e que comprovam que a metodologia de análise é valida. Observa-se que as análises são mais aprofundadas do que em um projeto conceitual convencional. 


\section{ANÁLISE DOS CRITÉRIOS DE ESTABILIDADE PARA MONOCOLUNA}

Mesmo com todas as evidências de reserva de estabilidade apresentadas pela monocoluna, não existe um critério totalmente adequado para ela. Ao enquadrar a monocoluna nos critérios de SS, a monocoluna falha ao não atender o critério de extensão de avaria, dado que esse foi gerado para plataformas multicolunas e não monolíticas.

Quando do surgimento dessa não compatibilidade, o estudo da monocoluna foi submetido à DNV por meio do relatório do caso MonoBR. A DNV fez a avaliação técnica e concedeu ao projeto conceitual MonoBR a certificação de que a plataforma cumpre com os requisitos de estabilidade para o casco (Figura 60), o que prova compatibilidade do mesmo com as normas em respeito à estabilidade e implica em reavaliação das normas para enquadramento da família monocoluna. Esse fato corrobora a validade da avaliação crítica das regras. 


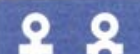 \\ U
}

DTN

\section{DET NORSKE VERITAS}

\section{MONOBR CONCEPT DESIGN APPRAISAL}

\author{
Client: USP - University of São Paulo
}

This is to confirm that MonoBR Concept Design Evaluation as carried out and documented in the DNV Report RSA-OSC-98_3 and according to the scope of work defined and agreed with University of São Paulo is feasible with respect to strength and stability requirements of the hull.

The main particulars and typical scantlings of MonoBR Unit have been evaluated and the design has been found to be in compliance with the Ultimate Limit State (ULS) requirements described in DNV OS-C101 Design of Offshore Steel Structure, General (LRFD-method) April 2004.

Høvik, March 8, 2005
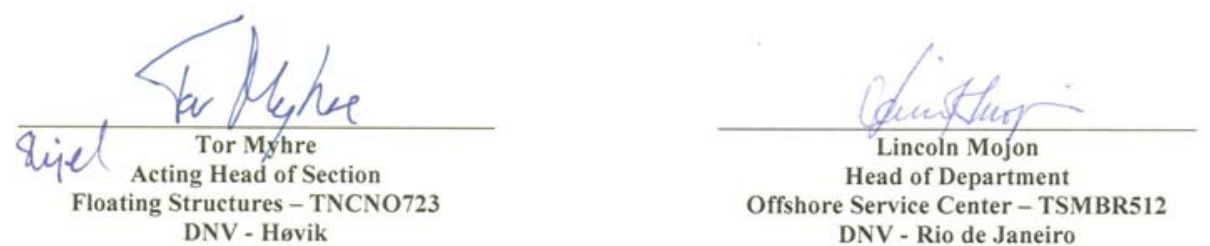

Figura 60. Certificação DNV para um design do conceito monocoluna 


\subsection{CONSOLIDAÇÃO DO CRITÉRIO PROPOSTO}

A partir dos cálculos de estabilidade, da evidência de reserva de estabilidade apresentada pelas análises, e da certificação DNV, é apresentado o enquadramento que deve ser dado à família monocoluna para as análises de estabilidade. Esse critério, que é um misto entre critérios de estabilidade para SS e para unidades de superfície foi discutido junto a DNV e Petrobras, e se tornou válido após a certificação garantida ao projeto MonoBR apresentado na Figura 60.

O critério de estabilidade intacta para monocolunas fica definido como o mesmo que é designado a plataformas semi-submersíveis de acordo com [2], [3], [4] e [5] (enquadramento de SS), pois é aplicável na íntegra à monocolunas.

Para o enquadramento da família monocoluna no critério de estabilidade avariada, é preciso alterar a definição de extensão de avaria, já que essa definição, no enquadramento de SS, não faz sentido para monocolunas devido ao formato monolítico de seu casco.

Após a validação do conceito pela DNV, foi discutido e aprovado que o critério para a extensão horizontal de avaria que deve ser adotado para a monocolunas é o de unidades de superfície. Enquadrando assim a monocoluna a um novo conjunto de normas, o critério proposto para extensão de avarias fica definido como um misto de unidades de superfície e unidades SS.

A seguir se apresenta os itens que definem o critério de extensão de avaria nas monocolunas, onde é possível notar de qual tipo de unidade vem cada cláusula:

- Ao avaliar a estabilidade em avaria da unidade monocoluna, nenhuma antepara vertical deve ser considerada danificada, exceto onde estas estejam espaçadas de uma distância menor que $3 \mathrm{~m}$; nesse caso, uma ou mais anteparas devem ser consideradas perdidas (unidades de superfície).

- Somente as colunas, casco e contraventamentos na parte periférica da unidade devem ser assumidos avariados, e a avaria deve ser considerada na parte exposta desses elementos (unidades SS).

- Colunas e contraventamentos devem ser consideradas inundadas por avaria com extensão vertical de $3 \mathrm{~m}$, ocorrendo em qualquer local compreendido entre $5 \mathrm{~m}$ acima e $3 \mathrm{~m}$ abaixo dos calados operacionais especificados no 
manual de estabilidade da plataforma. Quando existir antepara estanque nessa região, deve-se considerar que a avaria deve ter afetado os dois compartimentos (acima e abaixo da antepara em questão). Distâncias menores que essas citadas podem ser consideradas, levando em conta as condições de operação da plataforma (unidades SS).

- A região avariada deve ter no mínimo 1,5 m acima e abaixo do calado considerado (unidades SS).

- A penetração horizontal da avaria deve ser de 1,5 m (unidades SS).

- Quando operando em condição de trânsito, partes submersas do casco devem se submeter a todas as condições de avarias aqui descritas (unidades SS).

- Todas as tubulações, dutos de ventilação e túneis dentro da região de avaria definida, devem ser considerados avariados. Meios de fechar a passagem de água ao redor das avarias devem ser fornecidos de forma a prevenir o alagamento de outros espaços que deveriam estar intactos (unidades SS).

Com a alteração de uma das restrições, é possível um critério adequado para monocolunas, entretanto fica aberta a proposta de outras análises para rever os critérios vigentes, o que pode proporcionar ganhos de projeto operacionais no futuro.

\subsection{CRITÉRIOS PETROBRAS}

De acordo com as normas definidas, não é necessário o rompimento de anteparas se estas estiverem distantes por mais que $3 \mathrm{~m}$. Apesar disso, indo a favor da segurança a Petrobras exige que se considere sempre avarias de dois tanques adjacentes nas análises de monocolunas. Essa alteração gera um maior custo de construção, e onera a operação, já que implica em maior numero de tanques. Além das considerações obtidas após a validação dos critérios com a DNV, a 


\subsection{SÍNTESE DO CAPÍTULO}

Ao se comprovar adequadamente a condição de estabilidade da monocoluna e a não aplicabilidade de todas as normas vigentes com os enquadramentos de unidades em operação à época, o projeto foi submetido aprovação da DNV, que deu seu aceite e que confirmou a necessidade de revisão das normas, o que culminou em um enquadramento específico para monocolunas. Fica aberta assim a possibilidade de outros estudos que revisem as normas em seu estado atual, que pode proporcionar ganhos nos projetos e na operação das mesmas. 


\section{CONCLUSÃO}

Dentre os projetos de plataformas atuais, surgiu um novo conceito de plataformas para atender condições específicas de certos campos de produção, o qual foi batizado de monocoluna.

Esse novo conceito, atrelado a uma rígida metodologia de geração de cascos e a conceitos atuais de gerenciamento de projetos, gerou uma família de plataformas a qual foi dado o nome de família monocoluna, composta por plataformas podem ser projetadas para atender diversos campos de produção.

Foi constatado que o dimensionamento da monocoluna está diretamente ligado a estabilidade da plataforma, e observou-se também que os acidentes tem influência nos critérios de estabilidade

O trabalho deu origem a uma plataforma que teve sua estabilidade avalizada internacionalmente pela Det Norske Veritas (DNV) proporcionando à pesquisa um resultado singular e projetando a USP ao âmbito internacional.

Por apresentar um casco diferente da maioria em operação atual, foi constatado que as normas vigentes não se aplicam de maneira adequada à família monocoluna, e dessa forma foi definido um novo enquadramento de critérios a esse tipo de unidade, o que somente foi possível mais uma vez pela eficácia da metodologia de análise de estabilidade criada.

A análise do caso específico MonoGOM, apresenta uma plataforma projetada para o Golfo do México, e mostra a real viabilidade desse tipo de plataforma no cen'srio de produção de petróleo atual.

Esse trabalho deu origem a mais cinco dissertações de mestrado, duas de doutorado inúmeras publicações técnicas. 


\section{REFERÊNCIAS BIBLIOGRÁFICAS}

[1] ANP - Agência Nacional do Petróleo, Gás Natural e Biocombustíveis (2006) "Anuário Estatístico - 2006". Acedido em: 14/11/2007, em: http://www.anp.gov.br/conheca/anuario 2006.asp\#secao 2.

[2] IMO - MODU - International Maritime organization - Mobile Offshore Drilling Units Code, Chapter 3, (2001); Acedido em 07/01/2008, em http://www.imo.org/publications/mainframe.asp?topic id=740\&doc id $=2512$

[3] ABS - Guide for building and classing floating production units (2004); Acedido em 07/01/2008, em http://www.eagle.org/rules.html

[4] ABS - Rules for building and classing mobile offshore drilling units (2001); Acedido em 07/01/2008, em http://www.eagle.org/rules.html

[5] DNV - Det Norske Veritas - Code Publication (2001); Acedido em 07/01/2008, em www.dnv.co.uk/maritime/rulesandregulations/index.asp, Chapter OS - C301,

[6] Lewis, Edward V. (Ed). Principles of Naval Architecture, Second Revision. Jersey City: SNAME, 1988.

[7] Alves, Guilherme Tavares Malizia; Projeto Integrado de Estabilidade de Unidades Flutuantes; Dissertação (mestrado); PUC, Departamento de Engenharia Civil, 2006;

[8] K.J. Sharma, B. Bowonder (2004), "The making of Boeing 777: a case study in concurrent engineering", International Journal of Manufacturing Technology and Management - Vol. 6, No.3/4 pp. $254-264$

[9] Campos, F. C. R; Santos, B. R.; Rueda, G; (2005) I-RL-7000-00- 1350-941EHL-001 REV C - Stablility Analises for the MonoGOM Design, Department of Naval and Ocean Engineering; University of São Paulo.

[10] Torres, F. G.S., Cueva, M., Nishimoto, K., Malta, E. B. M., (2004), Projeto hidrodinâmico de uma plataforma do tipo monocoluna - MonoBR, Sobena 


\section{REFERÊNCIAS CONSULTADAS}

[11] Leite, A.J.P, Umeda, C. - "Wind Forces for FPSO design", OMAE (2001), Rio de Janeiro, Brazil;

[12] Campos, F. C. R.; Cueva, M; Nishimoto, K.; Costa, A. P. S. (2003), Stability Criteria and Analisys of a Monocolumn Concept;

[13] Campos, F. C. R., Cueva, M., Santos, B. M. R., Nishimoto, K., Costa A. P. S., (2004), Critério e análise de estabilidade para unidade de produção tipo monocoluna, SOBENA

[14] Santos, Bruno; Rueda, Guilherme; Matsumoto, Fabio; Campos, Felipe; Costa, Ana; Nishimoto, Kazuo, (2006); Stability Analysis of a MPSO (MonoColumn Floater, Production, Storage and Offloading Unit): MonoBR OMAE2006-92276

[15] Cueva, D.; Campos, F.;Donato, M.; Ferrari, J. A.;Torres, F.;Nishimoto, K. (2004), Dimensional Study for Brazilian FPSO;

[16] Barreira, R, Sphaier, SH, Masetti, IQ, Costa, AP and Levi, C, (2005), Behavior of a Mono-Column Structure (MONOBR) in Waves, OMAE05-67512, International Conference on Offshore, Mechanical and Artic Engineering, OMAE 2005, june 12-16, Halkidiki, Greece.

[17] Cueva M, Masetti, IQ, Corte, A, Nishimoto, K, Machado, G and Luis, O, (2005), Development of Deepwater System for GOM - MPSO - a Project Integration View, OMAE05-67346, International Conference on Offshore, Mechanical and Artic Engineering, OMAE 2005, june 12-16, Halkidiki, Greece

[18] Nishimoto, K; (2001); "A Study of Motion Minimization Devices of FPDSOs"; OMAE01-1131; Department of Naval and Ocean Engineering; University of São Paulo.

[19] Coelho, L.C.G, (2002), MG User's Manual;

[20] Coelho, L.C.G., Nascimento, A.A, (2003), SSTAB User's Manual. 